\title{
GENÓTIPOS DE MANDIOCA (Manihot esculenta CRANTZ) PARA PROGRAMAS DE SELEÇÃO NO RECÔNCAVO BAIANO
}

\author{
JORGE LUIZ LOYOLA DANTAS \\ Engenheiro Agrônomo
}

Orientador: Prof. Dr. AKIHIKO ANDO

Dissertação apresentada à Escola Superior de Agricultura "Luiz de Queiroz", da Universidade de São Paulo, para obtenção do título de Mestre em Agronomia. Área de Concentração: Genética e Melho. ramento de Plantas.

PIRACICABA

Estado de São Paulo - Brasil

Maio - 1984 


\begin{abstract}
A meu pai,
irmãos e a

Ana Cristina
\end{abstract}

OFEREÇO

A memória de minha mãe, Alice

e do meu irmão Janio 
AGRADECIMENTOS

Desejamos expressar nossos agradecimentos a todos aqueles que, direta ou indiretamente, contribuiram para a realização deste trabatho e, em especial, às seguintes pessoas e instituições:

- ao Prof. Akihiko Ando, pela valiosa orientação, ensinamentos, amizade e constante incentivo;

- à Empresa Brasileira de Pesquisa Agropecuāria,pela opor tunidade concedida,e ao Centro Nacional de Pesquisa de Mandioca e Fruticultura, pelas facilidades of erecidas para realização do curso;

- aos Professores José Branco de Miranda Filho e Natal An tonio Vello,pelo apoio e colaboração;

- ao Prof. Cláudio Lopes de Souza Junior,pelo estímulo e sugestões;

- ao Engọ Agrọ Hélio Wilson Lemos de Carvalho, pelo início deste trabalho;

- aos docentes do Departamento e Instituto de Genética, pẹ los ensinamentos recebidos;

- aos funcionários do Departamento e Instituto de Genética, pelos valiosos trabalhos prestados;

- aos amigos e colegas de estudo, pelo estímulo e companheirismo. 
INDICE

Pāgina

RESUMO $\ldots \ldots \ldots \ldots \ldots \ldots \ldots \ldots \ldots \ldots \ldots \ldots \ldots \ldots \ldots \ldots \ldots \ldots \ldots \ldots \ldots \ldots \ldots \ldots \ldots$

SUMMARY $\ldots \ldots \ldots \ldots \ldots \ldots \ldots \ldots \ldots \ldots \ldots \ldots \ldots \ldots \ldots \ldots \ldots \ldots \ldots \ldots \ldots \ldots \ldots \ldots$

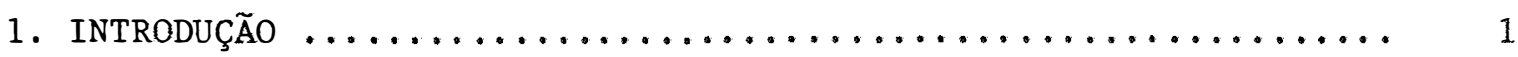

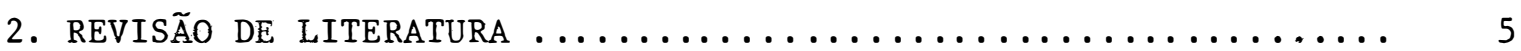

2.1. Variabilidade Genética e Aspectos Gerais do Me1hor amento da Mandioca ........................ 5

2.2. Coeficiente de Determinação Genotípica "b" ............ 14

2.3. Correlações Fenotípicas entre Caracteres Agro-

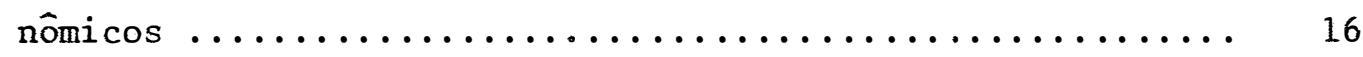

2.4. Efeito da Intensidade de Seleção sobre o Pro-

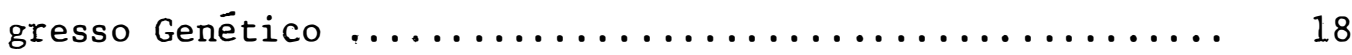

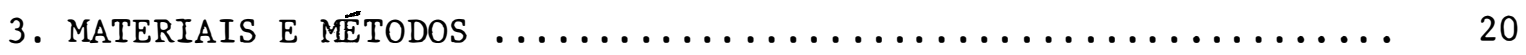

3.1. Local dos Experimentos, Clima e Solo ................ 20

3.2. Descrição dos Materiais ..................... 21

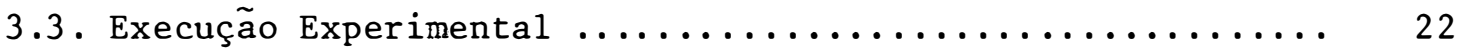

3.3.1. Experimentos do ano agrícola $1980 / 81 \ldots \ldots . \ldots . \ldots 22$

3.3.2. Experimentos do ano agrícola $1981 / 82 \ldots \ldots \ldots \ldots . \ldots 23$

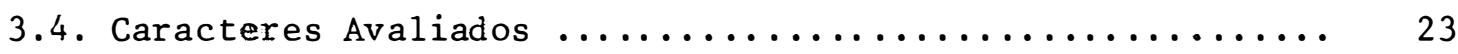

3.5. Tratamento Estatístico-Genético ................... 25

3.5.1. Anālises individuais e conjuntas da

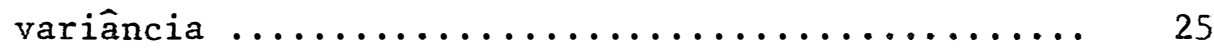

3.5.2. Estimativas do coeficiente de determinação gerrotípica (b) $\ldots \ldots \ldots \ldots \ldots \ldots \ldots \ldots \ldots \ldots \ldots$

3.5.3. Progresso realizado com a seleção ............. 28 
3.5.4. Estimativas do coeficiente de correlação

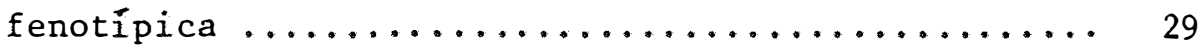

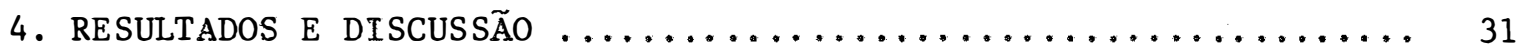

4.1. Comportamento dos Genótipos em 1980/81 .............. 31

4.2. Comportamento dos Genōtipos em 1981/82 ............. 34

4.3. Estimativas dos Parâmetros Genéticos e Fenotí-

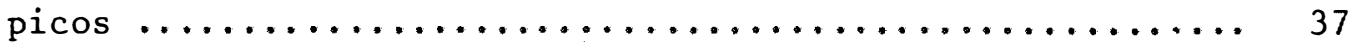

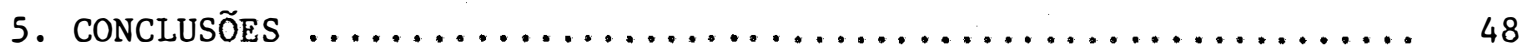

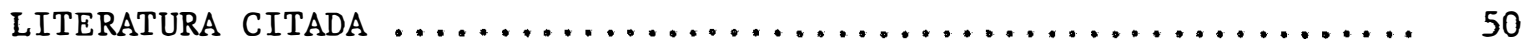

TABELAS $\ldots \ldots \ldots \ldots \ldots \ldots \ldots \ldots \ldots \ldots \ldots \ldots \ldots \ldots \ldots \ldots \ldots \ldots \ldots \ldots \ldots \ldots \ldots \ldots \ldots$

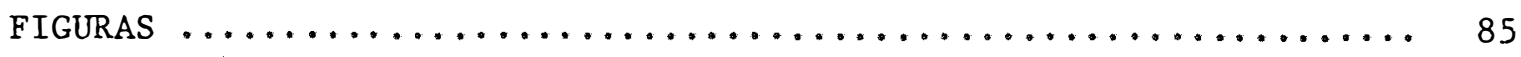

ANEXOS $\ldots \ldots \ldots \ldots \ldots \ldots \ldots \ldots \ldots \ldots \ldots \ldots \ldots \ldots \ldots \ldots \ldots \ldots \ldots \ldots$

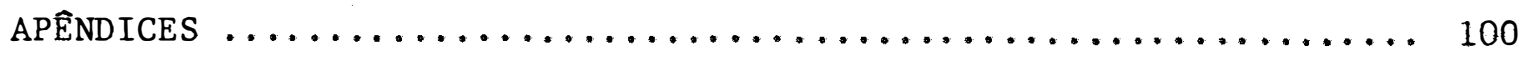


GENOTIPOS DE MANDIOCA (Manihot esculenta Crantz) PARA

PROGRAMAS DE SELEÇAOO NO RECÔNCAVO BAIANO

Jorge Luiz Loyola Dantas

Orientador: Prof. Dr. Akihiko Ando

RESUMO

o Brasil é o principal centro de origem da mandioca, mas pouco se sabe sobre a variabilidade genética dentro da espécie cultivada M. esculenta. A avaliação dessa variabilidade e seleção adequada do

germoplasma existente é, assim, de fundamental importância na criação de cultivares mais promissoras e melhor adaptadas.

Este trabalho objetivou avaliar a variabilidade genotípica entre germoplasmas de mandioca quanto a caracteres de interesse agronômico e estimar parâmetros genéticos e fenotípicos com a finalidade de verificar a eficiência do processo de seleção. Utilizou-se os dados obtidos em experimentos de competição de variedades, avaliadas em condições de campo nos anos agrícolas 1980/81 e 1981/82. Estes experimentos foram instalados no Centro Nacional de Pesquisa de Mandioca e Fruticultura - CNPMF, da Empresa Brasileira de Pesquisa Agropecuāria - EMBRAPA, 1ocalizado em Cruz das Almas, Bahia, que se encontra a $12^{\circ} 40^{\prime} 19^{\prime \prime}$ de latitü sul, $39^{\circ} 06^{\prime} 22^{\prime \prime}$ de longitude oeste, em uma altitude de 225 metros. 0 delineamento experimental usado foi o reticulados quadrados simples 
duplicado $4 \times 4$, com repetições instaladas com tratamentos diferenciāveis de adubação. Como a análise em reticulados quadrados não apresentou eficiência, os experimentos em ambos os anos foram analisados pelo delineamen to em blocos casualizados, segundo um modelo misto.

A alta significância encontrada para o efeito de tratamentos nas anālises individuais e conjuntas da variância e os elevados coeficientes de determinação genotípica estimados antes e apōs a prätica de seleção para os caracteres avaliados indicam a presença de una ampla variabilidade genética entre os genótipos de mandioca, de modo a permitir progressos nos programas de melhoramento. A ausência da interação tratamentos $\mathrm{x}$ adubação para a maioria dos caracteres revela que a avaliação e seleção das cultivares pode ser realizada na ausência ou na presença de adubação.

A seleção para produção de raízes deve ser feita com base em pelo menos dois anos agrícolas, para minimizar os efeitos da interação entre genótipos e anos agrícolas. Quando a seleção para produção de raízes basear-se em observações de um único ano agrícola, devem ser evitados percentuais seletivos inferiores a $15 \%$

O Indice de colheita, em função de ter valores altos de coe ficiente de determinação genotípica e de correlação fenotípica com produção de raízes, é indicado como importante fator auxiliar em programas de seleção para maior produção de raízes. O uso indiscriminado do índice de colheita na seleção para produção de raízes, entretanto, em função de sua associação negativa e significativa com a produção de ramas e produção de hastes e cepas, provoca redução do material de plantio. 


\title{
CASSAVA (Manihot esculenta Crantz) GENOTYPES FOR SELECTION PROGRAMS IN "RECONCAVO BAIANO"
}

\author{
Jorge Luiz Loyola Dantas \\ Adviser : Prof. Dr. Akihiko Ando
}

SUMMARY

Cassava (Manihot esculenta Crantz) is a perennial shrub which produces high yields of tuberous roots. Brazil is the main center of origin of the species. There are few reports on the genetic variability in $M$. esculenta, because the research on this crop has been neglected for a long time. The evaluation of this variability and the adequate germplasm selection represent a fundamental importance in the development of high yielding cultivars, having broad adaptation.

The present research had the purpose of evaluating the degree of available genotypic variability among cassava germplasms for some agronomic traits and estimating genetic and phenotypic parameters related to these traits. Data were obtained from cultivars yields trials, carried out and evaluated under field conditions during the years of 1980/81 and 1981/82, at the "Centro Nacional de Pesquisa de Mandioca e Fruticultura - EMBRAPA", located in Cruz das Almas, Bahia, Brazil ( $12^{\circ} 14^{\prime} 19^{\prime \prime}$ South latitude, $39^{\circ} 06^{\prime} 22^{\prime \prime}$ West longitude, and 225 meters of altitude). 
Experimental design was the $4 \times 4$ duplicated lattice design with four replications. Fertilizer application in two replications, but the other two were grown in absence of fertilizer application. As no efficiency was detected with lattice analysis, trials in both years were analyzed as randomized complete blocks, according to a mixed model.

High significant effects were detected among genotypes in both individual and combined analysis of variance; also, high values of coefficients of genotypic determination were estimated. These findings indicated the presence of broad genetic variability among cassava germplasms and, consequently good possibility of obtaining progress from selection among genotypes.

Lack of treatment $x$ fertilizer application levels interaction for most of characters under study suggested that cultivar evaluation and selection can be performed in presence as well as in absence of fertilizer application.

In order to minimize the genotype $x$ year interaction for root yield, selection for this character should be done based on two years trials, at least. In order to preserve the genetic variability, selection for root yield would be based on selection percentage above $15 \%$.

The harvest index, having both high coefficient of genotypic determination and positive correlation with root yield, is an important parameter in selecting for high yielding genotypes. However, this index presents a negative and significative association with the aerial part of the plant, reducing so the propagative material, that is, the amount of stem cuttings available for new plantings. 
1. INTRODUÇÃO

A mandioca (Manihot esculenta Crantz) è uma euforbiācea de origem americana, cultivada desde a antiguidade, sendo o Brasil, América Central e o México seus mais prováveis centros de origem. Encontra condições favoráveis ao seu desenvolvimento em todos os climas tropicais e subtropicais, abrangendo a faixa compreendida entre os paralelos de $30^{\circ}$ de latitude norte e sul, suportando altitudes que variam desde o nivel do mar até cerca de $2.000 \mathrm{~m}$, na região equatorial. A faixa ideal de temperatura se situa entre os limites de 18 a $35^{\circ} \mathrm{C}$, necessitando de precipitação pluvial de 1.000 a $1.500 \mathrm{~mm}$ anuais, com boa distribuição sazonal, principalmente nos estádios iniciais da cultura (DANTAS et alii, 1981).

Devido à sua ampla adaptação e extraordināria capacidade de produção de amido é cultivada na maioria dos países tropicais. A pro dução mundial de raỉzes atinge, atualmente, 100 milhões de toneladas por ano, assumindo o Brasil uma posição de destaque, visto que participa com $30 \%$ dessa produção, seguido pela Indonésia, Zaire, Tailândia, Nigéria e India (EZETA et alii, 1981). 
Em todos os estados brasileiros se produz mandioca, ocupando esta cultura, segundo IBGE (1982), uma área equivalente a 2 milhões de hectares, posicionando-se entre os principais produtos agrícolas. A produtividade média nacional tem sido de 12 toneladas de raízes por hectạ re, para um ciclo cultural de 6 meses na Amzônia e de 18 ou 20 meses no Sudeste e Sul. Em 1982, a região Nordeste atingiu o maior volume de produ ção, contribuindo com $54,17 \%$ do total produzido no país. As regiões Sul, Norte, Sudeste e Centro Oeste produziram 16,87\%, 13,67\%, $11,61 \%$ e 3,68\%, respectivamente.

Os melhores rendimentos médios têm sido apresentados por São Paulo (20,92 t/ha); Paraná (19,50 t/ha); Espírito Santo (17,86 t/ha); Rondônia (17,40 t/ha); Santa Catarina (16,00 t/ha); Acre (16,00 t/ha); Rio de Janeiro (15,28 t/ha); Mato Grosso do $\operatorname{Sul}(15,18 \mathrm{t} / \mathrm{ha})$ e Mato Grosso $(15,00 \mathrm{t} / \mathrm{ha})$. Pelo volume de produção destacam-se os Estados da Bahia, Maranhão, Rio Grande do Sul, Parä, Pernambuco, Minas Gerais, Paraná, Santa Catarina e Piauí.

Apesar de seu baixo nível de produtividade em muitos paí ses, a mandioca é uma das culturas alimentares que propicia os maiores ren dimentos nas regiões em desenvolvimento nos trópicos (CIAT, 1981). Capacị tada, potencialmente, a produzir grande quantidade de calorias por unidade de área, a planta pode ser integralmente utilizada na alimentação humana, animal e fabricação de vários produtos industriais, pois suas folhas são ricas em proteínas, vitaminas e sais minerais. Seu sistema radicular, além disso, apresenta elevados teores de carboidratos, conforme estudos realizą

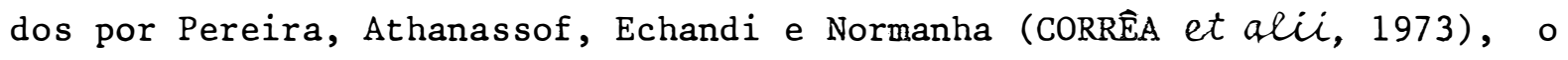
que se constitui na principal exploração dessa planta, apesar de 
amplamente sugerida a utilização da parte aérea na alimentação animal. BARRIGA (1980) salienta que o aumento da produtividade das raízes deve estar associado à exploração da parte aérea e prevê a existência de variabilidade genética para a produção de massa verde.

A mandioca é uma planta altamente heterozigota e apresenta elevada variação genotípica (ACOSTA-ESPINOZA, 1983). Apesar do Brasil se constituir no principal centro de origem de espécies do gênero Manihot, pouco se sabe, porém, sobre essa diversidade. KAWANO (1980) afirma que existe grande variabilidade genética dentro da M. esculenta para vários caracteres agronomicamente importantes, como produção de raízes, indice de colheita, conteúdo de matéria seca nas raízes, teor de ācido cianídrí co (HCN) e tempo de armazenamento pós-colheita, ressaltando que o total de variação do germoplasma dentro da espécie está bem acima do que vem sendo explorado.

A ampliação e enriquecimento da variabilidade tem sido realizada com a instalação de coleções envolvendo tanto espécies selvagens como domesticadas, cujas características e potencialidades para uso no melhoramento são quase desconhecidas, encontrando-se variações para diversos caracteres (MAGOON, 1969; SILVA, 1982). Alguns genótipos possuem alta capacidade de rendimento e outros têm resistência a determinadas pragas e doenças. Não se tem identificado, entretanto, nenhum indivíduo portador de todas as características desejáveis. A propagação vegetativa do cultivo e o modo aditivo de herança dos principais caracteres, todavia, tornam mais simples o esquema de hibridação para produção e seleção de novos clones (KAWANO, 1982). 
A avaliação e seleção do germoplasma existente é, assim, de fundamental importância para permitir a criação de materiais mais promissores e melhor adaptados. Assim sendo, este trabalho teve por objetivos: avaliar a variabilidade genotípica entre germoplasmas de mandioca, quanto aos caracteres de interesse agronômico, e estimar parâmetros genéticos e fenotípicos, com a finalidade de verificar as possibilidades do emprego da seleção no melhoramento dos caracteres estudados, nas condições ecológicas do Recôncavo Baiano. 
2. REVISÃo DE LITERATURA

2.1. Variabilidade Genética e Aspectos Gerais do Melhoramento da Mandioca

A mandioca é um dos mais importantes cultivos produtores de calorias nos trópicos. NESTEL (1974) comentou que cerca de 300 milhões de pessoas dependem basicamente da mandioca como fonte de calorias. Além de sua utilização na alimentação humana e animal, está sendo explorada pela indústria como fonte alternativa de energia na produção de ālcool.

E considerada uma espécie alotetraplóide, possuindo 36 cromossomos $(X=9)$, que formam 18 bivalentes na meiose (UMANAH e HARTMANN, 1973). É monóica e não apresenta nenhuma barreira genética ou fisiológica para impedir a autofecundação, que ocorre naturalmente junto com os cruzamentos. A ântese das flores femininas ocorre em torno de dez dias antes que a ântese das flores masculinas na mesma ramificação, embora as flores masculinas e femininas de diferentes ramificações possuam ânteses simultâneas. Além da reprodução sexual, pode tambēm ser propagada vegetativamente mediante estacas da haste, vantajosa por permitir a multiplicação indefini 
da de um determinado genōtipo, sem que ocorra nenhuma alteração (KAWANO et alii, 1978a).

Apesar do potencial da cultura ser de $90 \mathrm{t} / \mathrm{ha} / \mathrm{ano}$ de raízes segundo COCK (1978), o rendimento médio de 12 t/ha/ano a nível nacional evidencia uma baixa produtividade, que pode ser incrementada por melho ramento genético e pelo uso de práticas culturais adequadas.

ACOSTA-ESPINOZA (1983) salientou que a alta prolificidade da mandioca na região de Piracicaba-SP, a condição de espécie monóica, com flores de tamanho adequado para fácil manipulação, tanto em autofecundações, como em cruzamentos, e a possibilidade de se empregar propagação vegetativa e macho esterilidade, torna viável a aplicação de quase todos os métodos de melhoramento conhecidos.

Conforme citado por GRANER (1942) e NORMANHA (1971), os trabalhos de melhoramento com a cultura da mandioca tiveram início no Brasil e no mundo nas décadas de 30 e 40, com o plantio de sementes de polinização aberta, provenientes de genótipos portadores de características desejáveis e também com transplante de plântulas germinadas espontaneamente. Posteriormente, foi desenvolvido programa visando a obtenção de poliplóides com o uso da colchicina e realizou-se estudos sobre a hereditariedade da forma da folha, da coloração da película externa das raí zes, iniciando-se os trabalhos de cruzamentos controlados com o objetivo de se conseguir clones superiores.

Na mesma ocasião, começaram os trabalhos nos continentes africano e asiático, com coletas de germoplasmas e produção de híbridos intra e interespecíficos. As hibridações para aumento do teor de proteína 
não apresentaram resultados satisfatórios, conseguindo-se, porém, resistência às doenças mosaico africano e bacteriose através do cruzamento interespecífico de $M$. esculenta e M. glaziovii e três gerações de retrocruzamentos (HAHN et alii, 1980).

o objetivo principal dos programas atuais de melhoramento com a cultura é combinar alta produtividade e resistência às pragas e doenças economicamente importantes, com criação de milhares de novos genótipos, por meio de hibridações e sucessivas ava liações. Nos poucos trabalhos realizados, os métodos de melhoramento mais comuns envolvem seleção e hibridação.

ALLARD (1971) ressaltou que a experiência dos melhoristas indica que as variedades agrỉcolas propagadas assexuadamente são altamente heterozigotas, segregando amplamente quando se reproduzem por via sexual. Isso pode ser comprovado em mandioca, pela ampla variação em sua descendência quando se reproduz sexualmente, pela acentuada depressão por endogamia e pelo grande número de genótipos existentes. De acordo com levantamento efetuado pelo Centro Nacional de Recursos Genéticos (CENARGEN), citado por FUKUDA e SILVA (1979), existem no Brasil 1056 variedades de mandioca. Alēm do elevado número de variedades de M.esculen ta, existem ainda muitas espécies silvestres do gênero Manihot.

Existe uma ampla variabilidade genética ainda pouco utilizada, tanto para produção de raízes, como para outros importantes caracteres agronômicos, o que torna possível melhorar a produtividade do cultivo com seleção de tipos superiores. A exploração desta variabilidade pela simples seleção varietal poderá aumentar a produtividade de 
raízes e parte aérea em atē 100\% (CARVALHo, 1981). Estas informações estão de acordo com os resultados obtidos por KAWANO et alii (1978b), quando identificaram vārios genótipos com comportamento superior consistente em vários ambientes e com rendimentos que excederam aos genótipos locais em 50 a $150 \%$.

Anālises de ensaios de avaliação de germoplasmas confirmaram que o aumento de produtividade e obtenção de material resistente às principais doenças e pragas pode ser realizado a curto prazo, evidenciando, tambēm, a existência de variabilidade genética para a produção de maior quantidade de massa verde, de relevante importância na produção de proteína foliar. Essa variabilidade, segundo ABRAHAM (1970) e DEMPSEY (1972), é suficientemente ampla para ser usada em novas recombinações, no sentido de desenvolver cultivares mais produtivas.

Em mandioca, muitas das características importantes possuem alta herdabilidade, com predominância dos efeitos aditivos. A propagação vegetativa do cultivo e o modo aditivo de herança favorecem os processos de hibridação e seleção.

Durante o processo de desenvolvimento de novos clones, KAWANO (1982) observou altas correlações entre parentais e descendentes $\left(F_{1}\right)$ para os caracteres teor de matéria seca nas raízes, grau de deterioração das raízes após a colheita e índice de colheita, notando correlações baixas para produção de raízes. Essas baixas correlações, entretanto, não são problemáticas, visto que o índice de colheita, (proporção entre produção de raízes e produção total da planta), devido a sua alta herdabilidade, ser adotado pela maioria dos pesquisadores 
como o principal critério utilizado na seleção de pais para cruzamentos, nas seleções de plântulas, em testes de fileiras com cinco plantas e em ensaios de competição.

FUKUDA (1979) selecionou 261 híbridos com base no aspecto geral da planta, produção de raízes e indice de colheita. Os híbridos propagados sexuada e assexuadamente foram avaliados para os dois ültimos caracteres. As correlações entre os dois processos de reprodução fo ram significativas e positivas: $r=0,38$ e 0,51 para peso de raízes e Indice de colheita, respectivamente, comprovando a efetividade da seleção ao nível de plântulas individuais.

A seleção em mandioca, portanto, pode ser realizada em materiais provenientes de sementes ou reproduzidos vegetativamente. Normalmente, no primeiro ano a seleção é feita no material sexual e os ciclos posteriores são baseados em genótipos propagados por via assexuada, através dos ensaios de competição de variedades, onde genótipos diferentes são cultivados sob controle estatístico e avaliados nas características desejāveis previamente estabelecidas (ANDRADE, 1978).

As variedades promissoras melhoradas têm dado resultados muito variäveis quando cultivadas em regiões distintas daquelas onde fo ram selecionadas. BARRIGA (1980), em anālises de estabilidade com cultivares da Amazônia e de outras regiões, constatou que os genótipos mais estäveis tenderam a ser os menos produtivos, revelando que, para a mandio ca, maior ênfase tem sido dispensada à prätica de seleção em ambientes especificos. 
Na determinação prática da variabilidade genotípica a partir dos ensaios de competições entre cultivares, frequentemente conduzidos dada a disponibilidade de amplas coleções nas principais regiões pro dutoras, vários pesquisadores têm constatado variações de elevada magnitude para o rendimento de raízes, ramas, hastes, teores de matéria seca, amido e indice de colheita, apesar de não dispensarem enfoques genéticos aos estudos.

A avaliação de vārios genôtipos de mandioca apropriados ao consumo humano, animal e industrial, realizada em várias loçalidades da Baixada Fluminense durante o período de 1966 a 1970, forneceu rendi mentos médios de 3,00 a 35,50 t/ha, considerando-se todos os ensaios (BHLOW, 1971).

CORR $\widehat{E A}$ (1971), em trabalho experimental com cultivares bem produtivas em solos sob condições de cerrado, em Sete Lagoas-MG, obser vou que o rendimento de raízes variou de 21,23 a 29,72 t/ha, 18,00 a $25,00 \mathrm{t} / \mathrm{ha}$ e 25,48 a $37,08 \mathrm{t} / \mathrm{ha}$, nos anos de 1968, 1969 e 1970, respecti vamente. No Ceará, a variação observada foi de 10,43 a 26,61 t/ha (ALMEI DA e PAIVA, 1971). Em Recife-PE, Vasconcelos obteve rendimentos variá veis de 8,00 a $25,70 \mathrm{t} /$ ha (ALMEIDA e PAIVA, 1971).

No Município de Irarā-BA, a magnitude em variação para a produção de raízes foi de 12,68 a 30,70 t/ha (MATTOS e FERREIRA, 1975). Tribuzi relatou que se tem obtido produções de raízes variando desde 10 a $100 \mathrm{t} / \mathrm{ha}$, a depender das cultivares, climas, solos e tratos culturais (SILVA, 1977). 
FUKUDA e SILVA (1979) anotaram porcentagens de matéria seca e amido na raiz oscilando de 30 a $42 \%$ e 26 a $27 \%$, respectivamente. 0 rendimento de raízes variou de 2,70 a 38,80 t/ha, tendo $66 \%$ dos genótipos apresentado produções superiores às cultivares locais.

Em ensaio conduzido em Lagarto-CE, encontrou-se, para um grupo de dez genótipos avaliados, produções de raízes que variaram de 3,48 a 22,78 t/ha. Para o teor de amido, a variação observada foi de 21,55 a 32,18 t/ha (RIBEIRO et alii, 1974). Testando oito cultivares pa ra fins industriais em Cruz das Almas-BA, no período de três anos, CONCEIÇÃO e SAMPAIO (1975) obtiveram produções de 12,16 a 22,23 t/ha, destacando-se as cultivares Mata Negro, Maragogipe e Cavalo, mandiocas consideradas "mansas" pelo baixo teor de äcido cianídrico nas raízes e parte aérea.

Nos trabalhos desenvolvidos pelo Centro Nacional de Pesquisa de Mandioca e Fruticultura (CNPMF), em Cruz das Almas-BA, foi realizada uma série de avaliações em 1977, onde foram selecionados 26 clones com base, principalmente, no rendimento de raízes e matéria seca. Os clones selecionados apresentaram variações de 23,50 a 37,10 t/ha de raízes e de 8,40 a 12,60 t/ha de matéria seca (EMBRAPA/CNPMF, 1979). No ano agrícola de $1977 / 78$, os dez clones mais promissores apresentaram produtividade de raízes variando de 26,55 a $33,55 \mathrm{t} / \mathrm{ha}$, enquanto que a cultivar Cigana Preta, tradicionalmente cultivada na região, produziu apenas $20,60 \mathrm{t} / \mathrm{ha}$. 
Também foram encontradas variações de 48,10 a $61,05 \%$ para Indice de colheita, 9,3 a 12,2 t/ha para rendimento de matéria seca na raỉz e 32,86 a 37,75\% para teor de matéria seca na raiz. Os limites inferiores para os caracteres índice de colheita e rendimento de matéria seca nas raizes foram superiores aos valores obtidos para a cultivar Cigana Preta (EMBRAPA/CNPMF, 1980a).

Além do aproveitamento das raízes de mandioca, pode-se utilizar a sua parte aērea, rica em proteína bruta, cálcio e vitaminas para o forrageamento animal. A forragem de mandioca possui grande poten cial como fonte protéica, principalmente pelo seu baixo teor em fibras.

GRAMACHO (1975) divulgou resultados sobre um estudo químico-tecnológico de fenos de mandioca, chegando a conclusão de que o valor nutritivo teórico apresentado pelos diversos tipos de feno ē razoāvel, quando fabricado durante a colheita de raizes, com 10 a 14 meses de ciclo da planta. O farelo protéico obtido da moagem de feno, colocado em igualdade de condições com o feno de alfafa, supera-o em gordura, pro teîna e carboidratos e apresenta menor teor de fibra e de resíduo mineral, tendo uma relação nutritiva mais ampla que o feno de alfafa.

Basicamente, não se tem realizado trabalhos com a seleção para teor alimentício e produção de forragem. Todas as informações sobre a produtividade de massa verde da mandioca estão associadas com a produção de raízes. As folhas são colhidas vārias vezes durante o ciclo da cultura ou no momento da colheita das raízes (MOORE, 1978).

o caráter produção de ramas é tão variāvel quanto a produção de raízes, com variabilidade ūtil a ser aproveitada com êxito em 
esquemas seletivos. Essas observações foram comprovadas por BARRIGA (1980), quando estimou valores elevados para o coeficiente de determinação genotípica e amplitudes de variação de 3,62 a 44,41 t/ha.

ALBUQUERQUE (1969), em āreas experimentais de Belém-PA, avaliou a produção de ramas de dez variedades de mandioca, em ensaios realizados em värias zonas agrícolas da região. Os dados disponíveis acusaram magnitude de variação de 6,34 a 18,50 t/ha. Fazendo competir cinco cultivares com relação à produção de massa verde e submetendo-as a três cortes por ano em intervalos de quatro meses, MATTOS (1972), obteve produções variáveis de 14,50 a 24,50,t/ha, em Cruz das Almas-BA.

CONCEIÇÃO et alii (1973a) verificaram que certas variedades são mais produtivas em ramas que outras, existindo uma correlação negativa entre a produção de raízes e a produção de forragem. Em avalia ção de seis cultivares regionais de mandioca, nos anos de 1969 a 1972, visando explorar a produção de ramas para forragem, anotaram variações de 31,37 a $58,32 \mathrm{t} / \mathrm{ha}$ em $1969 / 70,27,38$ a $45,86 \mathrm{t} / \mathrm{ha}$ em $1970 / 71$ e 20,20 a 36,30 t/ha em 1971/72. As cultivares Platina, Graveto e Salangor Preta foram as maiores produtoras de massa verde.

Estes mesmos autores (1973b), em experimentos de competição de seis cultivares de aipim e mandioca para forragem, conduzidos por três anos, observaram rendimentos de ramas na faixa de 30,34 a 45,04 t/ ha, destacando-se a cultivar Maragogipe. 


\subsection{Coeficiente de Determinação Genotipica "b".}

Utilizando-se de um processo que relaciona a variância ge notípica entre as cultivares de efeito fixo e a variância fenotípica en tre as médias das cultivares, CESNIK (1972) estimou o coeficiente de

herdabilidade $\left(h^{2}\right)$ no sentido amplo, em cana-de-açūcar. Com metodologia idêntica, em trabalhos realizados com híbridos de amoreira, FONSECA (1978) obteve um coeficiente similar, o coeficiente de determinação genotípica "b", salientando que ambos os coeficientes são semelhantes ao coeficiente de herdabilidade, diferindo pelo fato dos tratamentos serem fixos e não aleatórios. Foram encontrados coeficientes superiores a $80 \%$ para as características foliares em amora, o que indica menor influência por alteraçăo nas condiçöes ambientes e maiores facilidades de modificaçãn por seleção.

0 coeficiente de determinação genotípica "b" mede a proporção da variância fenotípica total que é de natureza genëtica, com valores de 0 a 1. Quando toda a variāncia fenotípica for de natureza ambiental seu valor será 0 , assumindo valores iguais a 1 quando toda a variância fenotípica for de natureza genética. Sua estimativa baseada em mëdias de repetiçöes fica restrita ao tipo de experimento que levou à sua obtenção, não podendo ser comparada com aquelas obtidas de experimentos com delineamentos ou estruturas diferentes, o que seria possível com estimativas ao nível de plantas individuais (ACOSTA-ESPINOZA, 1983).

Na avaliação da variabilìdade de caracteres morfológicos e agronômicos em populiações de Desmodium, OLIVEIRA (1979) observou coeficientes de determinação genotípica relativamente elevados para a 
espécie 0 . uncinatum, especialmente para o caráter início de florescimento. Todos os valores estimados para D. intortum foram baixos, mostrando menor possibilidade de seleção para os caracteres analisados.

Outro estudo desenvolvido para estimar o coeficiente "b" foi realizado por SERA (1980), para o caräter produção do cafeeiro, clas sificando as cultivares quanto à variação genética disponível entre as progênies selecionadas, a partir desse coeficiente. Nesse trabalho, comentou que o coeficiente de determinação genotípica não è adequado para estimar o progresso, pois o material estudado sendo originado de seleções prévias não representa uma população base, mas constitui um conjunto fixo de entidades genéticas.

MONTEIRO (1980) estimou coeficientes de determinação genotípica ao nível de médias, para vários caracteres em populações de Centrosema pubescens Benth, concluindo que os coeficientes foram bons in dicadores da magnitude da variabilidade genética, devendo ser obtidas respostas rápidas na seleção, para as características que apresentaram maiores valores de "b": número de vagens produzidas por planta, comprimento médio dos internódios, número de ramificações primárias e peso da matēria verde.

Em trabalhos de avaliação de cultivares de trigo, em solos de cerrado, BRAZ (1983), com dados de produção de grãos, calculou o coeficiente de determinação genotípica ao nível de médias de tratamentos obtendo 0,66, mostrando ser possível alterar a produção com o emprego dos métodos usuais de melhoramento do trigo. 
Experimentos com cultivares de mandioca de procedência amazônica e extra-amazônica, permitiram a BARRIGA (1980) calcular o coe ficiente "b" ao nível de médias, encontrando valores elevados para produção de raízes $(0,52$ a 0,91) e ramas. No entanto, ACOSTA-ESPINOZA (1983), avaliando nove variedades de mandioca encontrou valores baixos de "b" para o carāter produção de raízes $(0,234)$, justificando essa diferença por suas estimativas terem sido baseadas em anālise de plantas individuais.

\subsection{Correlações Fenotípicas entre Caracteres Agronômicos.}

O estudo das correlações entre caracteres é de relevante importância nos trabalhos de melhoramento, pois em geral objetiva-se aprimorar os genótipos não para caracteres isolados, mas para um conjunto de caracteres simultaneamente (VENCOVSKY, 1978), através da seleção indireta de características desejáveis que estão associadas positivamente. Alēm desse valor prätico, essas correlações são de interesse em considerações téoricas da herança quantitativa dos caracteres (ROBINSON et alii, 1951).

Em mandioca, poucos trabalhos foram desenvolvidos visando determinar as relações existentes entre caracteres da parte aérea e produção de raízes. Os primeiros estudos foram realizados por MENDES(1940) e por GRANER (1946), concluindo que a produção de raízes está correlacionada positivamente com a produção de ramas, resultado este confirmado por ESTEVÃO et alii (1972) para uma só variedade, por ALMEIDA et alii (1976) e por SILVA (1977), ao trabalhar com um grupo de 60 variedades. 
NORMANHA e PEREIRA (1963) afirmaram que dentro de uma mes ma variedade existe uma correlação positiva entre produção de raízes e altura da planta, diâmetro da haste, altura do ponto de ramificação da haste principal, número e tamanho das folhas, comprimento dos pecíolos e intensidade de coloração verde da folhagem. Considerando diversas varie dades, entretanto, tal afirmativa ē sujeita a restrições, pois ESTEVÃo (1971), estudando o comportamento de dez variedades de mandioca, verificou que os genótipos com elevados rendimentos em raízes produziam menores quantidades de ramas. Resultados similares foram obtidos por CIAT (1975), CONCEIÇÃO (1979) e MATTOS et alii (1980).

Mais recentemente, SILVA et alii (1983), ao avaliarem 162 cultivares de mandioca, encontraram correlações positivas e significativas entre rendimento de raízes com o número de raízes comerciais e o índice de colheita, sugerindo o uso dessas características como critérios auxiliares na seleção de cultivares para produção de raízes. As correlações entre peso de hastes e peso de ramas com indice de colheita foram negativas e altamente significativas, evidenciando que um maior desenvolvimento da parte aérea implica, na maioria das vezes, em menores indices de colheita, em concordância com os resultados do CIAT (1975) e FUKUDA et alii (1983), que detectaram tambëm correlação positiva e significativa entre peso de raízes e peso total da planta.

BIRADAR et alii (1978) concluiram que para a identificação de genótipos de altos rendimentos é necessário utilizar-se do índice de colheita e do número de raízes por planta, devido a existência de uma forte correlação positiva entre essas características com a produção de raízes. 
ACOSTA-ESPINOZA (1983) revelou interesse na avaliação de correlação entre produção de raỉzes com caracteres da parte aérea que se manifestem precocemente. Salientou ainda, que a existência de algum caräter da parte aérea possuindo desenvolvimento precoce e alto valor de correlação com produção seria extremamente desejāvel, por facilitar a avaliação do potencial produtivo na fase inicial da cultura, abrevian do o intervalo de tempo entre ciclos de seleção.

\subsection{Efeito da Intensidade de Seleção sobre o Progresso Genético.}

o progresso que se pode obter no melhoramento de plantas è em grande parte função da variabilidade genética existente na população e do diferencial de seleção. A seleção a ser praticada depende da presença dessa variabilidade que, estimada por parâmetros genéticos, per mite fundamentar os trabalhos de melhoramento em bases mais sōlidas.

O efeito da seleção sobre a estrutura genética de uma população depende da precisão das estimativas das médias das progênies ava liadas, das frequências gênicas para os caracteres selecionados na população e da intensidade de seleção. Evidentemente, quanto maior for a intensidade de seleção, maior serä o progresso esperado, atê o limite em que os problemas advindos com a endogamia e com a oscilação genética pas sam a prejudicar o processo seletivo.

Um dos componentes importantes a ser considerado na seleção é a interação genótipo por ambiente (MÔRO, 1982). A ocorrência generalizada de interações entre genótipos e ambiente causa sērios transtornos no que concerne ao desenvolvimento de variedades melhoradas, sejam estas representadas por linhas puras, hỉbridos, ou qualquer outro 
material com o qual o melhorista possa estar trabalhando (EBERHART e RUSSEL, 1966), comprometendo o progresso al cançado com a seleção(COMSTOCK e MOLL, 1963). Com a interação genótipos por anos, pode ocorrer que com uma alta intensidade de seleção, os melhores genótipos num determinado ano tenham uma adaptação muito específica para as condições ambientais do ano e do local em que se realizou a seleção. Nessas situações, a seleção dos poucos genótipos mais produtivos poderá resultar em um progres so inferior ao esperado (PATERNIANI e MIRANDA FILHO, 1978).

Por tais considerações, muitos melhoristas preferem empregar intensidades de seleção mais brandas, esperando com isso que haja maiores chances de que o progresso obtido com a seleção em um ambiente possa ser extrapolado para outras regiões e para os anos subsequentes.

Um enfoque diferente do aspecto de predição de respostas pode ser abordado, quando, a partir de uma seleção já praticada em um gru po fixo de materiais, torna-se possível determinar o progresso realizado e então efetuar estudos pertinentes ao conjunto considerado.

Os resultados de progressos genéticos em mandioca são escassos, estando os trabalhos limitados a avaliações clonais e multiplicação dos materiais mais produtivos.

TINEO (1977), através de seleção massal estratificada, com duas populações da variedade "Llanera", obteve ganho de $20,44 \%$ para produção total de raízes e $24,71 \%$ para produção de raízes comerciais, na localidade de Baralt. Em Sucre, a produção total de raízes foi de 35,52 t/ha, o que representou um ganho de $19,43 \%$. 
3. MATERIAIS E METODOS

3.1. Local dos Experimentos, Clima e Solo,

0 presente trabalho foi realizado a partir de dados obtidos em experimentos conduzidos sob condições de campo, nos anos agrícolas 1980/81 e 1981/82, na ärea experimental da sede do Centro Nacional de Pes quisa de Mandioca e Fruticultura (CNPMF), da Empresa Brasileira de Pesquisa Agropecuária (EMBRAPA), em Cruz das Almas, Bahia, Brasil, que se encontra a $12^{\circ} 40^{\prime} 19^{\prime \prime}$ de latitude sul, $39^{\circ} 06^{\prime} 22^{\prime \prime}$ de longitude oeste, em uma altitude de 225 metros.

o clima da região, segundo a classificação de Köppen, é de tipo Aws, de transição entre Af e Aw, quente e úmido, com normais climatológicas médias anuais de $82 \%$ de umidade relativa do ar, evaporação de $962,1 \mathrm{~mm}$, insolação de 2704 horas, precipitação e temperatura média anuais de $1197 \mathrm{~mm}$ e $24,5^{\circ} \mathrm{C}$, respectivamente. Os dados climatológicos relativos ao período experimental são apresentados no Apêndice 1.

o solo onde foram instalados os experimentos é caracterizado como latossolo vermelho amarelo, coeso, A moderado, textura argilosa, 
de baixa fertilidade, fase floresta subperenifolia com relevo plano (EMBRAPA/SNLCS, 1977). As análises químicas, para os experimentos do ciclo 1980/81, encontram-se no Apêndice 2.

\subsection{Descrição dos Materiais.}

Foram utilizados para esse estudo materiais tidos como possuidores de potencialidade para cultivo comercial, segundo avaliações preliminares efetuadas no Banco de Germoplasma de Mandioca (BGM) do CNPMF. Os genótipos, constituidos de cultivares e clones obtidos por polinização aberta ou controlada, procedentes de distintas regiões do Brasil, México e Colombia, em número de 146, foram inicialmente avaliados em experimentos de competição, incluindo, como testemunhas comuns, as cultivares Aipim Bravo e Cigana Preta, tradicionalmente cultivadas na região.

Em uma segunda etapa, durante o ano agrícola 1981/82, foram avaliados 56 genótipos selecionados a partir do experimento anterior, incluindo os mesmos tratamentos testemunhas.

Os termos variedade e clone são normalmente usados como sinônimos de cultivar, entre agricultores e técnicos que trabalham com a cultura da mandioca. Na realidade, existe uma grande diferença no signi ficado dessas palavras (POEHLMAN, 1971; KING, 1974). Nesse trabalho, os materiais serão citados simplesmente por genótipos, objetivando abranger os termos descritos e simplificar as designações dos tratamentos. 


\subsection{Execução Experimental.}

\subsubsection{Experimentos do ano agrícola 1980/81}

Em julho de 1980 foram instalados dez experimentos de ava liação dos genótipos tidos como promissores no Banco de Germoplasma de Mandioca do CNPMF, na ärea experimental da EMBRAPA/CNPMF. O delineamento experimental usado para todos os experimentos foi o reticulados quadrados simples duplicado $4 \times 4$, com repetições instaladas com tratamentos diferenciáveis de adubação, a fim de observar o comportamento dos genótipos quando cultivados em solos adubados ou com fertilidade natural. Para isso, das quatro repetições utilizadas, duas receberam adubação de acordo com o resultado da análise do solo e as duas restantes não foram adubadas .

Os experimentos 1, 2, 3 e 4 foram instalados com dois tra tamentos comuns, 'Aipim Bravo'e rCigana Preta', para efeito de comparações. Por falta de material de plantio, houve somente a inclusão da'Cigana Pre ta'como tratamento testemunha nos seis $\vec{u} 1$ timos experimentos.

O espaçamento adotado para a cultura foi de 1,00m entre fileiras e 0,60m entre plantas dentro de fileiras. As parcelas experimentais foram formadas por quatro fileiras com $3,60 \mathrm{~m}$ de comprimento. Dessa forma, cada parcela ocupou ärea de $14,40 \mathrm{~m}^{2}$. A ärea ūtil de cada parcela constituiu-se de $7,20 \mathrm{~m}^{2}$, contendo as 12 plantas das duas fileiras centrais. O plantio foi realizado em sulcos com $10 \mathrm{~cm}$ de profundidade, colocando-se manivas-semente de $20 \mathrm{~cm}$ de comprimento em posição horizontal. Adubou-se as duas primeiras repetições com $80 \mathrm{~kg} / \mathrm{ha}$ de $\mathrm{P}_{2} \mathrm{O}_{5}$. 
As adubações nitrogenadas $\left(40 \mathrm{~kg} / \mathrm{ha}\right.$ de $\left.\mathrm{N}_{2}\right)$ e potāssicas (40 kg/ha de $\mathrm{K}_{2}$ 0) foram feitas em cobertura aos 45 e 90 dias após o plantio.

Durante a condução dos experimentos, observou-se o vigor dos genótipos e a época de florescimento. Caracteres como produção de raízes, produção de hastes e cepas, produção de ramas, produção total, indice de colheita e teor de amido foram avaliados ao nível de parcelas na época da colheita, realizada 12 meses após o plantio.

\subsubsection{Experimentos do ano agrícola $1981 / 82$}

Em função da produtividade de raízes e estabilidade de produção com e sem adubação, foram selecionados 56 genótipos que deram origem a quatro experimentos, com delineamento, espaçamento, tamanho de parcelas e número de plantas similares ao ano anterior. Todos os experimentos foram instalados com as testemunhas'Aipim Bravo'e'Cigana Preta!

Por ocasião do plantio, em agosto de 1981, a adubação de manutenção com $\mathrm{P}_{2} \mathrm{O}_{5}$ foi reduzida a $40 \mathrm{~kg} / \mathrm{ha}$, aproveitando-se o efeito residual desse nutriente.

A duração dos experimentos foi de um ano, ao fim do que foram anotadosa produção das raízes, produção das hastes e cepas, produção de ramas, produção total, Indice de colheita e teor de amido.

\subsection{Caracteres Avaliados}

Em todos os experimentos, ao final do período experimental, foram feitas as seguintes anotações: 
a) produção de raízes - foi calculada a partir do peso das raízes frescas das plantas üteis de cada parcela $\left(7,20 \mathrm{~m}^{2}\right)$, sendo transformada para $t / h a$;

b) produção de hastes e cepas - calculada através do peso de hastes e cepas das 12 plantas üteis de cada parcela, transforma da posteriormente para t/ha; estes termos são utilizados na cultura da mandioca para designar a parte aérea destinada à multiplicação. As cepas podem ser utilizadas em substituição de outras materiais nos fornos das usinas de processamento da mandioca;

c) produção de ramas - a avaliação foi realizada pesando-se conjuntamente as ramas das 12 plantas üteis de cada parcela

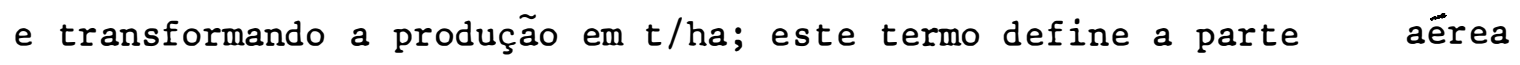
da mandioca destinada à alimentação humana e animal;

d) produção total - resultou da soma da produção de raí zes com a produção de hastes, cepas e produção de ramas;

e) Indice de colheita - foi determinado pela proporção entre a produção de raízes e a produção total das plantas, expressa em porcentagem;

f) teor de amido - a determinação do teor de matéria seca das raízes foi realizada em função do peso específico, pelo método da balança hidrostática tipo Reimann; subtraiu-se da porcentagem de matéria seca a constante 4,65 e foi calculada a porcentagem de amido dos genötipos. 


\subsection{Tratamento Estatístico-Genético}

3.5.1. Anālises individuais e conjuntas da variância

Em cada experimento foi feita uma anālise da variância segundo o delineamento experimental em reticulados quadrados utilizado para todos os caracteres. '́ exceção de índice de colheita e teor de ami do, que foram expressos em porcentagem, os caracteres foram analisados em t/ha. Os dados de teor de amido foram transformados em arc sen $\sqrt{\%}$, com a finalidade de se conseguir aproximação à distribuição normal, necessāria aos testes de hipóteses, conforme procedimento indicado por SNEDECOR e COCHRAN (1973). Por apresentarem distribuição normal, entretanto, os dados relativos ao indice de colheita não sofreram transformações.

Como as anālises em reticulados quadrados não apresentaram eficiência, os experimentos foram analisados pelo delineamento em blocos casualizados, em ambos os anos. Obedeceu-se a um modelo misto, onde os efeitos de blocos dentro de adubação e do erro foram considerados aleatórios e,o de tratamentos e da média geral, fixos. 0 modelo matemātico utilizado foi:

$$
Y_{i j k}=m+t_{i}+a_{j}+b_{k / j}+(t a)_{i j}+e_{i j k}
$$

onde:

$$
\begin{aligned}
Y_{i j k}= & \text { valor fenotípico do caráter na parcela com tratamento } \underline{\underline{i}} \text {, adu } \\
& \text { bação } \underline{j} \text { e repetição } \underline{\mathrm{k}} \\
\mathrm{m} \quad= & \text { média geral do caráter } \\
t_{i} \quad= & \text { efeito do tratamento } \underline{\underline{i}}(\underline{i}=1,2,3, \ldots, 16)
\end{aligned}
$$




$$
\begin{aligned}
& a_{j}=\text { efeito da adubação } \underline{j}(\underline{j}=1,2) \\
& b_{k / j}=\text { efeito de blocos } \underline{k} \text { dentro de adubação } \underline{j}(k=1,2) \\
& (t a)_{i j}=\text { efeito da interação entre o tratamento } \underline{i} \text { e a adubação } \underline{j} \\
& e_{i j k}=\text { erro experimental }
\end{aligned}
$$

A análise conjunta dos experimentos obedeceu ao seguinte modelo matemático, considerado misto, com $b_{k / j / \ell}$ aleatörio:

$$
Y_{i j k \ell}=m+s_{\ell}+t_{i / \ell}+a_{j / \ell}+b_{k / j / \ell}+(t a)_{i j / \ell}+e_{i j k \ell}
$$

onde:

$$
\begin{aligned}
& Y_{i j k \ell}= \text { valor fenotípico do caráter na parcela com tratamento } \underline{i}, \\
& \text { adubação } \underline{j} \text { e repetição } \underline{k} \text {, no experimento } \underline{\ell} \\
&= \text { média geral do caráter } \\
& s_{\ell} \text { efeito do experimento } \underline{\ell} \\
& t_{i / \ell}= \text { efeito do tratamento } \underline{i} \text { dentro de experimento } \underline{\ell} \\
& a_{j / \ell}= \text { efeito da adubação } \underline{j} \text { dentro de experimento } \underline{\ell} \\
& b_{k / j / \ell} \text { efeito de blocos } \underline{k} \text { dentro de adubação } \underline{j} \text { e dentro de experi- } \\
& \text { mento } \underline{\ell} \\
&(t a)=\text { efeito da interação entre o tratamento } \underline{i} \text { e adubação } \underline{j}, \\
& \text { no experimento } \underline{\ell} \\
& e_{i j k \ell} \text { erro experimental } \\
& \text { riância, com os respectivos testes } F, \text { são apresentados nos Anexos } 1 \text { e } 2,
\end{aligned}
$$
respectivamente.

$$
\text { Para avaliação da magnitude da interação tratamentos } \mathbf{x}
$$
anos foi também realizada anālise conjunta envolvendo somente os 56 
genótipos selecionados em 1980/81 e avaliados no ano subsequente, para cada um dos caracteres avaliados. A estrutura da análise é mostrada no Anexo 3.

3.5.2. Estimativas do coeficiente de determinação genotípica (b) Objetivando medir, entre os tratamentos, a proporção de variância fenotípica total que é de natureza genética, utilizou-se do coeficiente de determinação genotípica, segundo metodologia citada por CESNIK (1972), adotada também por FONSECA (1978), SERA (1980) e MONTEIRO (1980), onde se relaciona a variância genotípica entre os tratamentos de efeito fixo e a variância fenotípica entre as médias dos genötipos.

Os componentes necessärios para cálculo do coeficiente "b" foram estimados a partir da anālise conjunta da variância cujo esque ma é baseado no Anexo 2 e representado de forma resumida, como a seguir:

\begin{tabular}{lcc}
\hline Fontes de Variação & Q.M. & E(Q.M.) \\
\hline Tratamentos/Experimentos & $Q_{T}$ & $\sigma_{\mathrm{e}}^{2}+\mathrm{rV}_{\mathrm{T}}$ \\
Erro conjunto & $\mathrm{Q}_{\mathrm{R}}$ & $\sigma_{\mathrm{e}}^{2}$
\end{tabular}

onde:

$$
\begin{aligned}
\mathrm{Q}_{\mathrm{T}}= & \text { quadrado médio de tratamentos/experimentos, sem inclusão dos } \\
& \text { tratamentos comuns aos experimentos } \\
\mathrm{Q}_{\mathrm{R}}= & \text { quadrado médio do erro experimental } \\
\sigma_{\mathrm{e}}^{2}= & \text { variância do erro experimental } \\
\mathrm{V}_{\mathrm{T}}= & \text { componente quadrätico da variação entre genötipos } \\
\mathrm{r}= & \text { número de repetições }
\end{aligned}
$$


Dessa forma, o $V_{T}$ pode ser estimado pela seguinte expres são:

$\overrightarrow{\mathrm{V}}_{\mathrm{T}}=\frac{\mathrm{Q}_{\mathrm{T}}-\mathrm{Q}_{\mathrm{R}}}{\mathrm{r}}$

o coeficiente de determinação genotípica "b" foi determinado ao nível de médias de tratamentos, para todos os caracteres e em cada ano, utilizando-se da fórmula:

$$
\mathrm{b}=\frac{\hat{\mathrm{V}}_{\mathrm{T}}}{\frac{\mathrm{Q}_{\mathrm{T}}}{\mathrm{r}}}
$$

3.5.3. Progresso realizado com a seleção

A comparação entre médias, para a determinação do progres so realizado com a seleção, foi feita a partir das médias corrigidas para porcentagem, em função da produção dos tratamentos comuns aos experimentos. Usou-se esse critério devido à acentuada redução de rendimentos em 1981/82, para a maioria dos caracteres estudados, em decorrência de anormalidades climáticas.

Foram adotados valores de intensidade de seleção variāveis, para os cálculos relativos aos diferenciais de seleção e progressos realizados: $5 \%, 10 \%, 15 \%, 20 \%, 25 \%, 30 \%, 35 \%$ e $38 \%$. A intensidade de seleção de 38\% correspondeu à seleção de 56 genótipos em 1980/81.

Os diferenciais de seleção (ds) foram calculados da seguinte maneira: 


$$
\mathrm{ds}=\overline{\mathrm{X}}_{\mathrm{S}_{10 \text { ano }}}-\overline{\mathrm{X}}_{0}{ }_{10 \text { ano }}
$$

onde:

$$
\begin{aligned}
& \overline{\mathrm{X}}_{\mathrm{S}_{1 \mathrm{Q} \text { ano }}}=\text { média dos genótipos selecionados em 1980/81 } \\
& \overline{\mathrm{X}}_{0_{10 \text { ano }}}=\text { média dos } 146 \text { genótipos avaliados em 1980/81 } \\
& \text { Os ganhos por seleção (Gs) foram obtidos pela expressão: } \\
& G s=\bar{X}_{S_{2 \rho} \text { ano }}-\bar{X}_{0}{ }_{1 \rho \text { ano }}
\end{aligned}
$$

onde:

$$
\begin{aligned}
\overline{\mathrm{X}}_{\mathrm{S}_{2} \text { ano }}= & \text { média dos genótipos selecionados em } 1980 / 81 \text { e avalia- } \\
& \text { dos em } 1981 / 82 \\
\overline{\mathrm{X}}_{0_{1} \text { ano }}= & \text { média dos } 146 \text { genótipos avaliados em } 1980 / 81
\end{aligned}
$$

3.5.4. Estimativas do coeficiente de correlação fenotípica Foram estimados os coeficientes de correlação fenotípica entre todos os caracteres estudados, conforme a fórmula apresentada por FALCONER (1964).

$$
r_{F_{X Y}}=\frac{{ }^{\operatorname{ov}_{F}}(X, Y)}{\sigma_{F_{X}} \cdot \sigma_{F_{Y}}}
$$

onde:

$$
\begin{aligned}
& \mathrm{r}_{\mathrm{XY}}=\text { coeficiente de correlação fenotípica entre os caracteres } \mathrm{X} \text { e } \mathrm{Y} \\
& \operatorname{Cov}_{\mathrm{F}}(\mathrm{X}, \mathrm{Y}) \text { covariância fenotípica entre os caracteres } \mathrm{X} \text { e } \mathrm{Y} \\
& \sigma_{F_{X}} \text { e } \sigma_{F_{Y}}=\text { desvio padrão fenotípico dos caracteres } X \text { e } Y \text {, respect } \underline{\dot{i}}
\end{aligned}
$$


Os valores de $\operatorname{Cov}_{\mathrm{F}}(\mathrm{X}, \mathrm{Y}), \sigma_{\mathrm{F}}, \sigma_{\mathrm{F}_{\mathrm{Y}}}$ foram estimados a partir das médias dos genótipos em repetições e experimentos diferentes. Os caracteres correlacionados foram os seguintes: produção de raízes com produção total, produção de raízes com produção de ramas, produção de raízes com produção de hastes e cepas, produção de raízes com indice de colheita, produção de raízes com teor de amido, teor de amido com produção total, teor de amido com produção de ramas, teor de amido com produção de hastes e cepas, teor de amido com indice de colheita, índice de colheita com produção total, indice de colheita com produção de ramas, Indice de colheita com produção de hastes e. cepas, produção de hastes e cepas com produção total, produção de hastes e cepas com produção de ramas e produção de ramas com produção total.

Para os cảlculos da correlação fenotípica envolvendo o carāter teor de amido, em ambos os anos, foram utilizados os dados trans formados em arc sen $\sqrt{\%}$.

A significância dos coeficientes de correlação fenotípica foi verificada pelo teste $t$, com $n-2$ graus de liberdade, aos níveis de $5 \%$ e $1 \%$ de probabilidade, segundo procedimento adotado por STEEL e TORRIE (1980). 
4. RESULTADOS E DISCUSSÃO

\subsection{Comportamento dos Genótipos em 1980/81.}

As médias dos 146 genótipos, avaliados em dez experimen tos no período $1980 / 81$, e as amplitudes de variação para os caracteres produção de raỉzes, produção de hastes e cepas, produção de ramas, produção total, indice de colheita e teor de amido, são apresentadas no Anexo 4. Esses valores discriminados resultaram da média de quatro repetições, sendo que as duas primeiras foram adubadas e as ültimas não rece beram nenhum tipo de adubação.

$$
\text { Pode-se constatar amplitudes de variação de } 6,25 \text { a }
$$
41,32 t/ha; 4,76 a $28,71 \mathrm{t} / \mathrm{ha} ; 2,64$ a $14,44 \mathrm{t} / \mathrm{ha} ; 20,97$ a $74,72 \mathrm{t} / \mathrm{ha}$; 24,73 a $71,53 \%$ e 20,52 a $34,58 \%$, para os caracteres produção de raízes, produção de hastes e cepas, produção de ramas, produção total, indice de colheita e teor de amido, respectivamente. Essa ampla variação, observada em todos os caracteres avaliados, permite antever sucesso nos programas de seleção com mandioca. 
Os resultados das anālises individuais da variância para os seis caracteres considerados estão, de forma resumida, nas Tabelas 1 , $2,3,4,5$ e 6 . Nessas tabelas verifica-se que a maioria dos quadrados médios para tratamentos foram altamente significativos pelo teste F. Esses efeitos significativos evidenciam a existência de variabilidade genética entre os tratamentos, revelando que pelo menos um dos genótipos apresenta potencial genético contrastante, em relação aos caracteres estudados .

Feita a aplicação do teste $F$, detectou-se efeitos altamente significativos da adubação, em todos os experimentos, para produção de raízes e produção de hastes ecepas. $\bar{A}$ exceção dos experimentos de números 3, 4 e 7, para o caráter produção de ramas, e do experimento 4, pä ra produção total, a alta significância encontrada revela a influência da adubação na manifestação desses caracteres. Essa significância foi também observada na anālise conjunta dos experimentos, apresentada na Tabela 7 .

HOWELER (1982) comentou que os genótipos de mandioca possuem níveis de tolerância muito diferentes para a pouca disponibilidade de fósforo nos solos, sendo possível, por seleção de um grande nümero de cultivares, a obtenção de genótipos bem adaptados aos solos pobres, com uso mínimo de adubação. Como a aplicação de insumos é geralmente prática muito custosa para ser comumente recomendada, esses trabalhos seriam de grande interesse para a cultura da mandioca.

A significância da adubação, para os caracteres índice de colheita e teor de amido, não foi verificada na maioria dos experimentos 
e a análise conjunta também não revelou significância para o primeiro ca ráter. Esse tipo de resposta indica a alta estabilidade do caráter índice de colheita numa ampla diversidade de ambientes, conforme destacado pelo CIAT (1981). Este fato vem reforçar a importância de se utilizar o indice de colheita como base nos trabalhos de seleção.

Considerando como um dos pontos importantes o estudo da interação, os valores dos quadrados médios obtidos nas anālises individuais para a interação tratamentos $x$ adubação, quando comparados com o quadrado médio residual, evidenciaram significância estatística para alguns poucos experimentos e caracteres.

A análise conjunta dos dados, entretanto, só revelou significância para teor de amido, refletindo, à exceção desse caráter, o comportamento consistente dos genótipos em relação à presença ou ausência de adubação. Assim, a ausência da ințeração tratamentos $x$ adubação para a maioria dos caracteres indica que a avaliação e seleção dos genótipos pode ser realizada tanto na ausência, como na presença de adubação.

Pode-se verificar, também, na anālise conjunta, que os coeficientes de variação experimental foram maiores para alguns caracteres e menores para outros. Isso mostra que esses caracteres são influen ciados diferentemente pelos fatores do ambiente. Os que apresentaram coe ficientes mais elevados, como produção de ramas $(26,68 \%)$, produção de raí zes $(21,71 \%)$, produção de hastes e cepas $(20,47 \%) \cdots$ e produção total $(18,95 \%)$, são mais influenciados pelo ambiente e, possivelmente, devem ser controlados por maior número de genes do que os caracteres índice de 
colheita e teor de amido que apresentaram menores valores de coeficientes de variação.

De fato, pesquisas conduzidas por BARRIGA (1980) e ACOSTA-ESPINOZA (1983) mostraram que a produção de raízes é um carāter com tendência a ter coeficientes de variação mais elevados. Esse último autor sugeriu, como possível explicação, uma herança genética mais complexa da produção de raízes, em relação aos demais caracteres.

Os coeficientes de variação, classificados como altos para os dados de produção de ramas, raízes, hastes e cepas, e como médios para a produção total, conforme PIMENTEL GOMES (1982), indicam precisão experimental aceitável para esse tipo de avaliação. Para o índice de co Theita e o teor de amido os coeficientes de variação foram classificados como médios e baixos, respectivamente.

\subsection{Comportamento dos Genótipos em 1981/82.}

A partir dos experimentos realizados em 1980/81, foram selecionados 56 genótipos em função da produtividade de raízes e estabilidade de produção com e sem adubação. E interessante ressaltar, de iní cio, que estes caracteres constituiram-se nos fatores primordiais do presente estudo.

As médias dos tratamentos e as amplitudes de variação, pa ra todos os caracteres avaliados, considerando-se os 56 genótipos selecionados em 1980/81 e as médias desses mesmos materiais quando avaliados em 1981/82, são apresentadas nos Anexos 5 e 6, respectivamente. Observa-se que as médias dos dados obtidos no período 1981/82 sofreram grande 
redução, quando comparadas com as médias do período anterior, uma vez que a ausência de chuvas ocasionou plantio fora de época.

As amplitudes de variação para os 56 genótipos selecionados em 1980/81 foram de 16,93 a 41,32 t/ha; 8,54 a $28,72 \mathrm{t} / \mathrm{ha} ; 3,13$ a $14,37 \mathrm{t} / \mathrm{ha} ; 30,91$ a $74,72 \mathrm{t} / \mathrm{ha} ; 40,95$ a $71,53 \%$ e 20,52 a $34,58 \%$, para os caracteres produção de raízes, produção de hastes e cepas, produção de ramas, produção total, Indice de colheita e teor de amido, respectivamente. Para essa mesma sequência de caracteres, pode-se observar, para os 56 genótipos avaliados em 1981/82, amplitudes de variação da ordem de 4,69 a $19,35 \mathrm{t} / \mathrm{ha} ; 2,26$ a $15,04 \mathrm{t} / \mathrm{ha} ; 0,83$ a $4,38 \mathrm{t} / \mathrm{ha} ; 11,18$ a $31,90 \mathrm{t} / \mathrm{ha}$; 34,84 a $71,99 \%$ e 20,91 a $31,94 \%$.

Confrontando-se diretamente esses dados, constata-se que os valores para indice de colheita mantiveram aproximadamente a mesma am plitude, com médias de $56,24 \%$ no primeiro ano e $53,41 \%$ no segundo ano. Esse comportamento evidencia a alta herdabilidade do caräter, conforme destacado por KAWANO et alii (1978b) e CIAT (1981).

Para facilitar a visualização do efeito da escassez de chuvas, quando da época de plantio, na seleção para produção de raízes, foram construídos os polígonos de frequência representados nas Figuras 1 e 2. A Figura 1 mostra a distribuição dos 146 genótipos originais e dos 56 genótipos selecionados, verificando-se que estes apresentaram redução em suas médias. Com a produção de raízes, corrigida em função da porcen tagem das testemunhas comuns aos experimentos, a distribuição desses mes mos genótipos é ilustrada na Figura 2 . 
Nas Tabelas $8,9,10,11,12$ e 13, encontram-se os coeficientes de variação e os quadrados médios obtidos nas anālises individuais da variância, para os seis caracteres estudados. Os resultados da anālise conjunta estão sumarizados na Tabela 14 .

Através dessas análises pode-se verificar, de forma anäloga ao período anterior, que o teste $F$ mostrou-se altamente significativo para os efeitos de tratamentos, o que indica a existência de diferenças genéticas entre os tratamentos.

A apreciação dos resultados (teste F) evidencia, também, alta significância para o efeito de adubação, considerando-se os caracte res produção de raízes, produção de hastes e cepas, produção de ramas e a produção total. Para o índice de colheita e teor de amido não houve influência da adubação, haja vista que não se observou significância para quase todos os experimentos submetidos às análises individuais. Resul tados obtidos nos trabalhos conduzidos por ARRUDA et alii (1978), envolvendo duas variedades, confirmam a inexistência de efeitos de adubação sobre a porcentagem de amido.

A anälise conjunta dos dados de índice de colheita e produção de hastes e cepas revelou, para a fonte de variação tratamentos $x$ adubação, significância pelo teste $\mathrm{F}$ ao nível de $1 \%$ de probabilidade. A alta significância encontrada para estes caracteres evidencia comportamento diferencial dos genótipos, quando se utiliza ou não da prática de adubação.

Os coeficientes de variação mostrados na Tabela 14 são tị dos por PIMENTEL GOMES (1982) como baixos (< 10\%), médios (10 a 20\%) e 
altos (20 a 30\%). As magnitudes foram semelhantes às obtidas em 1980/81, sendo da ordem de $2,32 \%, 11,50 \%, 19,63 \%, 19,72 \%, 24,62 \%$ e $27,86 \%$, para teor de amido, Indice de colheita, produção total, produção de hastes e cepas, produção de raízes e produção de ramas, respectivamente. Isto sugere, a exemplo do que foi encontrado para o ano anterior, que os caracteres com valores mais elevados são, possivelmente, controlados por muitos genes.

\subsection{Estimativas dos Parâmetros Genéticos e Fenotípicos}

As estimativas obtidas no presente trabalho for am calcula das a partir de experimentos conduzidos em apenas uma localidade e em dois anos. Assim, possivelmente, tais estimativas tenham sido superestimadas devido ao componente de variação relativo à interação genótipo $x$ ambiente. Os resultados obtidos são vālidos para as condições ecológicas predominantes no Recôncavo Baiano.

o sucesso da seleção, em todos os programas de melhoramento, depende da magnitude da variabilidade genética. A variabilidade genética entre os genótipos de mandioca foi medida através dos coeficien tes de determinação genotípica (b). Estes coeficientes foram obtidos ao nível de médias, a partir das estimativas de componentes da variância das análises apresentadas nas Tabelas 15, 16 e 17. Nessas análises não foram incluidos os tratamentos comuns aos experimentos, a fim de evitar superestimação das estimativas. Referindo-se aos coeficientes "b", MONTEIRO (1980) afirmou que são bons indicadores da magnitude da variabilidade genética. 
As estimativas dos coeficientes de determinação genotípica, como calculadas no presente trabalho, oferecem uma idéia da eficiência de seleções futuras, a serem efetuadas no conjunto fixo de materiais. Os valores de "b", estimados para os caracteres dos 146 genótipos avalia dos em 1980/81, são apresentados na Tabela 18. Estes coeficientes, relativamente altos, indicam que parte significativa da variação fenotípica existente para todos os caracteres estudados é devida a causas genéticas.

Pesquisadores, como FONSECA (1978), OLIVEIRA (1979), MONTEIRO (1980), SERA (1980), MARTINS e VELLO (1981), PONTES e MARTINS (1982), salientaram que caracteres com valores de "b" próximos a 1 são pouco influenciados pelas alterações a ambiente, sendo mais facilmente alterados por seleção. Na realidade, o sucesso na seleção é função da magnitude da variância genética aditiva e da epistasia de tipo aditivo $\mathrm{x}$ aditivo, enquanto que o"b"reflete a magnitude da variância genotípica, incluindo variância aditiva, variância dominante e as epistasias do tipo aditivo $\mathrm{x}$ dominante $\mathrm{e}$ dominante $\mathrm{x}$ dominante. Para separação dos componentes aditivos e dominantes da variância, é necessārio utilizar esquemas apropriados de cruzamentos. Em mandioca, ACOSTA-ESPINOZA (1983) detalhou a metodologia de policruzamentos para estimação das variâncias ge néticas aditiva e dominante e dos demais parâmetros genéticos dependentes destas variâncias.

$$
\text { Observando-se os valores de"b"obtidos neste traba- }
$$

1ho, pode-se classificar os caracteres em ordem decrescente, de acordo com as possibilidades de se conseguir maiores progressos genéticos, 
conforme se segue: teor de amido, Indice de colheita, produção de hastes e cepas, produção de raízes, produção de ramas, produção total.

$\bar{A}$ semelhança dos resultados obtidos neste trabalho, BARRI GA (1980) constatou altos valores de" b" para a produção de raízes. Entretanto, torna-se interessante ressaltar que os resultados das duas pesqui sas não podem ser confrontados diretamente, visto que as estimativas baseadas em médias de repetições são restritas ao tipo de experimento que levou à sua obtenção. ACOSTA-ESPINOZA (1983) comeṇtou que estimativas obtidas ao nível de plantas individuais poderiam ser comparadas, mesmo quando os experimentos apresentassem delineamentos ou estruturas diferentes.

$\bar{E}$ esperado que, à medida que os ciclos de seleção se sucedam, ocorra diminuição da variação genética, tendo sido relatado que a maior redução de variabilidade aconteceria do material original para o material selecionado, ou seja, no primeiro ciclo de seleção. Neste trabalho aplicou-se intensidade de seleção de $38 \%$ sobre os 146 genótipos inicialmente avaliados. Exame dos valores de"b"para os 56 genótipos avaliados em 1981/82, b $=0,5070$ a 0,9347 (Tabela 18), em comparação com os valores de"b"para os 146 genótipos avaliados em 1980/81, b =0,8553 a 0,9280 (Tabela 18), permite a quantificação da redução da variabilidade genética com um ciclo de seleção. Observa-se que a diminuição mais acentuada, em torno de 34,83\%, ocorreu para o caráter produção total. Para a produção de raízes, produção de hastes e cepas, produção de ramas e Indice de colheita, as reduções foram da ordem de $13,36 \%, 7,46 \%, 8,68 \%$ e 2,49\%, respectivamente. 
Como o carāter teor de amido não foi utilizado na seleção dos genótipos superiores, espera-se que não ocorram mudanças nos valores de" b" do ciclo 0 para o ciclo 1. Possíveis alterações no teor de amido seriam consequências de resposta correlacionada à seleção praticada para outros caracteres, no caso presente, produção de raízes. Este fato poderia explicar o valor ligeiramente superior de"b"para os 56 genótipos avaliados no período $1981 / 82(b=0,9347)$ em relação ao encontrado entre os 146 genótipos originais $(b=0,9280)$ para o caráter teor de amido, observados na Tabela 18.

Assim, considerando-se que apōs a branda intensidade de seleção (is) praticada (is $=38 \%$ ), os genótipos avaliados ainda exibem variabilidade genética para todos os caracteres, tem-se que, com a continuidade do programa de seleção, progressos adicionais poderão ser alcançados.

Observando-se a Tabela 19, onde são relatados os quadrados mëdios e as respectivas significâncias da análise conjunta dos 56 genótipos selecionados em $1980 / 81$ e posteriormente avaliados, verificase que os efeitos de anos e da interação tratamentos * anos foram altamente significativos para os seis caracteres. Isso revela diferenças entre as condições ambientes relacionadas aos anos abrangidos na anālise e demonstra a influência negativa das variações ambientes previsíveis e/ou imprevisiveis no desempenho diferencial das cultivares (ALIARD e BRADSHAW, 1964), sendo necessária, portanto, a condução dos experimen-. tos em värios anos. 
A ocorrência de interação genótipos $x$ anos também afetou a magnitude do coeficiente de determinação genotípica. Este fato pode ser observado pela comparação dos valores de"b"para os 56 genótipos avaliados nos dois anos agrícolas (Tabela 18). Menores valores de"b" foram observados no ano agrícola com condições ambientes desfavoráveis (1981/82).

$$
\text { Apesar dos experimentos terem sido conduzidos em apenas }
$$

dois anos agrícolas, as modificações drásticas do ambiente de um ano para outro poderiam tornar a seleção de genótipos eficiente para adaptação ampla às condições ambientes variáveis. De fato, sILVA etalii (1963) relataram que dois anos agrícolas fornecem indicação confiável sobre o comportamento relativo de cultivares. No presente trabalho, como a seleção dos genótipos foi feita com base em um ano agrícola é de se esperar que a eficiência da seleção não seja a mais satisfatória. Tal fato pode ser visualizado pelos baixos coeficientes de correlação fenotípica entre os 56 genótipos avaliados nos dois anos. Assim, foram encontrados valores de 0,18 para produção de raízes, 0,33 para produção de ramas e 0,35 para produção total. Os caracteres índice de colheita, produção de hastes e cepas e teor de amido apresentaram coeficientes de 0,57,0,64 e 0,75 respectivamente, indicando serem menos influenciados pelos efeitos da interação tratamentos $\mathrm{x}$ anos.

A existência da interação genótipos $x$ anos e seus efeitos ligados ao progresso na seleção são amplamente reconhecidos (PATERNIANI, 1980). A Tabela 20 apresenta os valores dos diferenciais de seleção para o caráter produção de raízes e os ganhos realizados para todos os caracteres, aplicando-se intensidades de seleção variáveis de 5 a $38 \%$. 
$\bar{A}$ exceção da intensidade de seleção de $38 \%$, que correspondeu à seleção de 56 genótipos em 1980/81, todas as outras intensidades foram simuladas apōs o processo seletivo.

Os valores dos diferenciais de seleção para a produção de raízes foram maiores para as intensidades de seleção mais fortes, indicando que, na ausência da interação dos tratamentos com os anos, os progressos realizados para a produção de raízes seriam proporcionais a esses valores,

De maneira geral, porém, os progressos realizados em por centagem das testemunhas, foram crescentes àpenas até a intensidade de seleção de $15 \%$, revelando que com a aplicação de intensidades de $5 \%$ e $10 \%$, foram selecionados os genótipos melhor adaptados às condições do ano agrícola 1980/81, que não se repetiram no período 1981/82. Segundo PATERNIANI e MIRANDA FILHO (1978), considerando-se que a interação genótipos $x$ anos é um fato generalizado, pode ocorrer que os melhores genótipos em um determinado ano não sejam os superiores na média de vārios anos.

Na regiãc onde foram instalados os experimentos, variações climáticas anuais são constantes, modificando de maneira sensível o comportamento dos genótipos, semelhante ao que ocorreu nos dois anos agrícolas relativos ao presente estudo. Dessa forma, a interação genótipos $\mathrm{x}$ anos assume grande importância na seleção de genótipos indicados para a região do Recôncavo Baiano, determinando o emprego de maior nümero de repetições e intensidades de seleção mais brandas ou seleção baseada no comportamento dos genótipos em vários anos. 
o carāter teor de amido teve comportamento contraditório, apresentando ganhos inferiores com intensidades de seleção mais fortes. Isto pode ser explicado pela tendência de correlação negativa entre porcentagem de amido e produção de raỉzes, mostrada na Tabela 22. Como a seleção foi baseada, principalmente, na produtividade de raízes, à medida que se utilizou de intensidades de seleção mais fortes, genótipos mais produtivos em raízes foram sendo selecionados, que em função da res posta correlacionada possuem menores valores de teor de amido.

Como pode ser constatado pela apreciação dos resultados, os efeitos da interação contribuiram para diminuir a eficiência da seleção. Conforme destacado por PATERNIANI (1980), na ausência de interação, seleção muito intensa visa melhoramento a curto prazo, enquanto que utilizando-se de intensidades de seleção mais brandas, além de serem assegurados progressos genéticos a curto prazo, pode-se manter variabilidade genètica necessāria a progressos subsequentes.

Um outro parâmetro que pode ser ütil na orientação da seleção é a correlação entre os caracteres. Embora a produção de raízes seja o carāter de maior interesse, a produção de hastes e cepas, produção de ramas, produção total, indice de colheita e o teor de amido podem ser considerados na avaliação de genótipos de valor comercial.

Para os melhoristas de mandioca seria vantajoso poder ava liar o desenvolvimento das raízes pelo fenótipo da parte aērea. Por esta razão, foram determinados os coeficientes de correlação fenotípica en tre os värios caracteres estudados, obtidos nos períodos de 1980/81 e 1981/82 através das análises das variâncias e covariâncias, apresentados 
nas Tabelas 21 e 22. A discussão dos resultados serä feita isoladamente, para cada um dos anos e para as características mais importantes.

Pode-se observar, pelos dados da Tabela 21 , que a maioria dos coeficientes foi significativa ao nível de $1 \%$ de probabilidade, indicando que os mesmos diferem de zero e que os caracteres são correlacionados. Estes coeficientes são mais representativos que aqueles apresentados na Tabela 22, pois foram julgados com maior nümero de graus de 1iberdade, pelo teste t. Os caracteres cujos coeficientes não apresentaram significância devem possuir pouca ou nenhuma associação, sugerindo que foram selecionados independentemente ao longo do processo evolutivo da mandioca.

A produção de raízes apresentou correlação positiva e altamente significativa com o Indice de colheita, produção total e com a produção de hastes e cepas, sendo esta ūltima associação, porēm, de baixa magnitude. A associação da produção de raízes com o índice de colhei ta torna-se importante no processo de obtenção de cultivares superiores, porque permite usar o índice como indicador auxiliar nos trabalhos de se leção. Pesquisas desenvolvidas por BIRADAR et alii (1978), CIAT (1975), EMBRAPA/CNPMF (1980b), FUKUDA et alii (1983) e SILVA et alii (1983) apresentaram resultados semelhantes. De acordo com KAWANO (1982) só é viável obter-se altos rendimentos de raízes quando os índices de colheita forem superiores a 60\%. ACOSTA-ESPINOZA (1983) considerou a importância dos genótipos possuirem alto índice de colheita e alta produção de raízes, para maior produtividade. 
Entre a produção de raízes e produção de ramas praticamen te não houve correlação, jā que o coeficiente encontrado foi baixíssimo, mostrando uma ligeira tendência positiva. Estes resultados sugerem a independência dos caracteres, contrariando resultados verificados por MENDES (1940), GRANER (1946), ESTEVÃO et alii (1972) e ALMEIDA et alii (1976), que detectaram correlações positivas e significativas, assim como aqueles obtidos por CIAT (1975), PAULA (1976), CONCEIÇÃO (1979) e MATTOS et alii (1980), demonstrando que houve tendência no sentido de que as variedades com maior produtividade de raízes produzissem menor quantidade de ramas.

A produção de raízes também apresentou associações positivas e significativas com a produção de hastes e cepas e com o teor de amido. O teor de amido mostrou correlações positivas e significativas com quase todos os caracteres, embora as magnitudes desses coeficientes não fossen superiores a 0,28 .

As correlações entre produção de hastes e cepas com índice de colheita e produção de ramas com índice de colheita foram negativas e significativas, evidenciando, desta forma, que maior desenvolvimento da parte aérea implica, na maioria das vezes, na obtenção de menores índices de colheita. Resultados idênticos foram obtidos nos trabalhos realizados por CIAT (1975) e CONCEIÇÃO (1979), muito embora algumas exceções a esta tendência tenham sido observadas nas pesquisas de ACOSTA-ESPINOZA (1983).

Observando-se agora os coeficientes apresentados na Tabela 22, verifica-se que a produção de raízes apresentou correlação positiva e significativa com a produção de ramas. Este coeficiente $(r=0,39)$, 
entretanto, devido a sua baixa magnitude, sugere fraca correlação, a exemplo do que foi discutido para o primeiro ano. As correlações do índice de colheita com as produções de raízes, hastes e cepas, ramas e da produção de raízes com a produção de hastes e cepas, mostraram magnitudes semelhantes às obtidas no período 1980/81.

Os coeficientes de correlação fenotípica envolvendo o caráter teor de amido não apresentaram significância estatística, embora se identifique uma tendência de associação negativa desse caráter com o Indice de colheita $(r=-0,19)$ e com a produção de raízes $(r=-0,07)$. Para as correlações entre teor de amido e os demạis caracteres observaramrse tendências positivas de associação. Essa ausência de significância para os coeficientes não foi verificada no ano anterior, o que pode ser devido ao grande número de dados com que estes coeficientes foram julgados nos experimentos de 1980/81, dando maior sensibilidade ao teste $t$.

As cơrrelações fenotípicas sãode grande importância no me 1horamento, pois podem orientar a seleção, principalmente no que se refe re a intensidade a ser aplicada em cada caráter (VELLO et alï, 1973). o interesse pelo uso das correlações, no entanto, baseia-se especialmente nas associações genéticas entre os caracteres, que se existentes determi nam as respostas correlacionadas num programa de seleção. Assim, seria interessante a realização de um estudo das correlações genéticas entre caracteres de importância agronômica, que envolveria a determinação dos componentes genéticos de covariância entre indivíduos aparentados.

A grande variabilidade verificada entre as cultivares pelos altos valores dos coeficientes de determinação genotípica estimados 
para todos os caracteres sugere que o programa de seleção pode ser continuado.

Tendo-se em vista o grande interesse na formação de compostos obtidos pelo intercruzamento de genótipos, dando origem a populações base com maior quantidade de variabilidade genética (HALLAUER e EBERHART, 1966; PATERNIANI, 1967 e outros), será interessante a seleção de genótipos superiores dentre os avaliados visando a obtenção destes compostos. Após o intercruzamento inicial das cultivares, a recombina ção gênica poderá ser estabelecida depois de algumas gerações de cruzamentos ao acaso (HALLAUER e MIRANDA FILHO, 1981), o que se torna facilitado pelo florescimento frequente dos genótipos no Recôncavo Baiano, onde foram instalados os experimentos. E preciso salientar que as cultivares selecionadas devem apresentar ciclos reprodutivos semelhantes para coincidência da época de florescimento. A população será submetida aos processos dè seleção utilizáveis para plantas alögamas (ALLARD, 1971), após a recombinação gênica. Deve-se ressaltar que a propagação vegetativa da mandioca permite a manutenção indefinida dos genótipos selecionados, possibilitando a exploração de toda a variabilidade genética, aditiva e dominante.

De acordo com ACOSTA-ESPINOZA (1983), existe predominância de variância aditiva para produção em mandioca. Dessa forma, a seleção dos parentais para a síntese dos compostos de mandioca è facilitada, sendo função principalmente da capacidade geral de combinação dos parentais. 0 mesmo autor comenta a viabilidade de se utilizar policruzamentos em programas de melhoramento de mandioca. 
5. CONCLUSÕES

Os resultados obtidos em condições ecológicas do Recôncavo Baiano, permitem concluir que:

a. Existe ampla variabilidade genotípica para värios caracteres agronômicos, a ser explorada em programas de melhoramento de mandioca.

b. O efeito da adubação foi uniforme sobre os diferentes genótipos, indicando existir possibilidades da seleção para produtividade, ser pra ticada em solos de baixa fertilidade.

c. A seleção para produção de raízes deve ser feita com base em pelo menos dois anos agrícolas, para minimizar os efeitos da interação en tre genótipos e anos agrícolas.

d. Quando a seleção para produção de raízes basear-se em observações ex perimentais de um único ano agrícola, devem ser evitados percentuais seletivos inferiores a $15 \%$. 
e. Existe variabilidade genotípica remanescente entre os genótipos selecionados no primeiro ciclo, conforme valores de coeficiente de determinação genotípica antes e após a prática de seleção.

f. Indice de colheita è um caräter importante em programas de seleção para maior produção de raízes, devido ter valores altos de coeficien te de determinação genotípica e de correlação fenotípica com produção de raízes. o uso indiscriminado do indice de colheita, entretanto, em função de sua associação negativa e significativa com a produ ção de ramas e produção de hastes e cepas, provoca redução do material de plantio, limitando a utilização desse carāter. 


\section{LITERATURA CITADA}

ABRAHAM, A., 1970. Breeding work on tapioca cassava and a few other tropical tuber crops. Tropical Root and Tuber Crops Tomorrow. Mayaguez, $1: 76-80$.

ACOSTA-ESPINOZA, J., 1983. Eficiência de policruzamentos para recombinação gênica e estimação de parâmetros genéticos em mandioca (Manihot esculen ta Crantz). Piracicaba, ESALQ/USP, 79 p. (Dissertação de Mestrado).

ALBUQUERQUe, M.de, 1969. A mandioca na Amazônia. Belém, SUDAM, 277 p.

ALLARD, R.W. e A.D.BRADSHAW, 1964. Implications of genotype - environmental interactions in applied plant breeding. Crop Science. Madison, 4:503508.

ALLARD, R.W., 1971. Principios do melhoramento genético das plantas. Tra dução de A.Blumenschein, E.Paterniani, J.T.A.Gurgel e R.Vencovsky. São Paulo, Editora Edgard Blücher Ltda. 381 p. 
ALMEIDA, F.C.G. e J.B.PAIVA, 1971. Competição de variedades de mandioca, Manihot utilissima Pohl. Ciência Agronômica. Fortaleza, 1:27-29.

ALMEIDA, F.C.G., R.de P.NUNES e F.E.C.NUNES, 1976. Produção de raízes de mandioca (Manihot utilissima Poh1.) em regime de suplementação hídrica e suas relações com a produção de ramas. Ciência Agronômica. Fortale$2 a, \quad 6: 31-34$

ANDRADE, M.A.de, 1978. Métodos de melhoramento da mandioca. In: Curso de capacitação de técnicos para a cultura da mandioca. Lavras, Convênio INT/FANAT / FAEPE, D. 1-29.

ARRUDA, F.B., J.O.LORENZI, G.B.BARRETO e E.ABRAMIDES, 1978. Comportamento de duas variedades de mandioca sob dois níveis de umidade e de adubação do solo. Bragantia. Campinas, 37:109-116.

BARRIGA, R.H.M.P., 1980. Caracterização de cultivares de mandioca (Manihot esculenta Crantz) com relação à produção e estabilidade. Piracicaba, ESALQ/USP, 129 p. (Dissertação de Mestrado).

BIRADAR, R.S., P.G.RAGENDRAN e N.HRISNI, 1978. Genetic variability and correlation studies in cassava (Manihot esculenta Crantz). Journal of Root Crops. New York, 4:7-10.

BRASIL. Fundação Instituto Brasileiro de Geografia e Estatística, 1982. Anuärio Estatistico. Rio de Janeiro, $904 \mathrm{p}$. 
BRAZ, A.J.B.P., 1983. Interação genótipo $x$ ambiente em trigo (Trıtıcum aestevum L.) no centro-oeste brasileiro. Piracicaba, ESALQ/USP, 57 p. (Dissertaçāo de Mestrado).

BÜLOW, J.E.W.von, 1971. Comportamento de variedades de mandioca (Manehot esculenta) na Baixada Fluminense durante os anos de 1966 a 1970 . Pes. quusa Agropecuära Brasuleira. Rio de Janeiro, 6:209-213. (Série Agronómica).

CARVAlHo, H.W.L.de, 1981. Avaliaçäo de cultevares de mandioca no centro Nacional de Pesquesa de Mandioca e Fruticultura. Cruz das Almas, EMBRAPA/CNPMF. 2p (Série Pesquisa em Andamento, 7).

CENTRO INTERNACIONAL DE AGRICULtURA TROPICAL, 1975. Informe Anual. Cali, Colombia, p. B.36-B. 43 .

CENTRO INTERNACIONAL DE AGRICULTURA TROPICAL, 1981. Informe Anual dex Programa de yuca. Cali, Colombia, p.29-35.

CESNIK, R., 1972. Estudo da herdabilidade de alguns caracteres em canade-açúcar. Piracicaba, ESALQ/USP, 78 p. (Tese de Doutoramento).

COCK, J.H., 1978. Potencial agronomico para la producción de yuca. In: Curso de producción de yuca. Cali, Colombia, CIAT, D.31-39.

COMSTOCK, R.E. e R.H.MOLL, 1963. Genotype-environment interactions. In: HANSON, W.D. e H.F.ROBINSON, ed. Statistical Genetics and Plant Breeding. Washington, National Academy of Sciences, p.164-196. 
CONCEIÇÃO, A.J.da, C.V.SAMPAIO e M.A.MENDES, 1973a. Competição de variedades de mandioca para a produção de rama para forragem. In: Projeto Mandioca. Cruz das Almas, EAUFBA/BRASCAN NORDESTE, p.115-127.

CONCEIÇÃO, A.J.da, C.V.SAMPAIO e M.A.MENDES, 1973b. Competição de variedades de aipim e mandioca para forragem. In: Projeto Mandioca. Cruz das Almas, EAUFBA/BRASCAN NORDESTE, p. 129-142.

CONCEIÇÃO, A.J.da e C.V.SAMPAIO, 1975. Competição de cultivares de mandioca e aipim (Manihot esculenta Crantz) para fins industriais. In: Projete Mandioca. Cruz das Almas, EAUfBA/BRASCAN NORDESTE, p.71-78 (Sé rie Pesquisa, 1).

CONCEIÇÃO, A.J.da, 1979. A mandioca. Cruz das Almas, UFBA/EMBRAPA/BNB/ BRASCAN NORDESTE. $382 \mathrm{p}$.

CORRÊA, H., 1971. Possibilidades de aproveitamento do cerrado para a cu1 tura da mandioca. In: Reunião da Comissão Nacional de Mandioca. Sete Lagoas, IPEACO, p.18-32.

CORREิA, H., J.C.E.O.BEGAZO, S.S.BRANDÃO e F.R.GOMES, 1973. Efei to da poda de ramas de mandioca na produção de ramas e raízes. Revista Ceres. Viçosa, 20:148-157.

DANTAS, J.L.L., J.da S.SOUZA, A.R.N.FARIAS e M.M.C.NIACEDO, 1981. Cultivo da mandioca. Cruz das Almas, EMBRAPA/CNPMF. 24 p. (Série Circular Téc nica, 1). 
DEMPSEY, A.H., 1972. Genetics and cultivares of cassava. In: HENDER-SHOTT, C.E., Coord. A literature review and research recommendations on cassava (Manihot esculenta Crantz). Athenes, University of Georgia, p. 1536.

EBERHART, S.A. e W.A. RUSSEL, 1966. Stability parameters of comparing varieties. Crop Science. Madison, 6:36-40.

EMPRESA BRASILEIRA DE PESQUISA AGROPECUÁRIA. Centro Nacional de Pesquisa de Mandioca e Fruticultura, 1979. Relatōrio Técnico Anual - 1977. Cruz das Almas, EMBRAPA/CNPMF: 125p.

EMPRESA BRASILEIRA DE PESQUISA AGROPECUĀRIA. Centro Nacional de Pesquisa de Mandioca e Fruticultura, 1980a. Relatōrio Técnico Anual - 1978. Cruz das Almas, EMBRAPA/CNPMF. 147p.

EMPRESA BRASILEIRA DE PESQUISA AGROPECUĀRIA. Centro Nacional de Pesquisa de Mandioca e Fruticultura, 1980b. Relatörio Técnico Anual - 1979. Cruz das Almas, EMBRAPA/CNPMF. 183p.

EMPRESA BRASILEIRA DE PESQUISA AGROPECUĀRIA. Serviço Nacional de Levantamento e Conservação de Solos, 1977. Levantamento exploratōrio - reconhecimento de solos da margem direita do Rio São Francisco; Estado da Bahia. Rio de Janeiro. p.136-137 (Sério Boletim Técnico, 52).

ESTEVÃO, E.de M., 1971. Produção de raízes e de ramas e relação entre caracteres da parte aérea e produção de raízes em variedades de mandioca. Viçosa, UFV, 35 p. (Dissertação de Mestrado). 
ESTEVÃO, E.de M., J.C.E.O. BEGAZO, S.S. BRANDÃO e L.M. OLIVEIRA, 1972. Produção de raízes e ramas e relação entre caracteres da parte aérea e produção de raỉzes em variedades de mandioca. Revista Ceres. Viçosa, 19:311-327.

EZETA, F.N., J.da S. SOUZA e P.L.P. de MATOS, 1981. A mandioca como matêria prima na produção de älcool. Cruz das Almas, EMBRAPA/CNPMF. 36 p. (Série Documentos, 4).

FALCONER, D.S., 1964. Introduction to quantitative genetics. New York, The Ronald Press Company. 365p.

FONSECA, T.C., 1978. Estimação de parâmetros visando a seleção de híbridos artificiais de amoreira (Morus alba L.). Piracicaba, ESALQ/USP, 51 p. (Dissertação de Mestrado).

FUKUDA, W.M.G., 1979. Produção e seleção preliminar de novos híbridos de mandioca (Manihot esculenta Crantz I. In: I Congresso Brasileiro de Mandioca. Anais. Salvador, EMBRAPA/DID/SBM, 1:535-545.

FUKUDA, W.M.G. e S.de O. e SILVA, 1979. Escolha de variedades de mandioca (Manihot esculenta Crantz). In: III Curso Intensivo Nacional de Mandio ca. Cruz das Almas, EMBRAPA/CNPMF, 8 p.

FUKUDA, W.M.G., H.W.L. de CARVALHO, S.de O. e SILVA e R.C. CALDAS, 1983. Avaliação de clones de mandioca no Centro Nacional de Pesquisa de Mandioca e Fruticultura. Revista Brasileira de Mandioca. Cruz das Almas, $2: 1-7$. 
GRAMACHO, D.D., 1975. Contribuição ao estudo químico tecnológico do feno da mandioca. In: Projeto Mandioca. Cruz das Almas, EAUfBA/BRASCAN NOR DESTE, p. 153-158 (Série Pesquisa, 1).

GRANER, E.A., 1942. Genética de Manihot. I-Hereditariedade da forma da folha e da coloração da película externa das raízes em Manihot utilissima Poh1. Bragantia. Campinas, 2:13-22.

GRANER, E.A., 1946. Tratamento de mandioca pela colquicina. Análise com parativa entre clones diplóides e tetraplöides. In: Escola Superior de Agricultura "Luiz de Queiroz". Anais. Piracicaba, ESALQ/USP, 3: $99-140$.

HAHN, K., K.HOWLAND e R.TERRY, 1980. Correlated resistance of cassava to mosaic and bacterial blight diseases Nigeria. Euphytica. Wageningen, $29: 305-311$.

HALLAUER, A.R. e S.A.EBERHART, 1966. Evaluation of synthetic varieties of maize for yield. Crop Science. Madison, 6:423-427.

HALLAUER, A.R. e J.B.MIRANDA FILHO, 1981. Quantitative genetics in maize breeding. Ames, Iowa State University Press. 468 p.

HOWELER, R.H., 1982. Nutricion mineral y fertilizacion de la yuca. In: DOMINGUEZ, C.E., Coord. Yuca: investigaciōn, producciōn y utilizaciōn. Cali, Colombia, PNUD/ĆIAT, p.317-357. 
KAWANO, K., A.AMAYA, P.DAZA e M.RIOS, 1978a. Factors affecting efficiency of hibridization and selection in cassava. Crop Science. Madison, 18: $373-376$.

KAWANO, K., P.DAZA, A.AMAYA, M.RIOS e W.M.F.GONÇALVES, 1978b. Evaluation of cassava germplasm for productivity. Crop Science. Madison, 18:377380 .

KAWANO, K., 1980. Cassava. In: Hybridization of Crop Plants. Madison, American Society of Agronomy, Crop Science Society of America, p.225233.

KAWANO, K., 1982. Mejoramiento genético de yuca para productividad. In: DOMINGUEZ, C.E., Coord. Yuca: investigaciōn, producciōn y utilizaciōn. Cali, Colombia, PNUD/CIAT, p. 91-112.

KING, C.R., 1974. A dictionary of genetics. 2a ed. Toronto, Oxford University. $373 \mathrm{p}$.

MAGOON, M.L., 1969. Recent trends in cassava breeding in India. Proceedings of the Symposium on Tropical Root Crops. St. Augustine, Trinidad, University of West Indies, p. 100-117.

MARTINS, P.S. e N.A.VELLO, 1981. Performance and variability of agronomic characters in populations of Stylosantes guianensis (Aub1.) Sw. In: SMITH, J.A. e V.W.HAYS, Ed. Proceedings of the XIV International Grassland Congress. Kentucky, p. 15-24. 
MATTOS, P.L.P.de, 1972. Melhoramento da mandioca, Manihot esculenta Crantz; competição de variedades de mandioca para produção de massa verde. Cruz das Almas, IPEAL. 5 p. (Série Comunicado Técnico, 56).

MATTOS, P.L.P.de e J.R.FERREIRA, 1975. Competição de cultivares de mandioca (Manihot esculenta Crantz) no municipio de Irarä-Bahia. Cruz das Almas, EMBRAPA/IPEAL. 5 p. (Série Comunicado Técnico, 10).

MATTOS, P.L.P.de, J.M.M.SAMPAIO e R.C.CALDAS, 1980. Competição de cultivares de mandioca (Manihot esculenta Crantz) no municipio de Santa Terezinha-Bahia. Cruz das Almas, EMBRAPA/CNPMF. 6 p. (Série Comunicado Téc nico, 12).

MENDES, C.T., 1940. Contribuição para o estudo da mandioca. São Paulo, Secretaria de Agricultura e Comércio. $88 \mathrm{p}$.

MONTEIRO, W.R., 1980. Estudo da variabilidade e correlação entre caracteres agronômicos em populações de Centrosema pubescens Benth. Piracicaba, ESALQ/USP, 70 p. (Dissertação de Mestrado).

MOORE, P.C., 1978. El uso de forraje de yuca en la alimentacion de rumiantes. In: Curso de producción de yuca. Cali, Colombia CIAT, 2:659-675.

MÔRO, J.R., 1982. Efeito da alta intensidade de seleção no melhor amento de milho. Piracicaba, ESALQ/USP, 59 p. (Tese de Doutoramento). 
NESTEL, B., 1974. Current trends in cassava research. Ottawa, Canada, IDRC. $32 \mathrm{p}$.

NORMANHA, E.S. e A.S.PEREIRA, 1963. Cultura da mandioca. O Agronômico. Campinas, 15:22-24.

NORMANHA, E.S., 1971. O trabalho de melhoramento de mandioca no Instituto Agronômico do Estado de São Paulo. O Agronômico. Campinas, 23: $91-100$.

OLIVEIRA, E.M.P.de, 1979. Avaliação da variaḅilidade de caracteres morfológicos e agronômicos em populações de Desmodium uncinatum (Jacq.) D.C. e Desmodium intortum (Mi11.) Urb. Piracicaba, ESALQ/USP, 117 p. (Tese de Doutoramento).

PATERNIANI, E., 1967. Formação de compostos e avaliação de germoplasma para o melhoramento do milho. Relatório Científico do Departamento de Genética e Instituto de Genētica. Piracicaba, ESALQ/USP, 1:48-49.

PATERNIANI, E. e J.B.MIRANDA FILHO, 1978. Melhoramento de populações. In: PATERNIANI, E., Coord. Melhoramento e produção do milho no Brasil. Piracicaba, ESALQ/USP, p. 202-256.

PATERNIANI, E., 1980. Fatores que afetam a eficiência da seleção nas plantas. In: IV Congresso Latinoamericano de Genética. Actas. 2:37-43. 
PAULA, J.F.de, 1976. Comportamento de variedades de mandioca (Manihot esculenta Crantz), em Viçosa, Minas Gerais. Viçosa, UFV, 31 p. (Dis sertação de Mestrado).

PIMENTEL GOMES, F., 1982. Curso de Estatistica Experimental. 10 a ed. Piracicaba, Livraria Nobe1 S/A. 430 p.

POEHLMAN, J.M., 1971. Mejoramiento genético de las cosechas. México, Limusa-Wiley. 453 p.

PONTES, O.F.S. e P.S.MARTINS, 1982. Determinação de parâmetros genéticos relacionados à dormência de sementes em soja perene (Glycine wightii). Parte I. O Solo. Piracicaba, 1/2, p. 13-17.

RIBEIRO, J.V., P.L.P.de MATTOS e L.A.SIQUEIRA, 1974. Competição de cultivares de mandioca Manihot esculenta Crantz no Estado de Sergipe. Aracaju, SUDAP. $23 \mathrm{p}$.

ROBINSON, H.F., R.E.COMSTOCK e P.H.HARVEY, 1951. Genotypic and phenotypic correlations in corn and their implications in selection. Agronomy Journal. Madison, 43:282-287.

SERA, T., 1980. Estimação dos componentes da variância e do coeficiente de determinação genotípica da produção de grãos de café (Cob́fea arabica L.). Piracicaba, ESALQ/USP, 62 p. (Dissertação de Mestrado).

SILVA, S.de O.e, 1977. Capacidade de produção e características de raízes e ramas de 60 variedades de mandioca. Viçosa, UFV, 47 p. (Dissertação de Mestrado). 
SILVA, S.de O.e, 1982. Germoplasma de mandioca no Brasil. In: II Congresso Brasileiro de Mandioca. Anais. Vitōria, EMBRAPA/CNPMF/SBM, 1: 89-101.

SILVA, S.de O.e, W.M.G.FUKUDA, H.W.L.de CARVALHO e R.C.CALDAS, 1983. Estudo do comportamento de cultivares de mandioca no Centro Nacional de Pesquisa de Mandioca e Fruticultura. Revista Brasileira de Mandioca. Cruz das Almas, 2:9-16.

SILVA, W.J., L.T.de MIRANDA e G.P.VIEGAS, 1963. Estimativa do progresso genético médio em ensaios de cultivares de milho. Bragantia. Campinas, $22: 247-258$.

SNEDECOR, G.W. e G.COCHRAN, 1973. Statistical Methods. 6 ${ }^{\mathrm{a}}$ ed. Iowa, The Iowa State University Press. 593 p.

STEEL, R.G.D. e J.H.TORRIE, 1980. Principles and procedures of statistics 2a ed. New York, McGraw-Hill Book Company, Inc. 633 p.

TINEO, J.R., 1977. Selección massal en yuca. Revista de la Facultad de Agronomia de la Universidad del zulia. Maracaibo, 4:23-29.

UMANAH, E.E. e R.W.HARTMANN, 1973. Chromosome numbers and karyotypes of some Manihot species. Journal of the American Society for Horticultural Science. Mount Vernon, 98:272-274. 
VELLO, N.A., R.VENCOVSKY e I.O.GERALDI, 1973. Correlações genéticas e fe notípicas, respostas correlacionadas, ganho esperado na seleção e her dabilidade de alguns caracteres em capim gordura (Melinis minutiflona Beauv.). Relatório Científico do Departamento de Genética e Instituto de Genētica. Piracicaba, ESALQ/USP, 7:208-217.

VENCOVSKY, R., 1978. Herança quantitativa. In:PATERNIANI, E., Coord. Melhoramento e produção do milho no Brasil. Piracicaba, ESALQ/USP, p. $122-201$. 
TABELAS 


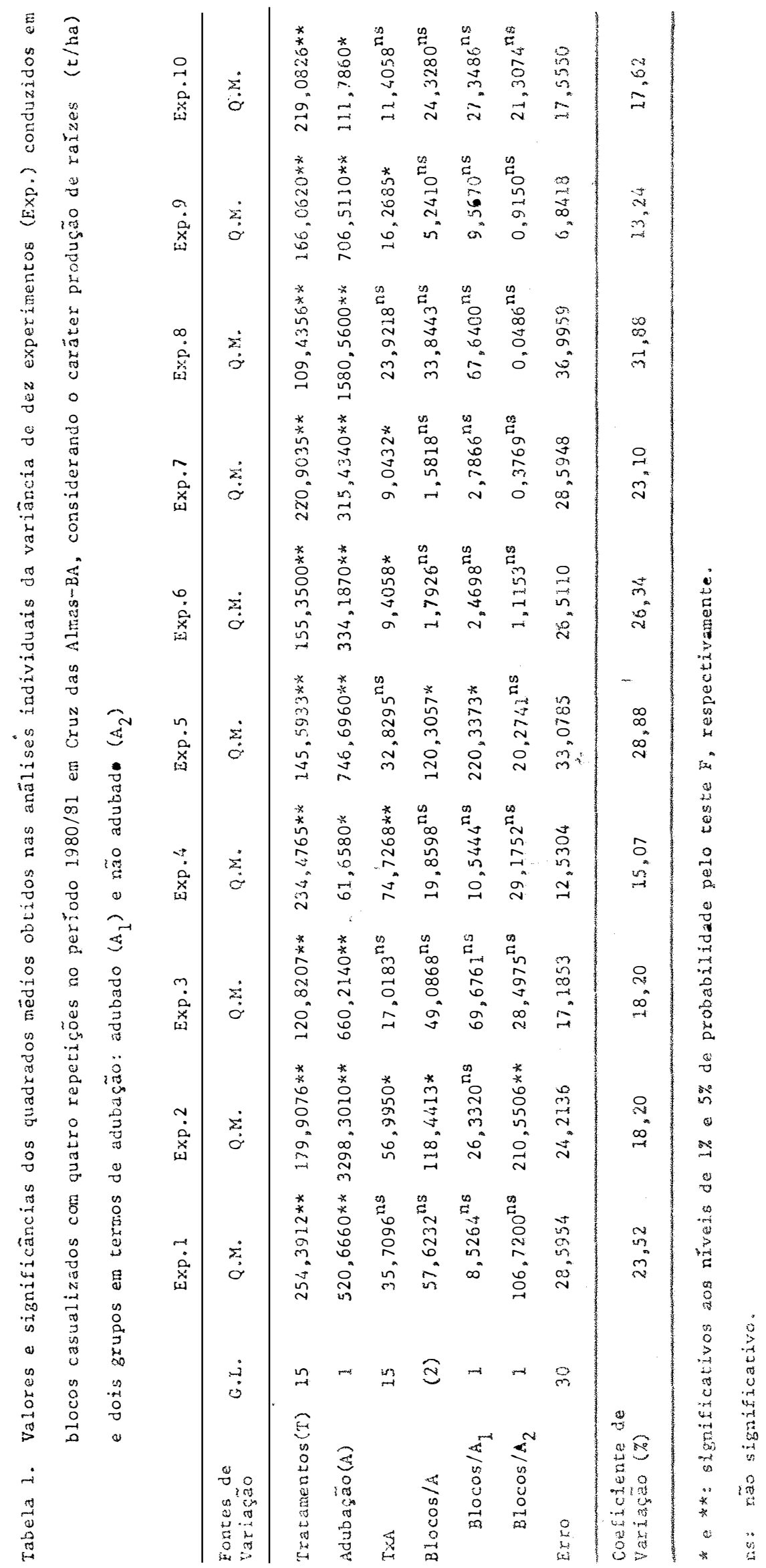




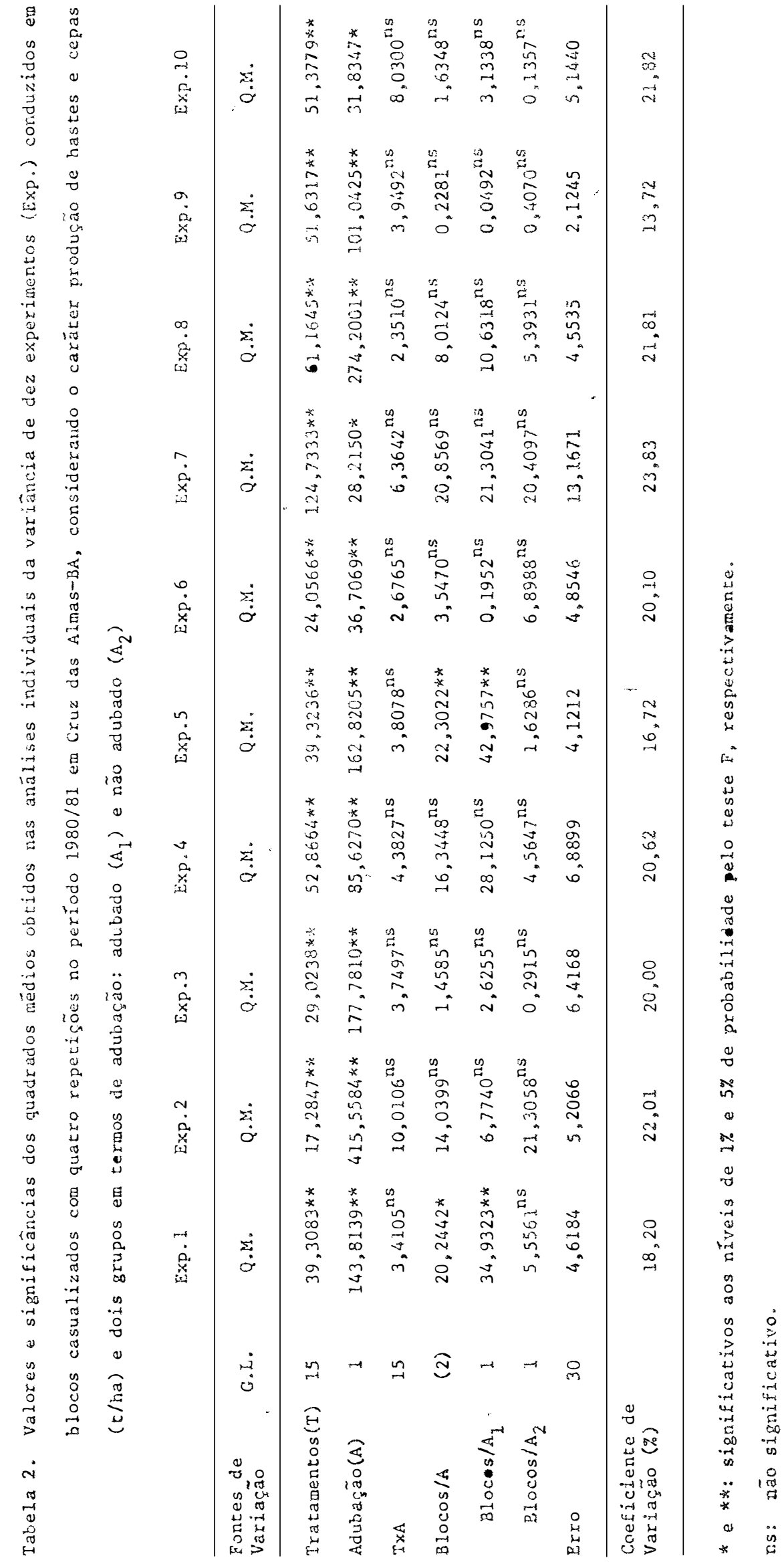




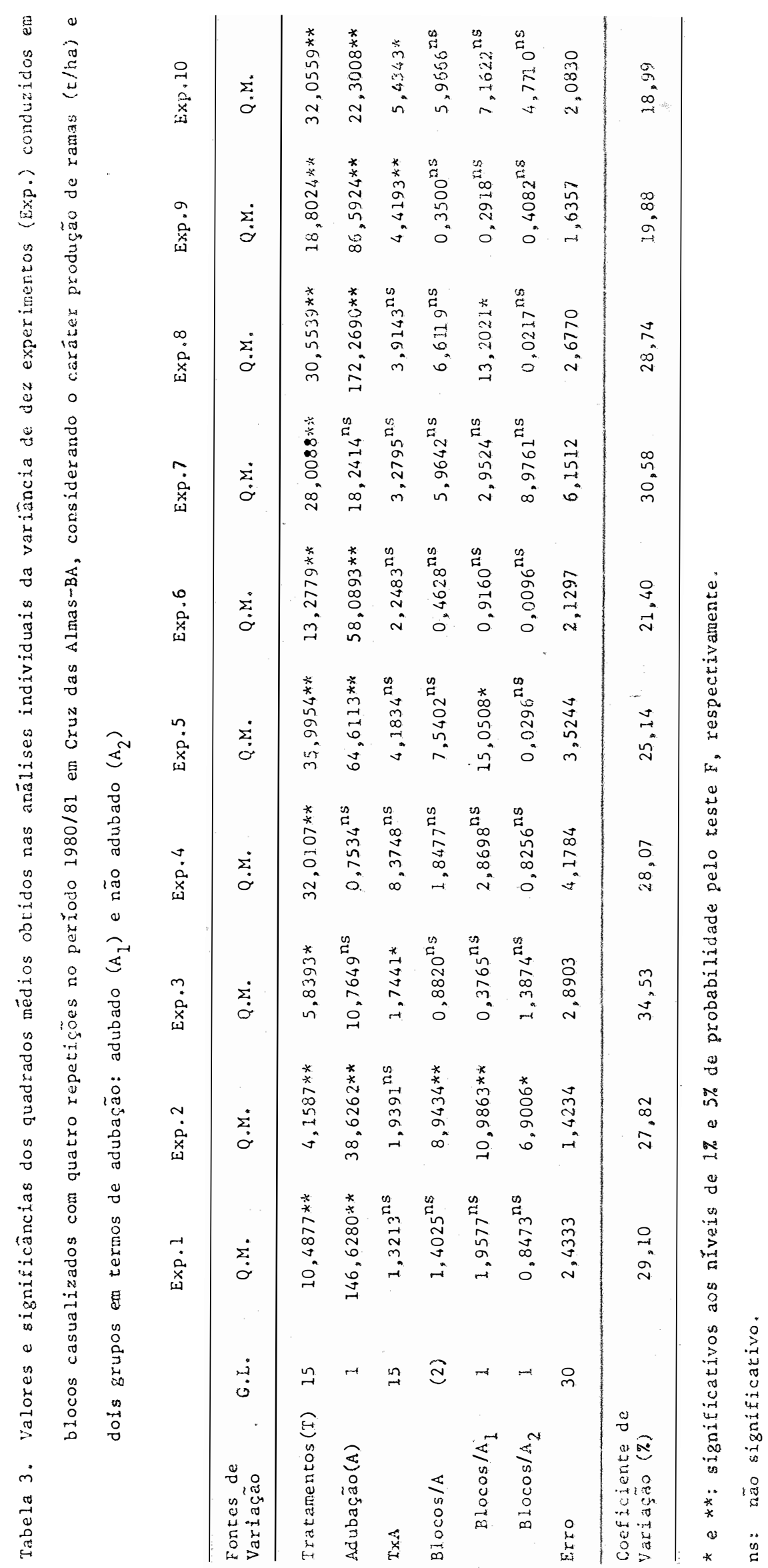




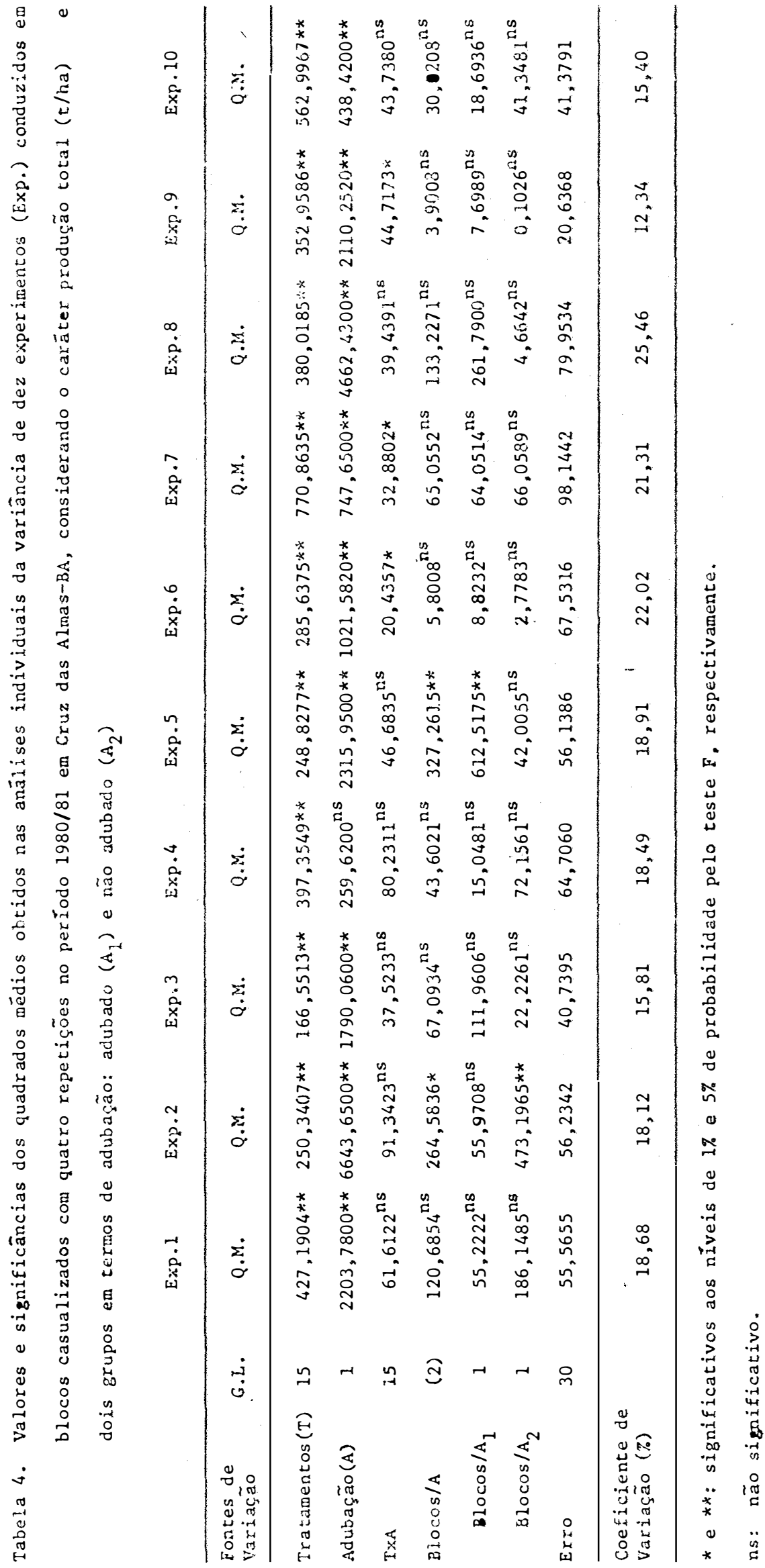




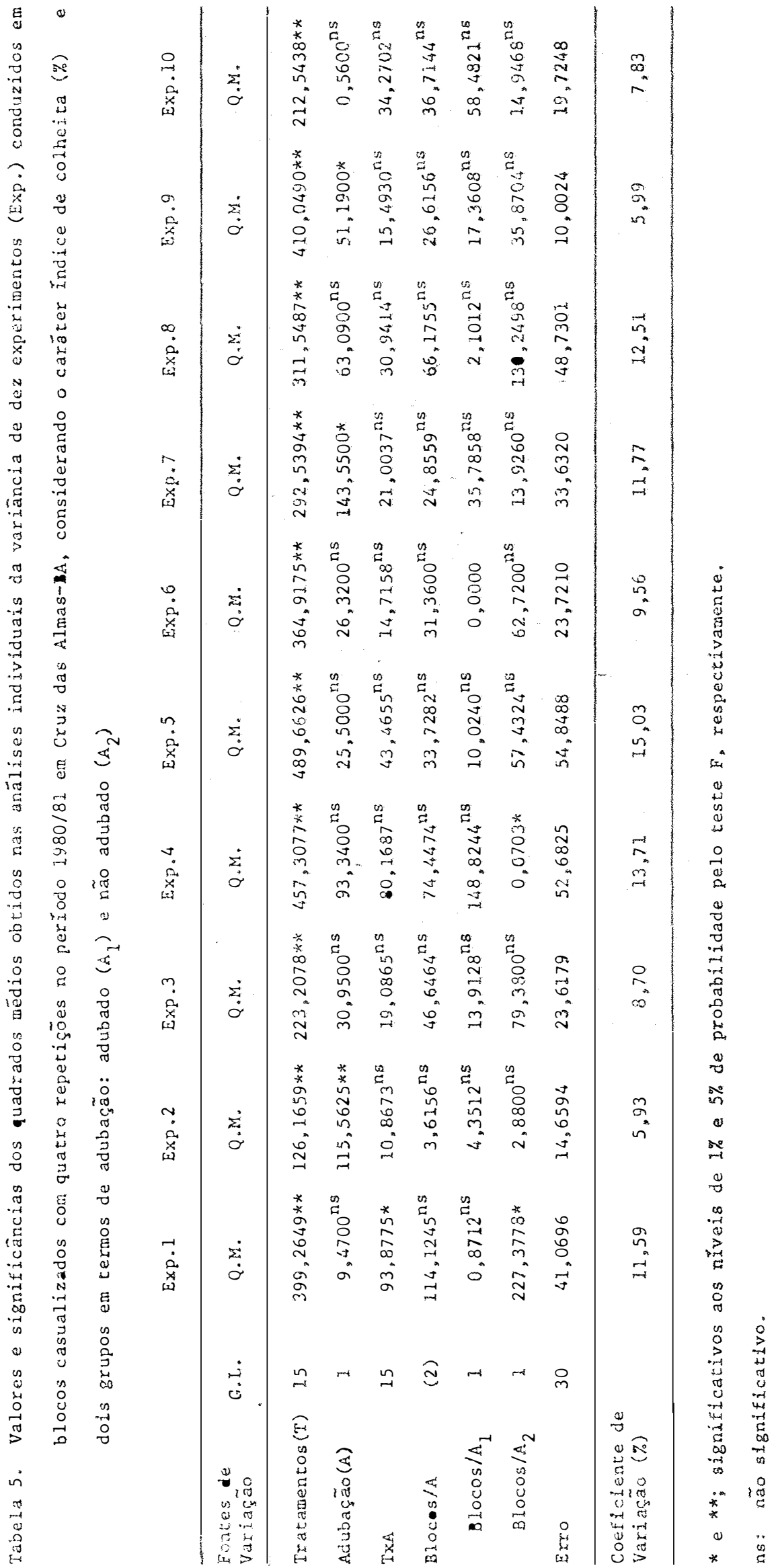




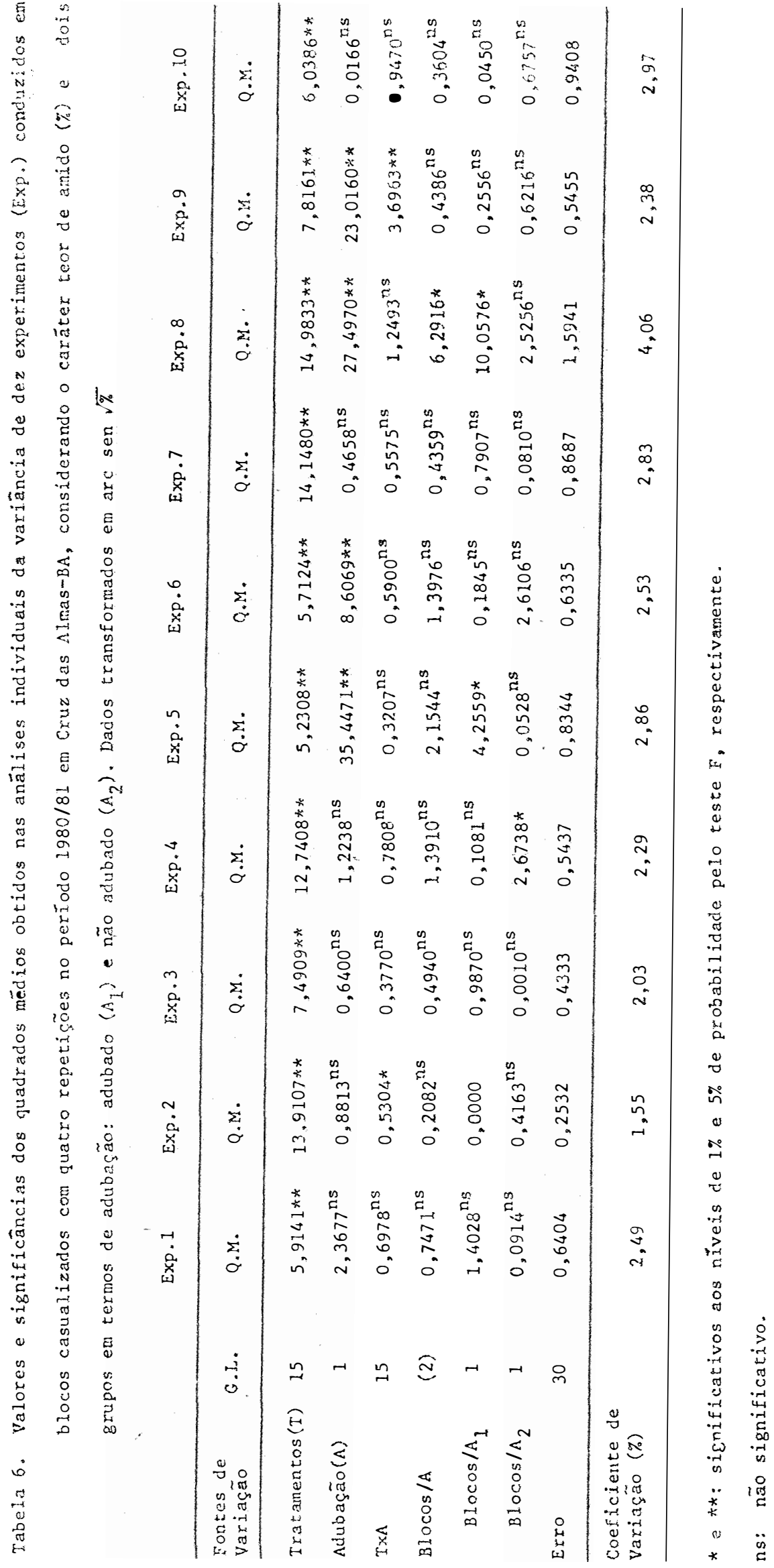




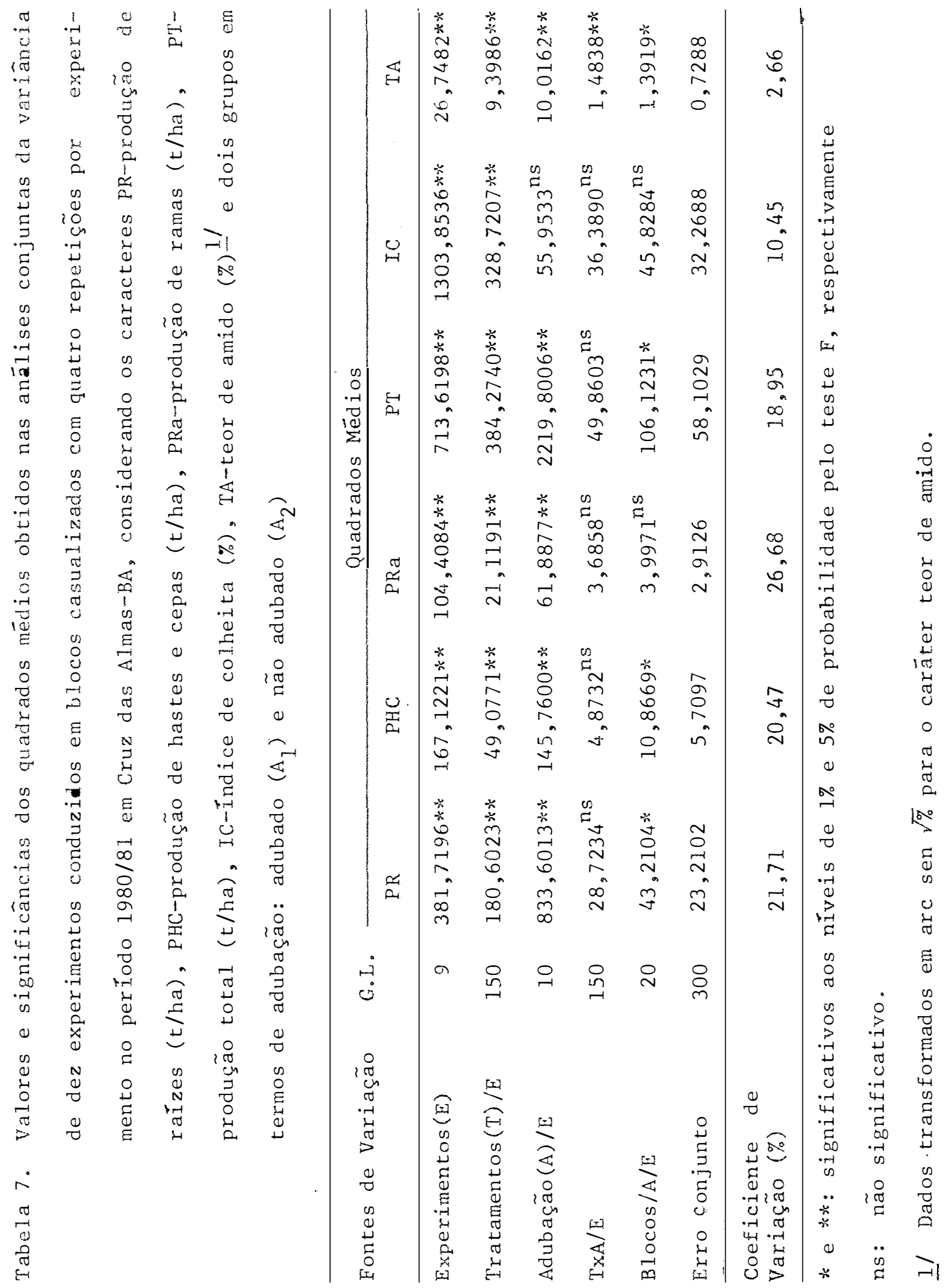


Tabela 8. Valores e significâncias dos quadrados mëdios obtidos nas anälises individuais da variância de quatro experimentos (Exp.)con duzidos em blocos casualizados com quatro repetições no período 1981/82 em Cruz das Almas-BA, considerando o caráter produção de raízes ( $t / h a)$ e dois grupos em termos de adubação: adubado $\left(A_{1}\right)$ e não adubado $\left(A_{2}\right)$

\begin{tabular}{|c|c|c|c|c|c|}
\hline & & Exp. 1 & Exp. 2 & $\operatorname{Exp} \cdot 3$ & Exp. 4 \\
\hline Fontes de Variação & G.L. & Q.M. & Q.M. & Q.M. & Q.M. \\
\hline Tratamentos $(\mathrm{T})$ & 15 & $41,6727 * *$ & $12,1724 *$ & $9,9165 * *$ & $14,0338 *$ \\
\hline Adubação (A) & 1 & $637,8655 * *$ & $297,2004 * *$ & $164,5897 * *$ & $58,6163 * *$ \\
\hline $\mathrm{TxA}$ & 15 & $8,4647^{n s}$ & $3,3000^{\mathrm{ns}}$ & $3,4488^{n s}$ & $6,3742^{\text {ns }}$ \\
\hline Blocos/A & $(2)$ & $6,3211^{\mathrm{ns}}$ & $7,9007^{\mathrm{ns}}$ & $0,5020^{\mathrm{ns}}$ & $2,1095^{\mathrm{ns}}$ \\
\hline $\mathrm{B} 10 \cos / \mathrm{A}_{1}$ & 1 & $4,7756^{\mathrm{ns}}$ & $3,1244^{\mathrm{ns}}$ & $0,9173^{\mathrm{ns}}$ & $0,7375^{\mathrm{ns}}$ \\
\hline Blocos $/ A_{2}$ & 1 & $7,8666^{\mathrm{ns}}$ & $12,6769^{\mathrm{ns}}$ & $0,0867^{\mathrm{ns}}$ & $3,4815^{n s}$ \\
\hline Erro & 30 & 7,4752 & 4,7476 & 2,6931 & 5,7565 \\
\hline $\begin{array}{l}\text { Coeficiente de } \\
\text { Variação }(\%)\end{array}$ & & 21,94 & 27,65 & 19,66 & 29,09 \\
\hline
\end{tabular}

* e **: significativos aos níveis de $1 \%$ e $5 \%$ de probabilidade pelo teste F, respectivamente.

ns: não significativo. 
rabela 9. Valores e significâncias dos quadrados mëdios obtidos nas anälises individuais da variância de quatro experimentos (Exp.) con duzidos em blocos casualizados com quatro repetições no periodo 1981/82 em Cruz das Almas-BA, considerando o caräter produção de hastes e cepas ( $t /$ ha) e dois grupos em termos de adubação: adubado $\left(A_{1}\right)$ e não adubado $\left(A_{2}\right)$

Exp.1 Exp.2 Exp.3 Exp.4

\begin{tabular}{|c|c|c|c|c|c|}
\hline Eontes de Variaçăo & $G . L$. & $\mathrm{Q} \cdot \mathrm{M}$ & $Q \cdot M$ & Q.M. & Q.M. \\
\hline Tratamentos $(\mathrm{T})$ & 15 & $16,3721 * *$ & $6,5055 \times \frac{2}{6}$ & $3,2907 * x$ & $4,7157 * x$ \\
\hline Adu ação(A) & 1 & $364,7236 * x$ & $106,1930 * *$ & $67,4287 * 2$ & $71,7748 \times * x$ \\
\hline TXA & 15 & $5,4037^{\mathrm{ns}}$ & $0,9406^{\mathrm{ns}}$ & $1,661.7^{\mathrm{ns}}$ & $3,2299 \div x$ \\
\hline Blocos/A & (2) & $1,8973^{\mathrm{ns}}$ & $1,5816^{\mathrm{ns}}$ & $0,5838^{\mathrm{ns}}$ & $4,4710 x$ \\
\hline$B 10 \cos / A_{1}$ & 1 & $0,5159^{\mathrm{ns}}$ & $0,0024^{\mathrm{ns}}$ & 0,0006 宛 & $2,5453^{\mathrm{ns}}$ \\
\hline $\mathrm{B} 10 \cos / \mathrm{A}_{2}$ & 1 & $3,2787^{\mathrm{ns}}$ & $3,1607^{\mathrm{ns}}$ & $1,1670^{\mathrm{ns}}$ & $6,3966 *$ \\
\hline Erro & 30 & 2,8564 & 1,0621 & 1,0640 & 1,0343 \\
\hline $\begin{array}{l}\text { Coeficiente de } \\
\text { Variação }(\%)\end{array}$ & & $3.7,34$ & 20,17 & 24,59 & 17,45 \\
\hline
\end{tabular}

* e **: significativos aos níveis de $1 \%$ e $5 \%$ de probabilidade pelo teste F, respectivamente.

ns: não significativo. 
Tabela 10. Valores e significâncias dos quadrados mëdios obtidos nas anälises individuais da variância de quatr• experimentos (Exp.) conduzidos em blocos casualizados com quatro repetições no período 1981/82 em Cruz das Almas-BA, considerando o caräter produção de ramas ( $t / h a)$ e dois grupos em termos de adubação: adubado $\left(A_{1}\right)$ e não adubado $\left(A_{2}\right)$

Exp.1 Exp.2 Exp.3 Exp.4

\begin{tabular}{lccccc}
\hline Fontes de Variação & G.L. & Q.M. & Q.M. & Q.M. & Q.M. \\
\hline Tratamentos(T) & 15 & $1,9962^{* *}$ & $1,3128 * *$ & $1,5591^{* *}$ & $1,6274 * *$ \\
Adubação(A) & 1 & $37,4452^{* *}$ & $31,8307^{\mathrm{ns}}$ & $41,4929 * *$ & $0,1088^{\mathrm{ns}}$ \\
TxA & 15 & $0,5222^{\mathrm{ns}}$ & $0,1742^{* *}$ & $0,8088^{\mathrm{ns}}$ & $0,454^{\mathrm{ns}}$ \\
Blocos/A & $(2)$ & $0,4673^{\mathrm{ns}}$ & $3,5657^{* *}$ & $0,7316^{\mathrm{ns}}$ & $0,1462^{\mathrm{ns}}$ \\
$\quad$ Blocos/A & 1 & $0,8831^{\mathrm{ns}}$ & $0,3190^{\mathrm{ns}}$ & $1,3899^{\mathrm{ns}}$ & $0,1183^{\mathrm{ns}}$ \\
$\quad$ Blocos/A & 1 & $0,0515^{\mathrm{ns}}$ & $0,2419^{\mathrm{ns}}$ & $0,0732^{\mathrm{ns}}$ & $0,1742^{\mathrm{ns}}$ \\
Erro & 30 & $0,3702^{2}$ & 0,3186 & 0,4070 & 0,4651 \\
\hline $\begin{array}{l}\text { Coeficiente de } \\
\text { Variação (\%) }\end{array}$ & & 21,44 & 25,37 & 32,63 & 34,96 \\
\hline
\end{tabular}

* e **: significativos aos níveis de $1 \%$ e $5 \%$ de probabilidade pelo teste F, respectivamente.

ns: não significativo. 
Tabela 11. Valores e significâncias dos quadrados médios obtidos nas anälises individuais da variância de quatro experimentos (Exp.) conduzidos em blocos casualizados com quatro repetições no período 1981/82 em Cruz das Almas-BA, considerando o caráter produção total ( $t /$ ha) e dois grupos em termos de adubação: adubado $\left(A_{1}\right)$ e não adubado $\left(A_{2}\right)$

Exp.1 Exp.2 Exp.3 Exp.4

\begin{tabular}{|c|c|c|c|c|c|}
\hline Fontes de Variação & G.L. & Q.M. & $Q \cdot M$. & $\mathrm{Q} \cdot \mathrm{M}$. & $Q \cdot M$. \\
\hline Trat amentos $(\mathrm{T})$ & 15 & $51,4812 * *$ & $14,9877^{\mathrm{ns}}$ & $13,9856^{\mathrm{ns}}$ & $13,7298^{\mathrm{ns}}$ \\
\hline Adubação(A) & 1 & $2547,5111 * *$ & $1026,5936 * *$ & $755,2729 * *$ & $203,6460 * *$ \\
\hline $\operatorname{TXA}$ & 15 & $17,3805^{\mathrm{ns}}$ & $9,5759^{\mathrm{ns}}$ & $7,3149^{n s}$ & $21,2981^{\mathrm{ns}}$ \\
\hline $\mathrm{B} 10 \cos / \mathrm{A}$ & $(2)$ & $2,2226^{\mathrm{ns}}$ & $30,5912^{\mathrm{ns}}$ & $2,8943^{n s}$ & $7,4310^{\mathrm{ns}}$ \\
\hline Blocos $/ A_{1}$ & 1 & $3,8566^{\mathrm{ns}}$ & $5,6709^{n s}$ & $4,6726^{\mathrm{ns}}$ & $7,8299^{\mathrm{nS}}$ \\
\hline$B 10 \cos / A_{2}$ & 1 & $0,5886^{\mathrm{ns}}$ & $55,5116 *$ & $1,1160^{\mathrm{ns}}$ & $7,0322^{n s}$ \\
\hline Erro & 30 & 15,0100 & 12,0723 & 7,4914 & 16,3194 \\
\hline $\begin{array}{l}\text { Coeficiente de } \\
\text { Variação (\%) }\end{array}$ & & 15,47 & 22,63 & 18,88 & 24,91 \\
\hline
\end{tabular}

* e **: significativos aos níveis de $1 \%$ e $5 \%$ de probabilidade pelo teste $F$, respectivamente.

ns: não significativo. 
Tabela 12. Valores e significâncias dos quadrados mëdios obtidos nas anālises individuais da variância de quatro experimentos (Exp.) conduzidos em blocos casualizados com quatro repetições no período 1981/82 em Cruz das Almas-BA, considerando o caräter índice de colheita (\%) e dois grupos em termos de adubação: adubado $\left(A_{1}\right)$ e não adubado $\left(A_{2}\right)$

$$
\text { Exp.1 Exp.2 Exp.3 Exp.4 }
$$

\begin{tabular}{|c|c|c|c|c|c|}
\hline Fontes de Variação & G.L. & Q.M. & Q.M. & Q.M. & Q.M. \\
\hline Tratamentos $(\mathrm{T})$ & 15 & $3 i 1,8268 * *$ & $365,5912 * *$ & $226,8999 * *$ & $227,8822 * *$ \\
\hline Adubação (A) & 1 & $8,5052^{\mathrm{ns}}$ & $99,9600^{\mathrm{ns}}$ & $404,1055 * *$ & $13,6761^{\mathrm{ns}}$ \\
\hline $\mathrm{TxA}$ & 15 & $79,4877 *$ & $73,9720^{\mathrm{ns}}$ & $57,9166 *$ & $87,1770 *$ \\
\hline Blocos/A & $(2)$ & $82,1612^{\mathrm{ns}}$ & $97,1260^{\mathrm{ns}}$ & $64,5307^{\mathrm{ns}}$ & $39,2722^{\mathrm{ns}}$ \\
\hline Blocos $/ A_{1}$ & 1 & $19,3800^{\mathrm{ns}}$ & $7,1858^{\mathrm{ns}}$ & $3,0535^{\mathrm{ns}}$ & $33,6139^{\mathrm{ns}}$ \\
\hline $\mathrm{B} 10 \cos / \mathrm{A}_{2}$ & 1 & $144,9423^{\mathrm{ns}}$ & $187,0662 *$ & $126,0078 *$ & $44,9305^{\mathrm{ns}}$ \\
\hline Erro & 30 & 34,8136 & 43,4273 & 26,3479 & 38,7741 \\
\hline $\begin{array}{l}\text { Coeficiente de } \\
\text { Variação }(\%)\end{array}$ & & 12,04 & 13,03 & 8,88 & 12,27 \\
\hline
\end{tabular}

* e**: significativos aos níveis de $1 \%$ e $5 \%$ de probabilidade pelo teste F, respectivamente.

ns: não significativo. 
Tabela 13. Valores e significâncias dos quadrados médios obtidos nas anälises individuais da variância de quatro experimentos (Exp.) conduzidos em blocos casualizados com quatro repetições no período 1981/82 em Cruz das Almas-BA, considerando o caráter teor de amido (\%) e dois grupos em termos de adubação: adubado ( $\mathrm{A}_{1}$ ) e não adubado $\left(\mathrm{A}_{2}\right)$. Dados transformados em arc sen $\sqrt{\%}$

Exp.1 Exp. $2 \quad$ Exp.3 Exp. 4

\begin{tabular}{|c|c|c|c|c|c|}
\hline Fontes de Variação & G.L. & Q.M. & Q.M. & Q.M. & Q.M. \\
\hline Tratamentos $(\mathrm{T})$ & 15 & $2,9437 * *$ & $13,7628 * *$ & $9,3003 * *$ & $5,1890 * *$ \\
\hline Adubação (A) & 1 & $0,2414^{\mathrm{ns}}$ & $0,0109^{\mathrm{ns}}$ & $1,2460^{\mathrm{ns}}$ & $0,2849^{\text {ns }}$ \\
\hline $\mathrm{TxA}$ & 15 & $0,9588 * *$ & $0,7403^{\mathrm{ns}}$ & $0,4098^{\mathrm{ns}}$ & $0,4286^{\mathrm{ns}}$ \\
\hline Blocos/A & (2) & $1,5530 * *$ & $0,4977^{\mathrm{ns}}$ & $0,4477^{\mathrm{ns}}$ & $1,4144^{\mathrm{ns}}$ \\
\hline Blocos / $A_{1}$ & 1 & $2,8980 * *$ & $0,7140^{\mathrm{ns}}$ & $0,8450^{\mathrm{ns}}$ & $1,7955^{\mathrm{ns}}$ \\
\hline $\mathrm{Blocos} / \mathrm{A}_{2}$ & 1 & $0,2080^{\mathrm{ns}}$ & $0,2813^{\mathrm{ns}}$ & $0,0504^{\mathrm{ns}}$ & $1,0332^{\mathrm{ns}}$ \\
\hline Erro & 30 & 0,2559 & 0,6275 & 0,4449 & 0,8175 \\
\hline $\begin{array}{l}\text { Coeficiente de } \\
\text { Variação (\%) }\end{array}$ & & 1,60 & 2,52 & 2,11 & 2,84 \\
\hline
\end{tabular}

* e **: significativos aos niveis de $1 \%$ e $5 \%$ de probabilidade pelo teste F, respectivamente.

ns: não significativo. 


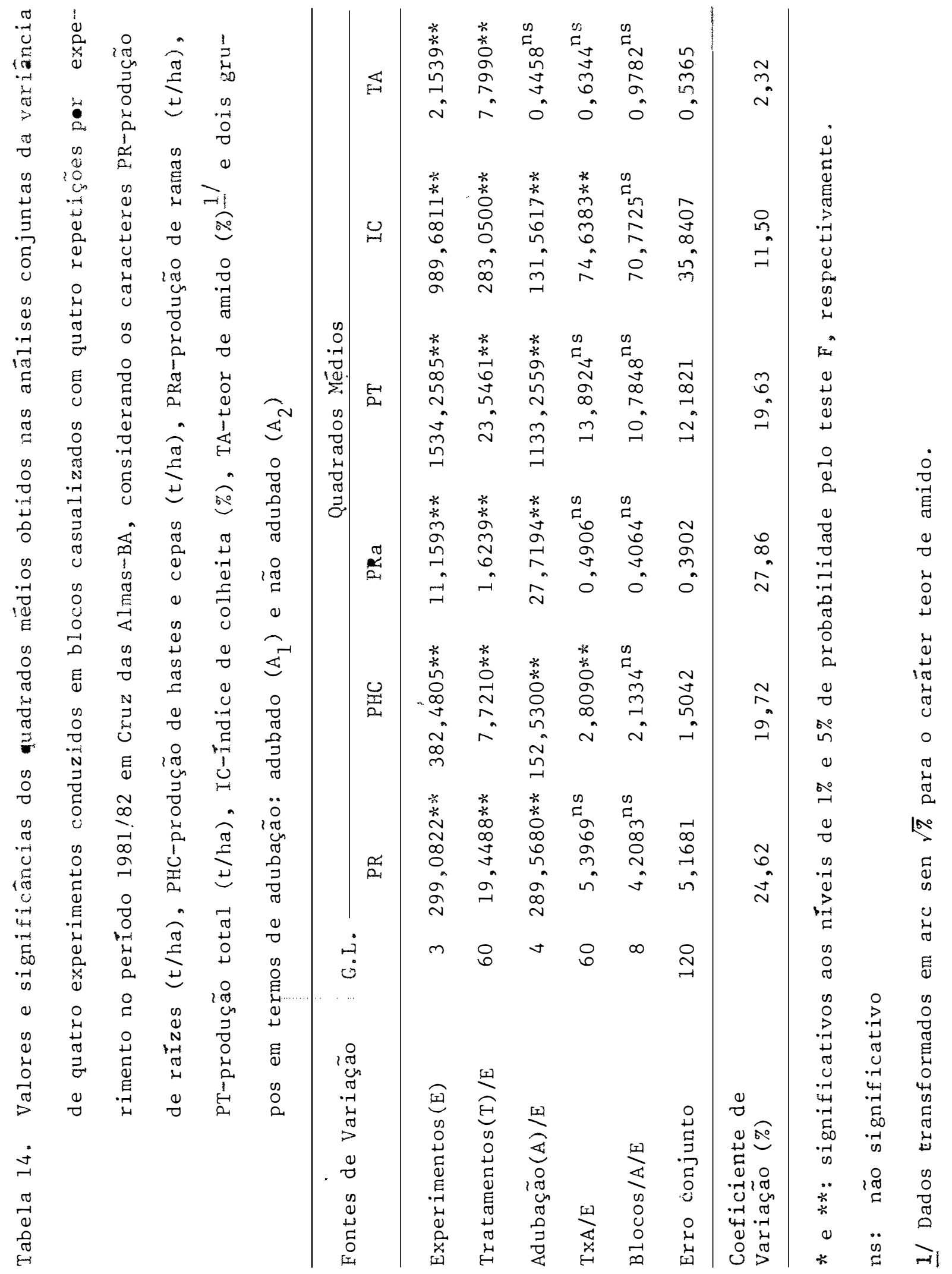




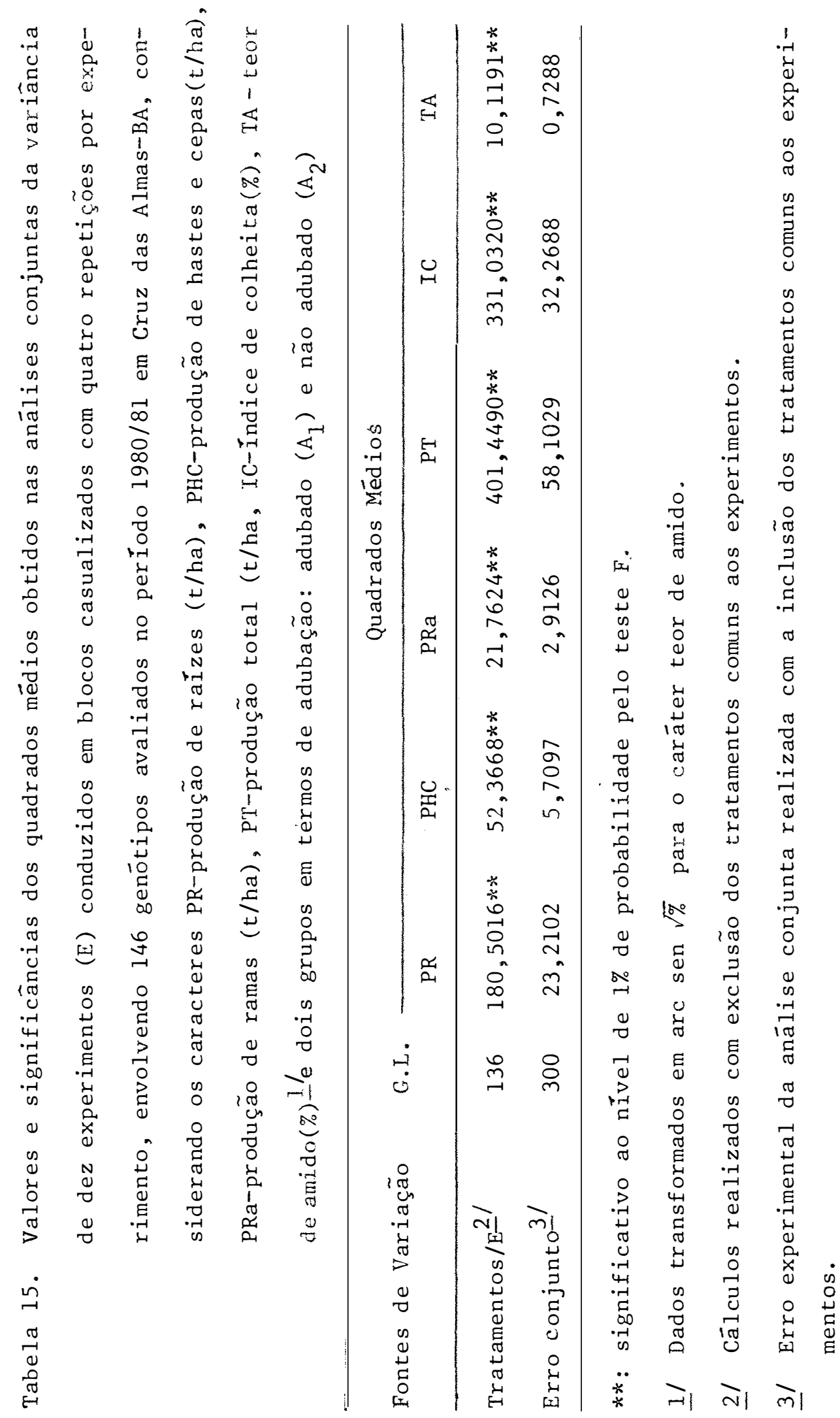




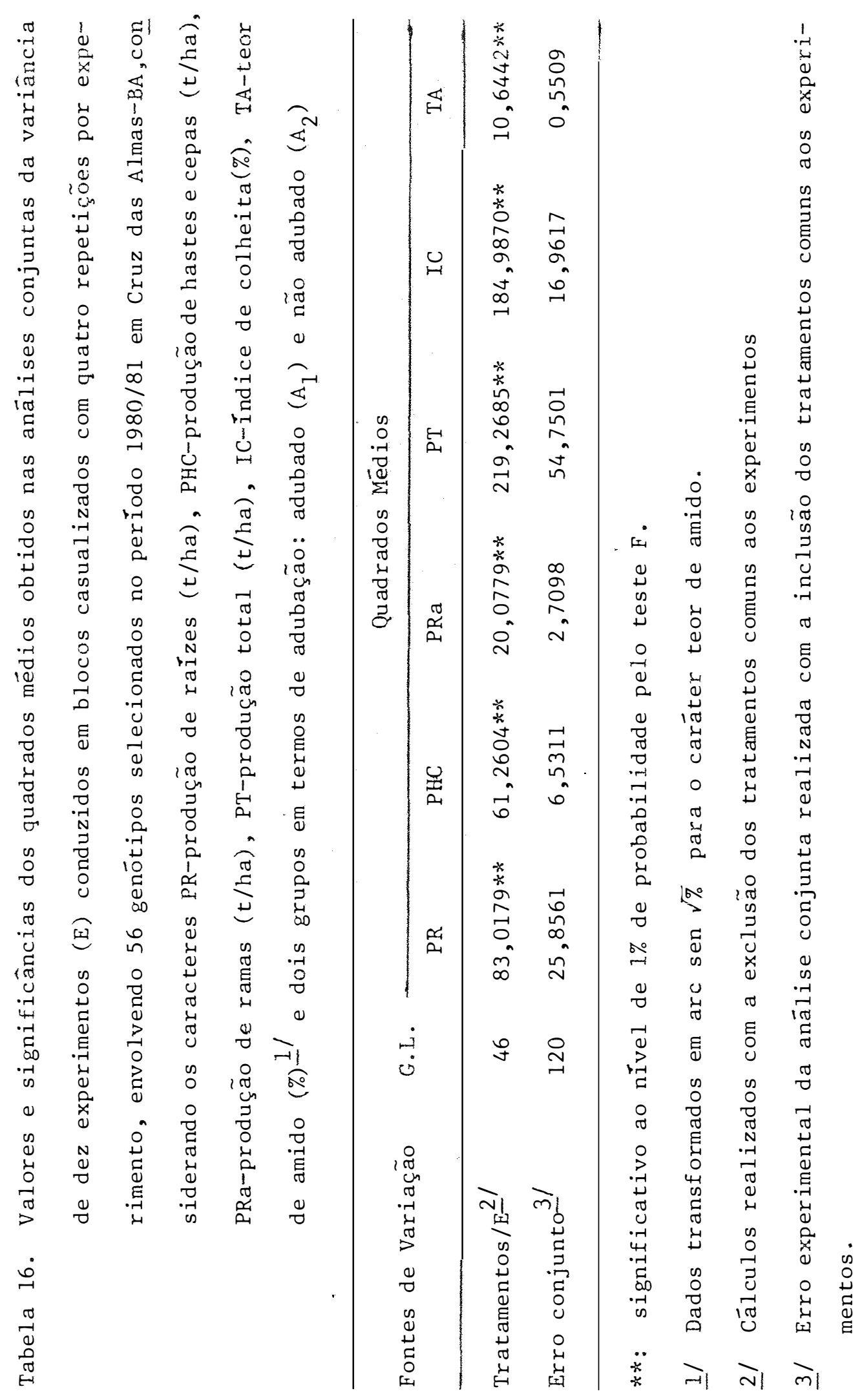




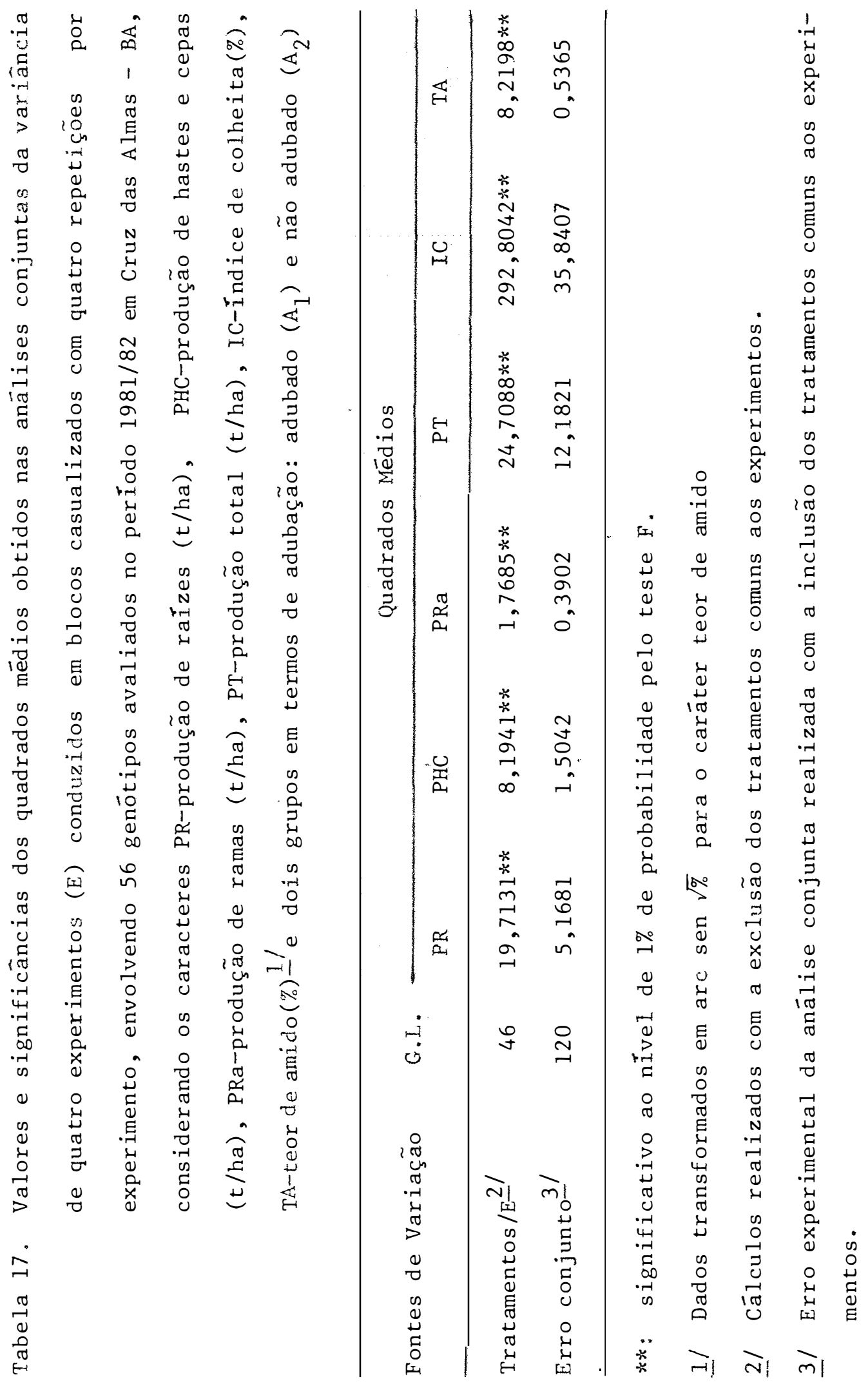


Tabela 18. Estimativas dos coeficientes de determinação genotípica "b", obtidos ao nível de médias para caracteres de 146 genótipos avaliados em 1980/81 ("b 1 "); caracteres de 56 genótipos selecionados em 1980/81 ("b 2 "); caracteres de 56 genótipos avaliados em 1981/82 ("b 3 "). Cruz das Almas-BA, 1980/81 e $1981 / 82$.

\begin{tabular}{lccc}
\hline Caracteres & "b $1 "$ & "b & "b $3 "$ \\
\hline Produção de raizes & 0,8714 & 0,7885 & 0,7378 \\
Produção de hastes e cepas & 0,8910 & 0,8934 & 0,8164 \\
Produção de ramas & 0,8662 & 0,8650 & 0,7794 \\
Produção total & 0,8553 & 0,7503 & 0,5070 \\
Indice de colheita & 0,9025 & 0,9083 & 0,8776 \\
Teor de amido & 0,9280 & 0,9482 & 0,9347 \\
\hline
\end{tabular}




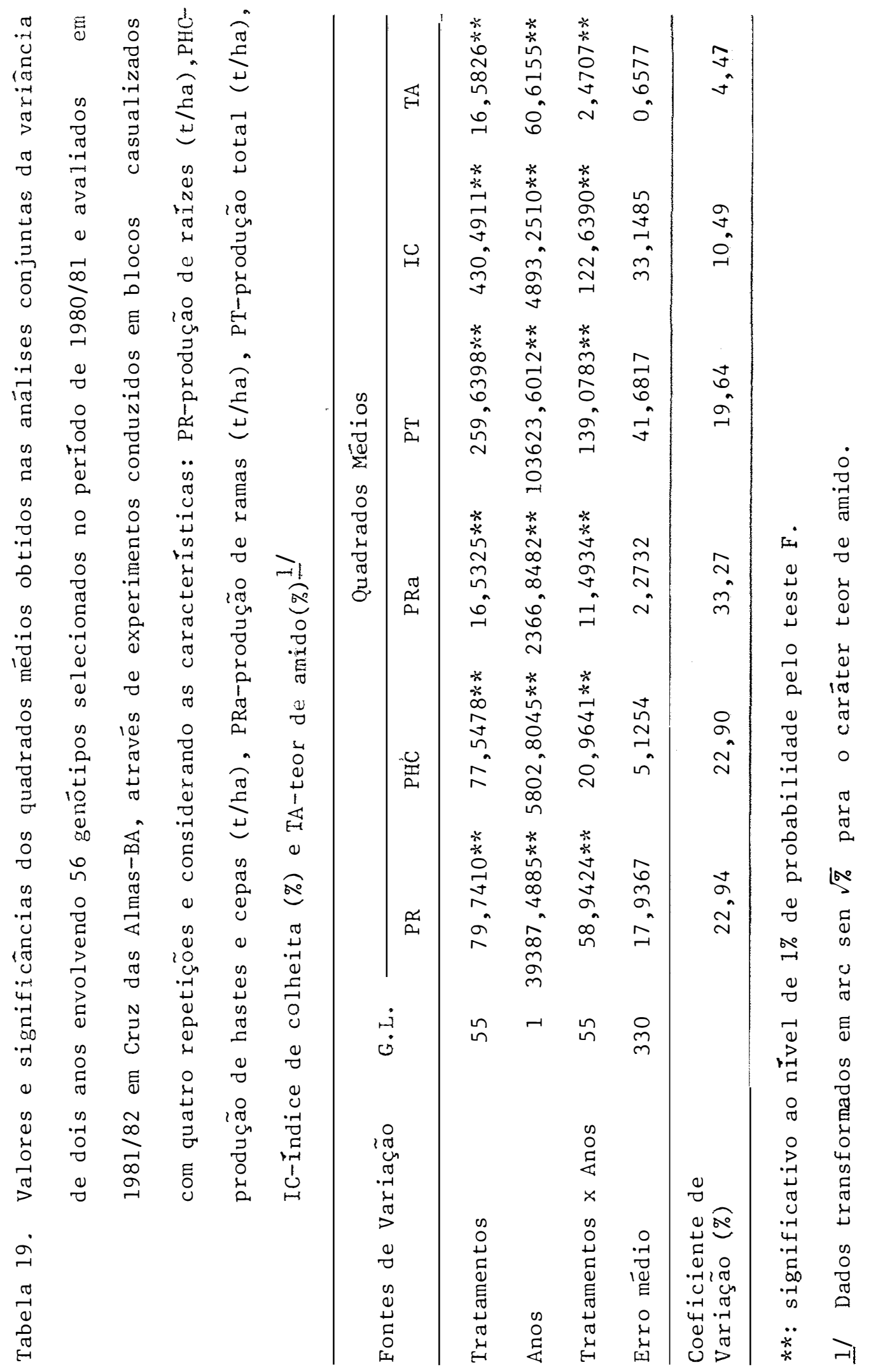




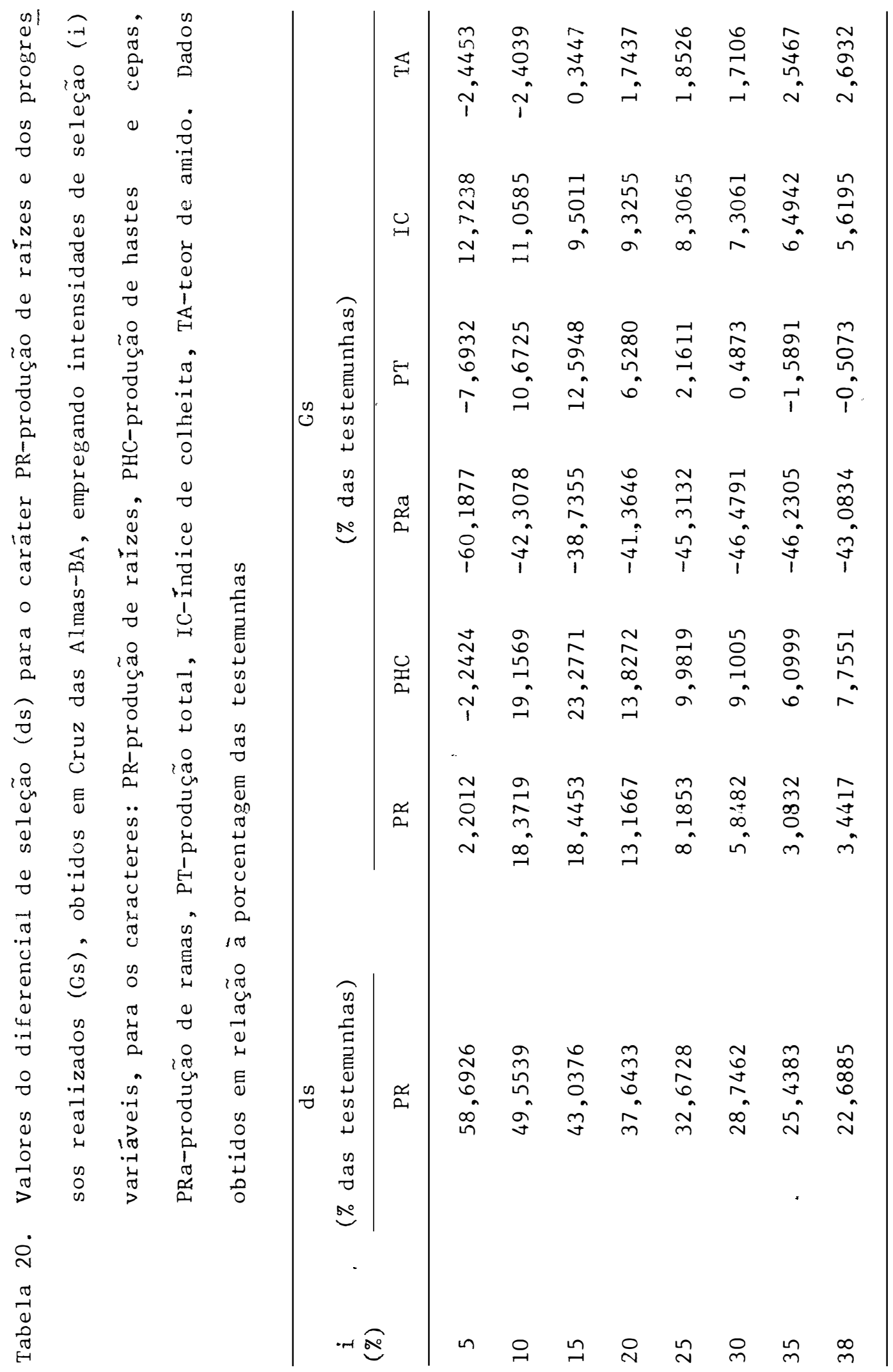


Tabela 21. Estimativas das correlações fenotípicas $\left(r_{F}\right)$ entre os caracteres: PR-produção de raízes ( $t / h a)$, PHC-produção de hastes e cepas ( $t / h a)$, PRa-produção de ramas ( $t / h a)$, PT-produção total $(t / h a)$, IC-índice de colheita $(\%)$, TA-teor de amido $(\%) \underline{1 /}$ de 156 genótipos de mandioca. Cruz das Almas-BA-1980/81

\begin{tabular}{|c|c|c|c|c|c|c|}
\hline Caracteres & $\frac{\mathrm{Y}_{1}}{\mathrm{PT}}$ & $\frac{\mathrm{Y}_{2}}{\mathrm{PRa}}$ & $\frac{\mathrm{Y}_{3}}{\mathrm{PHC}}$ & $\frac{\mathrm{Y}_{4}}{\mathrm{IC}}$ & $\frac{\mathrm{Y}_{5}}{\mathrm{TA}}$ & $\frac{\mathrm{Y}_{6}}{\mathrm{PR}}$ \\
\hline$Y_{1}$ & & $0,5277 * *$ & $0,7944 * *$ & $0,1485^{\mathrm{ns}}$ & $0,2812 * *$ & $0,8048 * *$ \\
\hline $\mathrm{Y}_{2}$ & & & $0,5722 * *$ & $-0,5372 * *$ & $0,2462 * *$ & $0,0990^{\mathrm{ns}}$ \\
\hline$Y_{3}$ & & & & $-0,3440 * *$ & $0,2487 * *$ & $0,4132 * *$ \\
\hline $\mathrm{Y}_{4}$ & & & & & $0,0469^{\mathrm{ns}}$ & $0,5914 * *$ \\
\hline$Y_{5}$ & & & & & & $0,1972 *$ \\
\hline
\end{tabular}

* e **: significativos aos níveis de $1 \%$ e $5 \%$ de probabilidade pelo teste $\mathrm{F}$, respectivamente.

ns: não significativo.

1/ Dados transformados em arc sen $\sqrt{\%}$ para o caráter teor de amido.

Tabela 22. Estimativas das correlações fenotípicas $\left(r_{F}\right)$ entre os caracteres: PR-produção de raízes ( $t / h a$ ), PHC-produção de hastes e cepas ( $t / h a)$, PRa-produção de ramas ( $t / h a)$, PT-produção total $(t / h a)$, IC-índice de colheita (\%), TA-teor de amido (\%) $1 /$ de 56 genótipos de mandioca. Cruz das Almas-BA-1981/82

\begin{tabular}{|c|c|c|c|c|c|c|}
\hline Caracteres & $\frac{Y_{1}}{P T}$ & $\frac{\mathrm{Y}_{2}}{\mathrm{PRa}}$ & $\frac{\mathrm{Y}_{3}}{\mathrm{PHC}}$ & $\frac{\mathrm{Y}_{4}}{\mathrm{IC}}$ & $\frac{\mathrm{Y}_{5}}{\mathrm{TA}}$ & $\begin{array}{l}\mathrm{Y}_{6} \\
\mathrm{PR}\end{array}$ \\
\hline $\mathrm{Y}_{1}$ & & $0,6046 * *$ & $0,8255 * *$ & $-0,1109^{\mathrm{ns}}$ & $0,0393^{n s}$ & $0,8339 * *$ \\
\hline $\mathrm{Y}_{2}$ & & & $0,4678 * *$ & $-0,3556 * *$ & $0,2243^{\mathrm{ns}}$ & $0,3978 * *$ \\
\hline$Y_{3}$ & & & & $-0,5699 * *$ & $0,0624^{\mathrm{ns}}$ & $0,4029 * *$ \\
\hline$Y_{4}$ & & & & & $-0,1992^{\mathrm{ns}}$ & $0,4251 * *$ \\
\hline$Y_{5}$ & & & & & & $-0,0759^{\mathrm{ns}}$ \\
\hline
\end{tabular}

* e **: significativos aos níveis de $1 \%$ e $5 \%$ de probabilidade pelo teste $\mathrm{F}$, respectivamente.

ns: não significativo. 
FI GURAS 


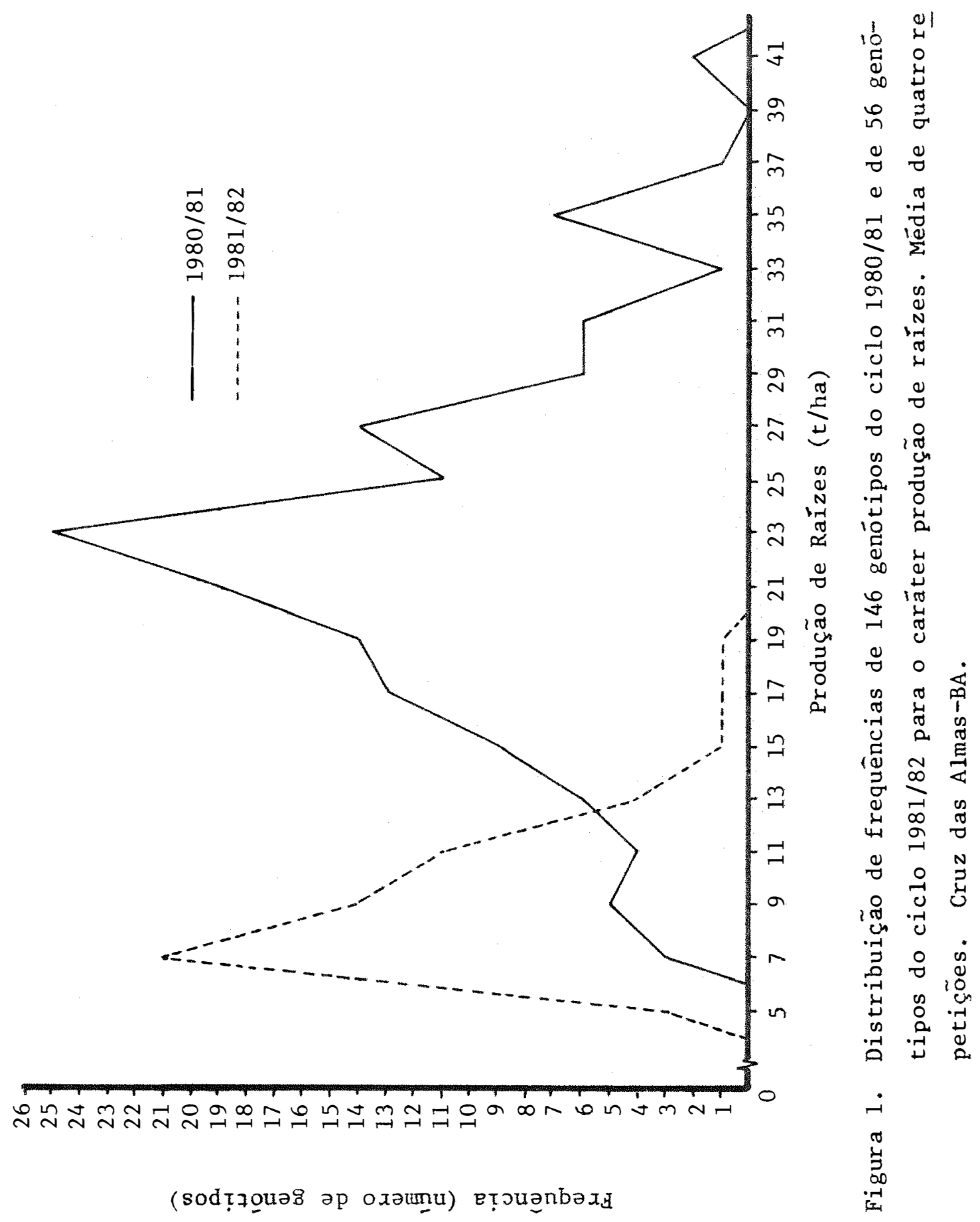




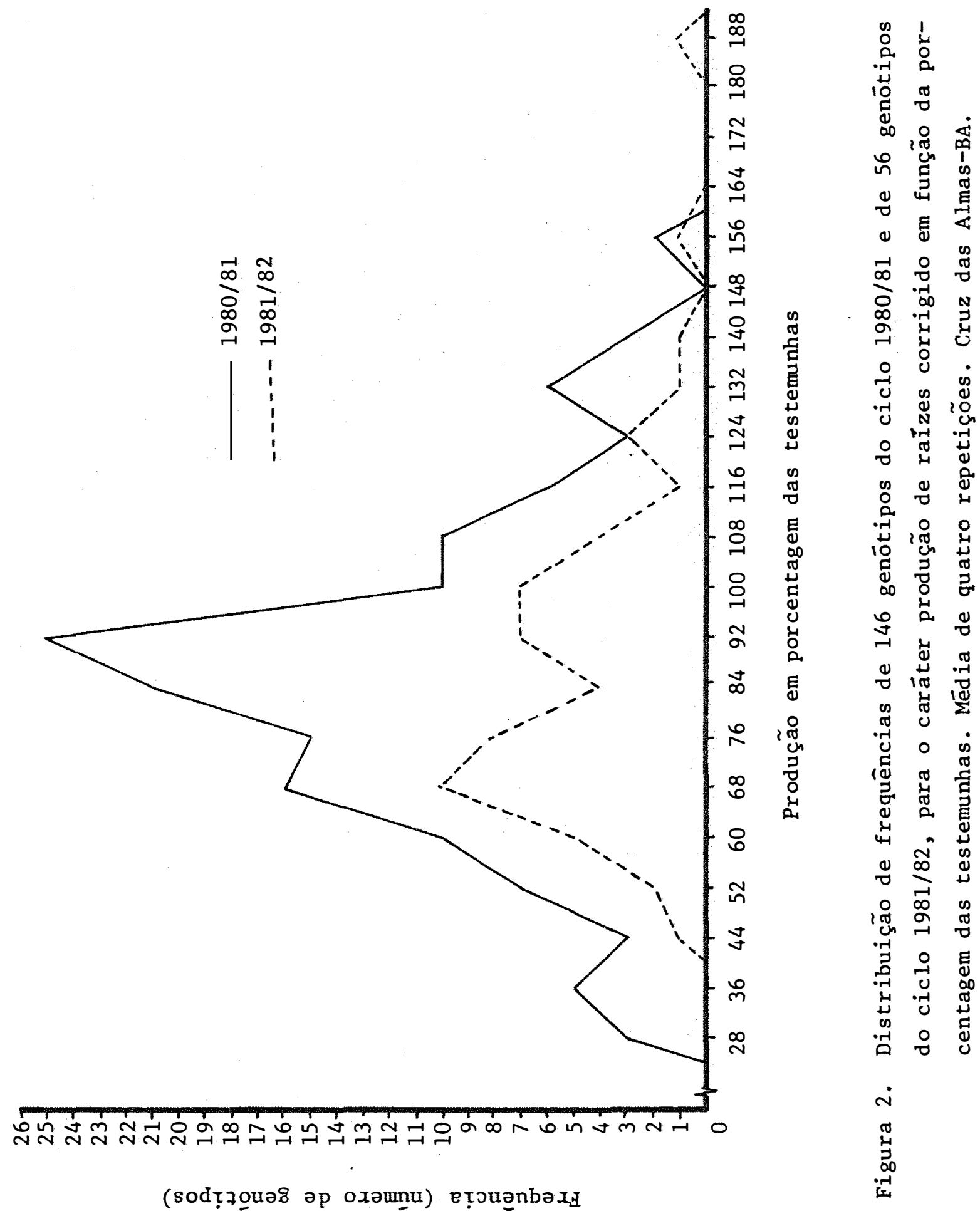


ANEXOS 
Anexo 1. Esquema da anālise individual da variância com os respectivos testes $\mathrm{F}$

\begin{tabular}{lccc}
\hline Fontes de Variação & G.L. & $\mathrm{Q}_{\text {M.M. }}$ & $\mathrm{F}$ \\
\hline Tratamentos (T) & $\mathrm{I}-1$ & $\mathrm{Q}_{1}$ & $\mathrm{Q}_{1} / \mathrm{Q}_{7}$ \\
Adubação (A) & $\mathrm{J}-1$ & $\mathrm{Q}_{2}$ & $\mathrm{Q}_{2} / \mathrm{Q}_{7}$ \\
TxA & $(\mathrm{I}-1)(\mathrm{J}-1)$ & $\mathrm{Q}_{3}$ & $\mathrm{Q}_{3} / \mathrm{Q}_{7}$ \\
Blocos/A & $\mathrm{J}(\mathrm{K}-1)$ & $\mathrm{Q}_{4}$ & $\mathrm{Q}_{4} / \mathrm{Q}_{7}$ \\
$\quad \mathrm{Blocos} / \mathrm{A}_{1}$ & $\mathrm{~K}-1$ & $\mathrm{Q}_{5}$ & $\mathrm{Q}_{5} / \mathrm{Q}_{7}$ \\
$\quad \mathrm{Blocos} / \mathrm{A}_{2}$ & $\mathrm{~K}-1$ & $\mathrm{Q}_{6}$ & $\mathrm{Q}_{6} / \mathrm{Q}_{7}$ \\
Erro & {$[(\mathrm{I}-1)(\mathrm{R}-1)-(\mathrm{I}-1)(\mathrm{J}-1)]$} & $\mathrm{Q}_{7}$ & \\
& & & \\
\hline
\end{tabular}

Anexo 2. Esquema da análise conjunta da variância com os respectivos testes $\mathrm{F}$

\begin{tabular}{lccc}
\hline Fontes de Variação & G.L. & $Q_{. M}$ & $F^{-}$ \\
\hline Experimentos(E) & $\mathrm{L}-1$ & $\mathrm{Q}_{1}$ & $\mathrm{Q}_{1} / \mathrm{Q}_{6}$ \\
Tratamentos(T)/E & $\mathrm{L}(\mathrm{I}-1)$ & $\mathrm{Q}_{2}$ & $\mathrm{Q}_{2} / \mathrm{Q}_{6}$ \\
Adubação(A)/E & $\mathrm{J}-1$ & $\mathrm{Q}_{3}$ & $\mathrm{Q}_{3} / \mathrm{Q}_{6}$ \\
TxA/E & $\mathrm{L}(\mathrm{I}-1)(\mathrm{J}-1)$ & $\mathrm{Q}_{4}$ & $\mathrm{Q}_{4} / \mathrm{Q}_{6}$ \\
Blocos/A/E & $\mathrm{L}(\mathrm{K}-1)(\mathrm{J}-1)$ & $\mathrm{Q}_{5}$ & $\mathrm{Q}_{5} / \mathrm{Q}_{6}$ \\
Erro conjunto & $\mathrm{L}[(\mathrm{I}-1)(\mathrm{R}-1)-(\mathrm{I}-1)(\mathrm{J}-1)]$ & $\mathrm{Q}_{6}$ & \\
\end{tabular}


Anexo 3. Anälise conjunta da variância com os respectivos testes $F$

\begin{tabular}{lccc}
\hline Fontes de Variação & G.L. & Q.M. & $F$ \\
\hline Tratamentos & $\mathrm{I}-1$ & $\mathrm{Q}_{1}$ & $\mathrm{Q}_{1} / \mathrm{Q}_{4}$ \\
Anos & $\mathrm{A}-1$ & $\mathrm{Q}_{2}$ & $\mathrm{Q}_{2} / \mathrm{Q}_{4}$ \\
Tratamentos x Anos & $(\mathrm{I}-1)(\mathrm{A}-1)$ & $\mathrm{Q}_{3}$ & $\mathrm{Q}_{3} / \mathrm{Q}_{4}$ \\
Erro médio & $\mathrm{A}(\mathrm{I}-1)(\mathrm{R}-1)$ & $\mathrm{Q}_{4}$ & \\
\hline
\end{tabular}


Anexo 4. Médias obtidas de quatro repetiçöes e suas respectivas amplitudes para os caracteres, PR-produção de raízes (t/ha), PHCprodução de hastes e cepas ( $t / h a)$, PRa-produção de ramas(t/ha), PT-produção total ( $t / h a)$, IC-índice de colheita (\%), TA-teor de amido (\%), dos 146 genótipos avaliados em 1980/81. Cruz das Almas-BA-1980/81

\begin{tabular}{|c|c|c|c|c|c|c|}
\hline Genōtipos & $\mathrm{PR}$ & PHC & $\mathrm{PRa}$ & $\mathrm{PT}$ & IC & $\mathrm{TA}$ \\
\hline IAC $7-127$ & 33,5988 & 11,5100 & 5,7805 & 52,8893 & 67,5500 & 28,6575 \\
\hline VARIEDADE 77 & 34,5048 & 10,4163 & 7,7600 & 52,6810 & 66,3250 & 27,1900 \\
\hline PAULO ROSA & 30,7548 & $.15,1298$ & 5,9370 & 51,8215 & 57,0250 & 26,6225 \\
\hline SÃO JOÃO I & 16,9268 & 9,9475 & 4,0360 & 30,9103 & 54,5500 & 30,9225 \\
\hline MARACAN $\tilde{A}$ & 33,5413 & 17,0570 & 9,3485 & 59,9468 & 55,6000 & 29,6125 \\
\hline PALMEIRA PRETA & 29,0360 & 9,7393 & 3,3330 & 42,1083 & 69,1750 & 29,4300 \\
\hline CM $425 / 4$ & 16,8485 & 9,6093 & 5,3123 & 31,7703 & 52,6500 & 28,6100 \\
\hline IAC $5 / 165$ & 18,7755 & 9,9738 & 4,1663 & 32,8655 & 55,8000 & 29,0225 \\
\hline SEM NOME & 18,4368 & 12,4215 & 5,4160 & 36,2743 & 51,1250 & 30,0925 \\
\hline PERIQUITA I & 24,0098 & 19,3485 & 6,1975 & 49,5558 & 47,8250 & 29,8250 \\
\hline ROXINHA PRETA & 20,5723 & 10,3383 & 6,1978 & 37,1083 & 54,8500 & 29,5275 \\
\hline VASSOURINHA ROXA & 8,7093 & 14,8695 & 5,6768 & 29,2555 & 25,8700 & 26,5725 \\
\hline JOAQU INZINHA & 14,1403 & 8,7495 & 3,7495 & 26,6393 & 52,1750 & 27,5825 \\
\hline CMC 59 & 17,1353 & 9,6870 & 5,5205 & 32,3428 & 52,3250 & 23,0425 \\
\hline VASSOURINHA IP & 35,3815 & 10,0343 & 4,6523 & 50,0680 & 70,6500 & 30,4700 \\
\hline AIPIM PRETO M.N. & 41,3190 & 11,8050 & 4,3398 & 57,4638 & 71,0250 & 21,7600 \\
\hline TOLA ROXA & 34,0968 & 12,7773 & 4,7218 & 51,5958 & 66,3750 & 29,9900 \\
\hline PRETINHA I & 21,5620 & 7,3955 & 3,4373 & 32,3948 & 66,9000 & 30,4450 \\
\hline MARIA PAU & 35,2078 & 13,1248 & 6,4580 & 49,7905 & 70,4000 & 33,5325 \\
\hline PALMEIRA & 26,2840 & 11,1803 & 3,8385 & 41,3528 & 62,5500 & 31,1650 \\
\hline PERU BRANCA & 27,6733 & 8,1245 & 3,2288 & 39,0265 & 70,7750 & 26,8025 \\
\hline PEDRO BARÃO & 21,5273 & 9,3398 & 3,2288 & 34,0958 & 61,9500 & 29,6000 \\
\hline PERIQUITA & 23,5068 & 10,2078 & 3,6108 & 37,3253 & 62,6750 & 30,0300 \\
\hline CM $344 / 4$ & 20,9718 & 10,3468 & 6,2148 & 37,4883 & 55,0250 & 24,0150 \\
\hline CM 344/12 & 21,2495 & 6,4648 & 2,7775 & 30,4918 & 69,7000 & 31,0225 \\
\hline CM $375 / 2$ & 23,3330 & 8,8880 & 4,5480 & 36,7698 & 63,0500 & 29,9225 \\
\hline CM 424/6 & 23,0553 & 13,0550 & 5,1385 & 41,2488 & 55,7000 & 27,2850 \\
\hline
\end{tabular}


Anexo 4. Continuação

\begin{tabular}{|c|c|c|c|c|c|c|}
\hline Genótipos & $\mathrm{PR}$ & PHC & $\mathrm{PRa}$ & $\mathrm{PT}$ & IC & TA \\
\hline CMC 99 & 21,4578 & 9,0623 & 3,9230 & 34,4430 & 61,7750 & 29,9100 \\
\hline CM 368/1 & 22,7425 & 10,7980 & 5,7983 & 39,3388 & 57,6500 & 31,3850 \\
\hline SURUí & 23,0898 & 19,7565 & 7,7078 & 50,5540 & 46,1500 & 34,0000 \\
\hline BALAIADA & 22,3263 & 12,7773 & 6,0758 & 41,1793 & 54,2000 & 28,0625 \\
\hline LIGEIRINHA & 19,0925 & 9,7220 & 3,2983 & 32,1170 & 59,2000 & 28,3150 \\
\hline SFG $2-187$ & 22,2913 & 13,2980 & 6,1455 & 41,7348 & 52,5250 & 28,5125 \\
\hline SABARA & 20,4163 & 11,4233 & 4,6525 & 36,4920 & 56,2500 & 27,5375 \\
\hline CLONE 452-54-6 & 13,8885 & 10,9370 & 5,3813 & 30,2068 & 45,9250 & 28,7950 \\
\hline BAHIA & 23,5760 & 11,9093 & 4,4090 & 39,8943 & 59,1000 & 29,8825 \\
\hline GIGANTE PRETA & 15,3815 & 11,8400 & 5,5898 & 32,8113 & 45,6750 & 30,2475 \\
\hline PRETA DO QUILOMBO & 16,9438 & 15,0345 & 5,6593 & 37,6375 & 44,6250 & 25,3525 \\
\hline VASSOURINHA & 23,7145 & 9,9995 & 3,1248 & 36,8388 & 63,9750 & 25,9750 \\
\hline CONGONHAS & 26,1105 & 17,1523 & 4,3748 & 47,6375 & 54,7500 & 27,9100 \\
\hline CRAVO & 23,6455 & 12,8120 & 4,4438 & 40,9013 & 56,8500 & 29,9100 \\
\hline CM $344 / 5$ & 25,4163 & 9,9998 & 4,3748 & 39,7908 & 63,9000 & 26,3700 \\
\hline CASCO GROSSO & 11,0853 & 7,8120 & 3,4718 & 22,3690 & 46,9275 & 27,3650 \\
\hline CM $344 / 1$ & 16,5620 & 10,3470 & 3,8885 & 30,7975 & 52,8500 & 28,7525 \\
\hline CIAT-NÃO IDENTIEI & 19,4090 & 11,7008 & 8,3675 & 39,4773 & 49,6250 & 22,7750 \\
\hline SM $82 / 1$ & 20,8330 & 9,8955 & 10,3468 & 41,1428 & 50,6750 & 25,5650 \\
\hline IAC $105 / 66$ & 27,6038 & 10,0343 & 5,4510 & 43,0890 & 63,9000 & 28,4125 \\
\hline EMB IGODE IRA & 9,3398 & 13,1593 & 5,4858 & 27,9848 & 31,5000 & 30,0500 \\
\hline MANJAR I & 20,8328 & 15,9718 & 14,3743 & 51,2463 & 40,9500 & 34,5750 \\
\hline $\begin{array}{r}\text { SÃO PEDRO MIRIM } \\
\text { PAMPAS }\end{array}$ & 26,2495 & 22,2913 & 8,7150 & 57,2558 & 46,0750 & 31,0250 \\
\hline MUCUR I & 18,6803 & 15,7288 & 10,4858 & 44,8945 & 41,5500 & 29,8675 \\
\hline SERTANEJA & 27,9508 & 12,2913 & 7,8815 & 48,1235 & 57,5500 & 30,8825 \\
\hline MECU 159 & 24,5135 & 10,4855 & 5,6245 & 40,6235 & 60,3432 & 26,6825 \\
\hline AIPIM BRAVO BRANCO & 34,0970 & 12,2913 & 6,3190 & 52,7073 & 65,7500 & 27,6950 \\
\hline CM $425 / 9$ & 22,2910 & 12,8815 & 6,8048 & 41,9773 & 50,2250 & 25,5650 \\
\hline MMEX 59 & 31,8398 & 8,8190 & 4,6175 & 45,0263 & 70,9000 & 28,8500 \\
\hline JACOBINA I & 25,5898 & 11,8053 & 5,6940 & 43,0890 & 58,9250 & 27,5725 \\
\hline
\end{tabular}


Anexo 4. Continuação

\begin{tabular}{|c|c|c|c|c|c|c|}
\hline Genōtipos & $P R$ & $\mathrm{PHC}$ & $\mathrm{PRa}$ & $\mathrm{PT}$ & IC & $\mathrm{TA}$ \\
\hline IAC $5-51$ & 29,4788 & 15,4858 & 5,2773 & 50,2418 & 57,6400 & 29,2025 \\
\hline ROXONA & 21,2495 & 19,7913 & 14,4440 & 55,4848 & 37,8200 & 27,1150 \\
\hline NÚMERO 9 & 16,9095 & 16,2495 & 10,6593 & 43,8183 & 35,8325 & 27,9925 \\
\hline CANGAIBA & 22,9855 & 13,6103 & 6,5618 & 43,1575 & 53,1575 & 27,8050 \\
\hline AMAZONAS & 25,4858 & 11,1800 & 7,2218 & 43,8875 & 57,4625 & 30,9950 \\
\hline SM $1-150$ & 21,9093 & 10,4858 & 8,1593 & 40,5543 & 54,1325 & 24,5050 \\
\hline AIP IM CAIXÃO & 26,1803 & 11,4233 & 4,1313 & 41,7348 & 62,3025 & 28,9625 \\
\hline CM $424 / 9$ & 26,7008 & 9,9303 & 5,8328 & 42,4638 & 61,1925 & 27,0175 \\
\hline M COL 677 & 13,2983 & 8,4715 & 10,9370 & 32,7068 & 40,1175 & 31,6575 \\
\hline EAB 503 & 20,2773 & 13,7495 & 6,2843 & 40,3110 & 50,7550 & 27,3850 \\
\hline VISSAID & 16,7695 & 7,6040 & 3,2635 & 27,6378 & 60,8450 & 28,5700 \\
\hline SM $91 / 2$ & 6,2498 & 9,7910 & 9,8955 & 25,9363 & 24,7250 & 25,1825 \\
\hline MANDIOCA OSSO & 14,8955 & 13,6108 & 10,2428 & 38,7490 & 39,1000 & 28,4575 \\
\hline MVEN 218 & 15,7635 & 10,3468 & 5,5900 & 31,7003 & 45,0675 & 28,4400 \\
\hline CM $367 / 8$ & 6,7703 & 10,0343 & 7,9510 & 24,7555 & 27,6625 & 24,7350 \\
\hline SEG 393 & 27,0830 & 15,6940 & 6,4928 & 49,2698 & 55,0875 & 27,3725 \\
\hline SFG 379 & 21,7358 & 9,7565 & 7,8120 & 39,3043 & 55,1675 & 28,4850 \\
\hline CM 375/1 & 27,3953 & 13,0203 & 6,1450 & 46,5605 & 58,2950 & 28,6150 \\
\hline CMC $344 / 11$ & 13,6800 & 9,1318 & 5,2078 & 28,0195 & 48,3600 & 27,9200 \\
\hline CM $425 / 7$ & 24,1313 & 12,2218 & 7,6388 & 43,9918 & 54,7850 & 25,3125 \\
\hline MMEX 23 & 19,8260 & 12,1523 & 7,5343 & 39,5125 & 49,5325 & 28,7100 \\
\hline SM $91 / 4$ & 22,5690 & 9,3050 & 4,4785 & 36,3525 & 61,2800 & 26,5625 \\
\hline MUCURI & 23,5065 & 12,6038 & 5,7635 & 41,8738 & 55,8100 & 30,4175 \\
\hline IAC $24 / 2$ & 18,1940 & 7,6730 & 4,0970 & 29,9615 & 60,7200 & 24,4125 \\
\hline CM $425 / 1$ & 18,1593 & 12,8120 & 8,5065 & 39,4778 & 45,8275 & 24,3550 \\
\hline MVEN 119 & 8,1248 & 7,6385 & 5,5550 & 21,3183 & 36,5225 & 26,4550 \\
\hline VEADA & 23,7148 & 10,7983 & 10,4163 & 44,9293 & 52,0350 & 29,9250 \\
\hline DESCONHECIDA & I 23, 2980 & 14,7563 & 9,0275 & 47,0818 & 49,4200 & 27,2150 \\
\hline CM $425 / 3$ & 12,8120 & 9,6523 & 8,0203 & 30,4845 & 41,2625 & 27,8225 \\
\hline CANGAIBINHA & 20,6590 & 18,7843 & 7,3958 & 46,8390 & 44,1750 & 32,8700 \\
\hline
\end{tabular}


Anexo 4. Continuação

\begin{tabular}{|c|c|c|c|c|c|c|}
\hline Genōtipos & $\mathrm{PR}$ & PHC & $\mathrm{PRa}$ & PT & IC & $\mathrm{TA}$ \\
\hline SACAI & 22,7080 & 15,5900 & 8,2635 & 46,5615 & 48,6525 & 33,1375 \\
\hline DESCONHECIDA II & 37,7425 & 24,9300 & 12,0480 & 74,7205 & 50,5250 & 30,2350 \\
\hline DESCONHECIDA & 19,9648 & 9,7565 & 4,5135 & 34,2348 & 58,1775 & 28,6950 \\
\hline LAGOA I & 29,0275 & 18,0898 & 12,3955 & 59,5128 & 48,9925 & 33,3200 \\
\hline SFG 696 & 31,4232 & 28,7148 & 12,4648 & 72,6028 & 43,6450 & 31,2625 \\
\hline CMC 84 & 30,6245 & 11,3538 & 8,3675 & 50,3458 & 61,1425 & 32,4325 \\
\hline PAINEIRA & 22,8120 & 10,9025 & 6,6663 & 40,3808 & 56,7550 & 28,7950 \\
\hline SFG 593-PASSARINHO & 13,9230 & $11,4928^{\circ}$ & 9,9650 & 35,3808 & 40,0725 & 32,3775 \\
\hline GOSTOSA & 20,4162 & 14,6175 & 9,5830 & 44,6168 & 45,7075 & 31,0225 \\
\hline MARIC $\bar{A}$ & 24,0970 & 19,5483 & 7,8813 & 51,5265 & 46,6000 & 28,1175 \\
\hline CENOURA OU ROSADA & 7,2565 & 10,2428 & 4,6873 & 22,1865 & 29,2925 & 23,0175 \\
\hline CHIFRE DE BODE & 29,6178 & 14,5133 & 8,3330 & 52,4640 & 56,2325 & 27,6675 \\
\hline RIO BRANCO & 20,5553 & 8,9928 & 5,1385 & 34,6865 & 59,2625 & 25,7350 \\
\hline DESCONHECIDA II & 16,4233 & 13,6105 & 6,9788 & 37,0125 & 42,2200 & 27,1575 \\
\hline AIPIM MISTURA & 18,6800 & 12,6385 & 11,1105 & 42,4290 & 43,5400 & 32,9550 \\
\hline ENGOLE BOI & 19,9303 & $8,860.8$ & 6,9438 & 34,2348 & 57,2025 & 30,2775 \\
\hline CAIABANA & 15,1730 & 7,0135 & 4,1315 & 26,3180 & 57,7675 & 27,6525 \\
\hline CHAGAS & 21,4580 & 17,2220 & 9,1663 & 47,8463 & 41,7300 & 26,1425 \\
\hline NIGAMINA & 30,6245 & 18,5065 & 9,7565 & 58,8875 & 52,2225 & 88,9775 \\
\hline RIO VERDE & 19,7218 & 8,7840 & 3,7148 & 32,2205 & 61,0025 & 26,5125 \\
\hline AIPIM P ÃO & 21,9085 & 8,6455 & 3,9928 & 34,5475 & 62,4450 & 25,9025 \\
\hline OURO DO VALE & 17,4648 & 6,0758 & 3,5413 & 27,0818 & 64,7500 & 25,6100 \\
\hline BAIANA & 16,9095 & 7,5340 & 2,7075 & 27,1510 & 60,2100 & 27,9075 \\
\hline IAC $5 / 66$ & 31,8398 & 9,2010 & 3,3675 & 44,4083 & 71,5300 & 20,5200 \\
\hline CM $424 / 8$ & 16,8050 & 4,9438 & 5,0690 & 27,5678 & 61,0525 & 27,4300 \\
\hline CANO DE ESPINGARDA & 19,4788 & 10,4510 & 5,3468 & 35,2765 & 55,1050 & 28,3150 \\
\hline GIGANTE PRETA & 17,6733 & 13,8883 & 9,9995 & 41,5610 & 38,6475 & 27,3300 \\
\hline CM $367 / 2$ & 11,0758 & 5,8328 & 4,2355 & 21,1440 & 50,3375 & $23 ; 5625$ \\
\hline IPEACS $\quad 44-54-1$ & 15,9720 & · $\quad 8,2980$ & 4,1660 & 28,4360 & 54,0650 & 22,4225 \\
\hline HIBRIDA I & 24,2355 & 15,5205 & 11,3190 & 51,0750 & 47,4575 & 27,8525 \\
\hline
\end{tabular}


Anexo 4. Continuação

\begin{tabular}{|c|c|c|c|c|c|c|}
\hline Genōtipos & $P R$ & PHC & $\mathrm{PRa}$ & $\mathrm{PT}$ & IC & $\mathrm{TA}$ \\
\hline ENTRE RIOS & 24,0273 & 19,2703 & 7,1525 & 50,4500 & 47,6125 & 23,7000 \\
\hline SM $1-150$ & 24,0968 & 11,7358 & 8,4025 & 44,2350 & 53,9450 & 24,5075 \\
\hline CM $327 / 2$ & 17,2565 & 5,9373 & 4,6870 & 27,8808 & 60,8875 & 25,5800 \\
\hline ROSADA II & 8,3675 & 11,4928 & 8,5763 & 28,4365 & 28,5150 & 23,9725 \\
\hline CM 368/1 & 23,8885 & 11,4928 & 7,9855 & 43,3668 & 54,2350 & 25,2750 \\
\hline $\mathrm{EAB} 503$ & 27,7428 & 11,9438 & 4,6175 & 44,3040 & 62,5000 & 28,6250 \\
\hline CLONE 264 & 23,8540 & 13,9928 & 5,4858 & 43,3325 & 54,9075 & 28,2575 \\
\hline $\begin{array}{l}\text { MANDIOCA TAQUA- } \\
\text { RI 5-18-7 }\end{array}$ & 28,0203 & 9,3748 & 4,5828 & 41,9779 & 66,8725 & 28,2725 \\
\hline CM 425/6 & 18,4368 & 9,7218 & 5,1730 & 33,3315 & 54,9675 & 26,7925 \\
\hline CMC 9 & 13,1595 & 6,5620 & 5,4510 & 25,1725 & 52,1300 & 25,7625 \\
\hline $\begin{array}{r}\text { VERMELHINHA DAS } \\
\text { CACIMBAS }\end{array}$ & 14,7218 & 5,7983 & 3,0900 & 23,6100 & 61,8000 & 28,9775 \\
\hline IAC $7-158$ & 22,4650 & 11,2843 & 7,3608 & 41,1100 & 54,6525 & 26,9775 \\
\hline CM $367 / 9$ & 11,1790 & 8,5410 & 7,1523 & 26,8723 & 41,3075 & 24,0025 \\
\hline MCOL 673 & 10,2080 & 7,5690 & 8,0553 & 25,8323 & 39,4575 & 31,2350 \\
\hline MECU 159 & 27,6385 & 10,3123 & 8,2983 & 46,2490 & 59,8800 & 27,8225 \\
\hline PÃO DO CHILE I & 41,2145 & 19,6873 & 10,2773 & 71,1790 & 58,1100 & 28,2175 \\
\hline MANIVA GRANDE & 34,2355 & 13,9923 & 9,0968 & 57,3245 & 59,8700 & 30,3450 \\
\hline CASCA ROXA & 9,5483 & 4,7565 & 6,6663 & 20,9710 & 45,4350 & 26,0875 \\
\hline CM $375 / 2$ & 18,2288 & 8,0553 & 5,2775 & 31,5615 & 56,2500 & 31,3050 \\
\hline CACAUZINHA & 15,8328 & 5,6248 & 2,6385 & 24,0960 & 66,0025 & 27,9500 \\
\hline MANIVAINHA & 24,7218 & 9,9998 & 3,5760 & 38,2975 & 64,4500 & 25,6125 \\
\hline VASSOURINHA I & 26,2495 & 8,9925 & 7,2913 & 42,5333 & 61,7050 & 27,7800 \\
\hline CM $425 / 5$ & 23,1245 & 8,5413 & 5,5553 & 37,2210 & 61,9450 & 30,9050 \\
\hline ALAGOAS & 15,4163 & 11,8745 & 10,6938 & 37,9845 & 39,9425 & 29,2050 \\
\hline CAVALO GRANDE & 21,6315 & 8,3675 & 12,3605 & 42,3595 & 51,9275 & 31,9675 \\
\hline QUEBRADINHA & 23,1940 & 9,3745 & 6,8745 & 39,4430 & 59,0150 & 29,3875 \\
\hline CACAU VERMELHO & 23,0900 & 10,4510 & 8,8190 & 42,3600 & 54,4825 & 31,2050 \\
\hline ARREBENTA BURRO & 26,8398 & 10,6258 & 7,6735 & 45,1390 & 59,4750 & 30,8675 \\
\hline IAN 26 & 23,5413 & 14,8930 & 11,7010 & 50,1330 & 46,8150 & 29,1200 \\
\hline $\begin{array}{l}\text { Amplitude } \\
\text { de variação }\end{array}$ & 35,0692 & 23,9583 & 11,8055 & 53,7495 & 46,8050 & 14,0550 \\
\hline
\end{tabular}


Anexo 5. Médias obtidas de quatro repetições e suas respectivas amplitudes para os caracteres: PR-produção de raízes (t/ha), PHC-produção de hastes e cepas ( $t /$ ha), PRa-produção de ramas (t/ha), PT-produção total ( $t / h a)$, IC-índice de colheita (\%), TA-teor de amido (\%), dos 56 genótipos selecionados do ensaio realizado em 1980/81. Cruz das Almas-BA-1980/81

\begin{tabular}{|c|c|c|c|c|c|c|}
\hline Genötipos & PR & PHC & $\mathrm{PRa}$ & PT & IC & $\mathrm{TA}$ \\
\hline AIPIM PRETO M.N. & 41,3190 & 11,8050 & 4,3398 & 57,4638 & 71,0250 & 21,7600 \\
\hline PÃO DO CHILE I & 41,2145 & 19,6873 & 10,2773 & 71,1790 & 58,1100 & 28,2175 \\
\hline DESCONHECIDA III & 37,7425 & 24,9300 & 12,0480 & 74,7205 & 50,5250 & 30,2350 \\
\hline IAC $7-127$ & 35,5988 & 11,5100 & 5,7805 & 52,8893 & 67,5500 & 28,6575 \\
\hline VASSOURINHA IP & 35,3815 & 10,0343 & 4,6523 & 50,0680 & 70,6500 & 30,4700 \\
\hline MARIA PAU & 35,2078 & 13,1248 & 6,4580 & 49,7905 & 70,4000 & 33,5325 \\
\hline VARIEDADE 77 & 34,5048 & 10,4163 & 7,7600 & 52,6810 & 66,3250 & 27,1900 \\
\hline MANIVA GRANDE & 34,2355 & 13,9923 & 9,0968 & 57,3245 & 59,8700 & 30,3450 \\
\hline AIPIM BRANCO BRAN- & 34,0970 & 12,2913 & 6,3190 & 52,7073 & 65,7500 & 27,6950 \\
\hline TOLA ROXA & 34,0968 & 12,7773 & 4,7218 & 51,5958 & 66,4000 & 29,9900 \\
\hline MARACANÃ & 33,5413 & 17,0570 & 9,3485 & 59,9468 & 55,6000 & 29,6125 \\
\hline MMEX 59 & 31,8398 & 8,8190 & 4,6175 & 45,0263 & 70,9000 & 28,8500 \\
\hline IAC $5 / 66$ & 31,8398 & $9,20 \hat{10}$ & 3,3675 & 44,4083 & 71,5300 & 20,5200 \\
\hline SFG 696 & 31,4232 & 28,7148 & 12,4648 & 72,6028 & 43,6450 & 31,2625 \\
\hline PAULO ROSA & 30,7548 & 15,1298 & 5,9370 & 51,8215 & 57,0250 & 26,6225 \\
\hline NIGAMINA & 30,6245 & 18,5065 & 9,7565 & 58,8875 & 52,2225 & 28,9775 \\
\hline CMC 84 & 30,6245 & 11,3538 & 8,3675 & 50,3458 & 61,1425 & 32,4325 \\
\hline CHIFRE DE BODE & 29,6178 & 14,5133 & 8,3330 & 52,4640 & 56,2325 & 27,6675 \\
\hline IAC $5-51$ & 29,4788 & 15,4858 & 5,2773 & 50,2418 & 57,6400 & 29,2025 \\
\hline PALMEIRA PRETA & 29,0360 & 9,7393 & 3,3330 & 42,1083 & 69,1750 & 29,4300 \\
\hline LAGOA I & 29,0275 & 18,0898 & 12,3955 & 59,5128 & 48,9925 & 33,3200 \\
\hline $\begin{array}{l}\text { MANDIOCA TAQUARI } \\
5-18-7\end{array}$ & 28,0203 & 9,3748 & 4,5828 & 41,9779 & 66,8725 & 28,2725 \\
\hline SERTANEJA & 27,9508 & 12,2913 & 7,8815 & 48,1235 & 57,5500 & 30,8825 \\
\hline MECU 159 & 24,5135 & 10,4855 & 5,6245 & 40,6235 & 60,3432 & 26,6825 \\
\hline IAC $105 / 66$ & 27,6038 & 10,0343 & 5,4510 & 43,0890 & 63,9000 & 28.4125 \\
\hline CM 375/1 & 27,3953 & 13,0203 & 6,1450 & 46,5605 & 58,2950 & 28,6150 \\
\hline SFG 393 & 27,0830 & 15,6940 & 6,4928 & 49,2698 & 55,0875 & 27,3725 \\
\hline
\end{tabular}


Anexo 5. Continuação

\begin{tabular}{|c|c|c|c|c|c|c|}
\hline Genótipos & $P R$ & PHC & $\mathrm{PRa}$ & $\mathrm{PT}$ & IC & $\mathrm{TA}$ \\
\hline ARREBENTA BURRO & 26,8398 & 10,6258 & 7,6735 & 45,1390 & 59,4750 & 30,8675 \\
\hline CM $424 / 9$ & 26,7008 & 9,9303 & 5,8328 & 42,4638 & 61,1925 & 27,0175 \\
\hline SÃO PEDRO MIRIM & 26,2495 & 22,2913 & 8,7150 & 57,2558 & 46,0750 & 31,0250 \\
\hline VASSOURINHA I & 26,2495 & 8,9925 & 7,2913 & 42,5333 & 61,7050 & 27,7800 \\
\hline AIPIM CAIXÃO & 26,1803 & 11,4233 & 4,1313 & 41,7348 & 62,3025 & 28,9625 \\
\hline CONGONHAS & 26,1105 & 17,1523 & 4,3748 & 47,6375 & 54,7500 & 27,9100 \\
\hline JACOBINA I & 25,5898 & 11,8053 & 5,6940 & 43,0890 & 58,9250 & 27,5725 \\
\hline AMAZONAS & 25,4858 & 11,1800 & 7,2218 & 43,8875 & 57,4625 & 30,9950 \\
\hline CM $344 / 5$ & 25,4163 & 9,9998 & 4,3748 & 39,7908 & 63,9000 & 26,3700 \\
\hline MAN IVAINHA & 24,7218 & 9,9998 & 3,5760 & 38,2975 & 64,4500 & 25,6125 \\
\hline MECU 159 & 27,6385 & 10,3123 & 8,2983 & 46,2490 & 59,8800 & 27,8225 \\
\hline HIBRIDA I & 24,2355 & 15,5205 & 11,3190 & 51,0750 & 47,4575 & 27,8525 \\
\hline MARIC $\bar{A}$ & 24,0970 & 19,5483 & 7,8813 & 51,5265 & 46,6000 & 28,1175 \\
\hline ENTRE RIOS & 24,0273 & 19,2703 & 7,1525 & 50,4500 & 47,6125 & 23,7000 \\
\hline CLONE 264 & 23,8540 & 13,9928 & 5,4858 & 43,3325 & 54,9075 & 28,2575 \\
\hline VEADA & 23,7148 & 10,7983 & 10,4163 & 44,9293 & 52,0350 & 29,9250 \\
\hline VASSOURINHA & 23,7145 & 9,9995 & 3,1248 & 36,8388 & 63,9750 & 25,9750 \\
\hline BAHIA & 23,5760 & 11,9093 & 4,4090 & 39,8943 & 59,1000 & 29,8825 \\
\hline MUCURI & 23,5065 & 12,6038 & 5,7635 & 41,8738 & 55,8100 & 30,4175 \\
\hline CM 425/5 & 23,1245 & 8,5413 & 5,5553 & 37,2210 & 61,9450 & 30,9050 \\
\hline SURUI & 23,0898 & 19,7565 & 7,7078 & 50,5540 & 46,1500 & 34,0000 \\
\hline CM 424/6 & 23,0553 & 13,0550 & 5,1385 & 41,2488 & 55,7000 & 27,2850 \\
\hline CANGAIBA & 22,9855 & 13,6103 & 6,5618 & 43,1575 & 53,1575 & 27,8050 \\
\hline CM 368/1 & 22,7425 & 10,7980 & 5,7983 & 39,3388 & 57,6500 & 31,3850 \\
\hline IAC $7-158$ & 22,4650 & 11,2843 & 7,3608 & 41,1100 & 54,6525 & 26,9775 \\
\hline SF,G 2-187 & 22,2913 & 13,2980 & 6,1455 & 41,7348 & 52,5250 & 28,5125 \\
\hline MANJARI & 20,8328 & 15,9718 & 14,3743 & 51,2463 & 40,9500 & 34,5750 \\
\hline EAB 503 & 20,2773 & 13,7495 & 6,2843 & 40,3110 & 50,7550 & 27,3850 \\
\hline SÃO JOÃO I & 16,9268 & 9,9475 & 4,0360 & 30,9103 & 54,5500 & 30,9225 \\
\hline \multicolumn{7}{|l|}{ Amplitude } \\
\hline de variação & 24,3922 & 20,1735 & 11,2495 & 43,8102 & 30,5800 & 14,0550 \\
\hline
\end{tabular}


Anexo 6. Médias obtidas de quatro repetições e suas respectivas amplitudes para os caracteres: PR-produção de raízes (t/ha), PHCprodução de hastes e cepas ( $t / h a)$, PRa-produção de ramas(t/ha), PT-produção total ( $t / h a)$, IC-índice de colheita (\%), TA-teor de amido (\%), dos 56 genótipos selecionados em 1980/81 e avaliados em 1981/82. Cruz das Almas-BA-1981/82

\begin{tabular}{|c|c|c|c|c|c|c|}
\hline Genōtipos & $\mathrm{PR}$ & PHC & PRa & $\mathrm{PT}$ & IC & $\mathrm{TA}$ \\
\hline AIPIM PRETO M.N. & 8,0555 & 6,0647 & 2,2918 & 14,8958 & 53,9275 & 22,4650 \\
\hline PÃO DO CHILE I & 7,1180 & 7,9165 & 1,6668 & 16,7013 & 41,2650 & 25,4550 \\
\hline DESCONHECIDA III & 8,5415 & 12,0488 & 2,1528 & 22,7430 & 36,9425 & 27,8800 \\
\hline IAC-7 -127 & 9,1668 & 5,0698 & 1,8753 & 16,1118 & 57,0325 & 29,1900 \\
\hline VASSOURINHA-IP & 8,7500 & 3,6458 & 1,5278 & 13,9235 & 62,4625 & 28,8250 \\
\hline MARIA PAU & 10,1735 & 2,2570 & 0,9375 & 13,3680 & 71,9900 & 28,8950 \\
\hline VARIEDADE 77 & 10,8680 & 3,1943 & 2,4305 & 16,4928 & 65,0475 & 20,9100 \\
\hline MANIVA GRANDE & 10,1390 & 10,1043 & 2,0140 & 22,2573 & 45,9000 & 27,0900 \\
\hline AIPIM BRAVO BRANCO & 9,5833 & 3,6458 & 1,5970 & 14,8260 & 64,8225 & 24,4950 \\
\hline TOLA ROXA & 6.8403 & 4,0973 & 1,8055 & 12,7430 & 51,7550 & 27,9925 \\
\hline MARACANÃ & 14,7225 & 9,7223 & 2,5248 & 26,9795 & 54,9375 & 25,4825 \\
\hline MMEX 59 & 16,1803 & 8,3333 & 4,0625 & 28,5760 & 58,0175 & 27,4425 \\
\hline IAC $5 / 66$ & 9,7915 & 4,4095 & 2,2918 & 16,4928 & 59,8850 & 21,3375 \\
\hline SFG 696 & 10,0348 & 15,0348 & 3,0555 & 28,1250 & 35,1200 & 28,4275 \\
\hline PAULO ROSA & 19,3488 & 9,0103 & 3,5415 & 31,9008 & 59,9250 & 27,7525 \\
\hline NIGAMINA & 11,0765 & 10,5560 & 2,5695 & 24,2020 & 44,9300 & 28,3150 \\
\hline CMC 84 & 7,5000 & 4,8263 & 2,9515 & 15,2778 & 48,1500 & 29,7825 \\
\hline CHIFRE DE BODE & 13,2640 & 9,6530 & 2,9863 & 25,9033 & 52,0500 & 27,1325 \\
\hline IAC 5-51 & 10,2778 & 5,6595 & 1,8055 & 17,7428 & 58,0425 & 28,2175 \\
\hline PALME IRA. PRETA & 9,4095 & 4,2365 & 1,3888 & 15,0348 & 63,3475 & 27,2450 \\
\hline LAGOA I & 12,8125 & 12,5348 & 4,3750 & 29,7223 & 40,0150 & 30,7975 \\
\hline MANDIOCA TAQUARI & 10,1735 & 6,5275 & 1,4930 & 18,1940 & 56,7275 & 28,5125 \\
\hline SERTANEJA $\quad 5-18-7$ & 5,0695 & 4,6875 & 2,2570 & 12,0140 & 39,6275 & 27.6125 \\
\hline MECU 159 & $6,1460^{\circ}$ & 5,3125 & 2,7430 & 14,2015 & 43,9625 & 27,9225 \\
\hline IAC $105 / 66$ & 6,0418 & 3,4028 & 1,7360 & 11,1805 & 54,2175 & 28,5000 \\
\hline CM $375 / 1$ & 9,8265 & 6,2845 & 1,8053 & 17,9163 & 55,3625 & 31,3325 \\
\hline
\end{tabular}


Anexo 6. Continuação

\begin{tabular}{|c|c|c|c|c|c|c|}
\hline Genótipos & PR & PHC & PRa & PT & IC & $\mathrm{TA}$ \\
\hline SFG 393 & 10,4863 & 6,7015 & 1,2153 & 18,4030 & 56,9950 & 25,6100 \\
\hline ARREBENTA BURRO & 9,9653 & 4,5835 & 2,5693 & 17,1180 & 57,1100 & 31,4050 \\
\hline CM $424 / 9$ & 11,0765 & 3,7500 & 2,2570 & 17,0835 & 66,0925 & 27,4425 \\
\hline SÃO PEDRO MIRIM & 6,0068 & 8,4723 & 2,1878 & 16,6668 & 34,8425 & 28,5125 \\
\hline VAS SOURINHA PAMPAS & $S_{4,6875}$ & 5,5208 & 2,0485 & 12,2568 & 37,6675 & 26,2850 \\
\hline AIPIM CAIXÃO & 7,1873 & 3,5070 & 1,1108 & 11,8050 & 63,6400 & 27,3575 \\
\hline CONGONHAS & 7,3955 & 5,8680 & 1,8750 & 15,1385 & 48,2450 & 28,9075 \\
\hline JACOBINA I & 7,9863 & 4,7568 & 1,2840 & 14,0278 & 56,9225 & 26,8650 \\
\hline AMAZONAS & 7,3613 & 4,4930 & 2,7430 & 14,5973 & 48,4925 & 30,0925 \\
\hline CM $344 / 5$ & 8,1945 & 3,6458 & 1,8058 & 13,6460 & 61,4100 & 26,0050 \\
\hline MANIVAINHA & 12,8473 & 8,8885 & 1,7708 & 23,5065 & 57,0700 & 25,9475 \\
\hline MECU 159 & 6,8405 & 6,4930 & 2,9515 & 16,2850 & 41,9550 & 26,7225 \\
\hline HIBRIDA I & 7,0483 & 4,2710 & 1,4583 & 12,7775 & 51,8750 & 28,4425 \\
\hline MARICĀ & 8,8543 & 4,9305 & 1,9790 & 15,7638 & 57,1850 & 27,5400 \\
\hline ENTRE RIOS & 6,1803 & 7,6040 & 1,2848 & 15,0690 & 40,0050 & 25,3975 \\
\hline CLONE 264 & 9,7915 & 9,9308 & 2,3960 & 22,1183 & 43,7825 & 27,2300 \\
\hline VEADA & 10,7290 & 4,5488 & $2,3960^{\circ}$ & 17,6738 & 60,6450 & 28,7250 \\
\hline VAS SOURINHA & 6,9445 & 5,1040 & 1,6318 & 13,6803 & 51,7550 & 25,9900 \\
\hline BAHIA & 5,1040 & 4,6875 & 2,1528 & 11,9443 & 39,5075 & 28,8100 \\
\hline MUCURI & 6,6668 & 4,6530 & 0,8330 & 15,2083 & 55,2575 & 28,1750 \\
\hline CM $425 / 5$ & 7,7780 & 5,8333 & 2,6738 & 16,2850 & 47,4200 & 28,8875 \\
\hline SURUI & 7,5695 & 6,0068 & 3,4025 & 16,9788 & 45,7075 & 31,9400 \\
\hline CM $424 / 6$ & 6,9098 & 5,1043 & 2,5348 & 14,5488 & 45,8025 & 28,3450 \\
\hline CANGAIBA & 7,6043 & 3,9235 & 1,8403 & 13,3680 & 57,4000 & 27,4275 \\
\hline CM $368 / 1$ & 9,1320 & 5,7640 & 1,9445 & 16,8405 & 53,6825 & 29,3750 \\
\hline IAC $7-158$ & 6,4930 & 8,3683 & 2,7083 & 17,5695 & 35,3825 & 25,7075 \\
\hline SFG $2-187$ & 8,7153 & 5,4513 & 3,5070 & 17,6735 & 49,1650 & 29,1475 \\
\hline MANJARI & 6,9790 & 6,9795 & 3,0558 & 17,0143 & 41,0900 & 30,6150 \\
\hline EAB 503 & 11,9095 & 8,5763 & 2,6043 & 23,0900 & 50,9400 & 26,6375 \\
\hline SÃO JOÃO I & 13,1945 & 7,0485 & 2,9860 & 23,2290 & 56,7075 & 27,9925 \\
\hline $\begin{array}{l}\text { Amplitude } \\
\text { de variação }\end{array}$ & 14,6613 & 12,7778 & 3,5420 & 20,7203 & 37,1475 & 11,0300 \\
\hline
\end{tabular}


Apêndice 1. Temperaturas máximas, mỉnimas, médias, precipitação pluvial e umidade relativa dos anos $1980 / 81 / 82$ referentes ao período experimental. Campus Experimental do Centro Nacional de Pesqui sa de Mandioca e Fruticultura 1/, Cruz das Almas-BA.

\begin{tabular}{|c|c|c|c|c|c|}
\hline \multicolumn{6}{|c|}{ Dados Climatológicos de 1980} \\
\hline \multirow{2}{*}{ Meses } & \multicolumn{3}{|c|}{ Temperaturas $\left({ }^{\circ} \mathrm{C}\right)$} & \multirow{2}{*}{$\begin{array}{l}\text { Precipitação } \\
\text { pluvial (mm) }\end{array}$} & \multirow{2}{*}{$\begin{array}{l}\text { Umidade } \\
\text { Relativa(\%) }\end{array}$} \\
\hline & Média & Máxima & Mínima & & \\
\hline Janeiro & 25,0 & 33,1 & 19,8 & 209,4 & 80 \\
\hline Fevereiro & 24,6 & 31,4 & 20,2 & 245,6 & 84 \\
\hline Março & 24,2 & 31,1 & 19,5 & 65,9 & 83 \\
\hline Abril & 24,3 & 32,1 & 19,4 & 53,6 & 82 \\
\hline Maio & 23,1 & 30,1 & 17,8 & 87,2 & 87 \\
\hline Junho & 22,1 & 28,6 & 17,6 & 79,7 & 85 \\
\hline Julho & 21,4 & 29,0 & 16,4 & 78,0 & 87 \\
\hline Agosto & 21,4 & 28,7 & 16,4 & 84,2 & 84 \\
\hline Setembro & 22,5 & 36,8 & 17,6 & 82,5 & 85 \\
\hline Outubro & 23,2 & 31,0 & 17,7 & 53,6 & 79 \\
\hline Novembro & 24,3 & 31,8 & 20,0 & 31,6 & 81 \\
\hline Dezembro & 25,7 & 33,8 & $20 ; 7$ & 28,6 & 75 \\
\hline \multicolumn{6}{|c|}{ Dados Climatológicos de 1981} \\
\hline Janeiro & 25,1 & 33,5 & 20,0 & 66,2 & 75 \\
\hline Fevereiro & 24,7 & 33,1 & 19,8 & 57,4 & 76 \\
\hline Março & 25,3 & 36,5 & 20,0 & 237,4 & 80 \\
\hline Abril & 23,7 & 31,0 & 19,1 & 109,5 & 84 \\
\hline Maio & 22,3 & 29,2 & 37,7 & 115,2 & 86 \\
\hline Junho & 21,5 & 28,8 & 17,1 & 160,0 & 89 \\
\hline Julho & 20,5 & 27,5 & 16,0 & 87,7 & 87 \\
\hline Agos to & 20,8 & 27,8 & 15,9 & 49,3 & 84 \\
\hline Setembro & 21,6 & 29,4 & 15,4 & 14,1 & 77 \\
\hline Outubro & 23,8 & 31,4 & 18,3 & 46,9 & 79 \\
\hline Novembro & 24,7 & 31,7 & 19,8 & 24,2 & 77 \\
\hline Dezembro & 24,9 & 33,1 & 19,2 & 98,6 & 75 \\
\hline
\end{tabular}


Apêndice 1. Continuação

\begin{tabular}{|c|c|c|c|c|c|}
\hline \multicolumn{6}{|c|}{ Dados Climatológicos de 1982} \\
\hline \multirow{2}{*}{ Meses } & \multicolumn{3}{|c|}{ Temperaturas $\left({ }^{\circ} \mathrm{C}\right)$} & \multirow{2}{*}{$\begin{array}{l}\text { Precipitação } \\
\text { pluvial (mm) }\end{array}$} & \multirow{2}{*}{$\begin{array}{l}\text { Umidade } \\
\text { Relativa(\%) }\end{array}$} \\
\hline & Média & Māxima & Mínima & & \\
\hline Janeiro & 25,3 & 32,9 & 20,0 & 15,2 & 73 \\
\hline Fevereiro & 24,7 & 32,8 & 20,1 & 89,4 & 78 \\
\hline Março & 26,0 & 35,2 & 19,8 & 5,8 & 72 \\
\hline Abril & 24,2 & 33,4 & 19,2 & 92,5 & 83 \\
\hline Maio & 22,4 & 29,6 & 18,1 & 140,2 & 88 \\
\hline Junho & 22,0 & 27,8 & 18,2 & 132,4 & 89 \\
\hline Julho & 21,2 & 28,0 & 16,2 & 124,0 & 88 \\
\hline Agosto & 21,6 & 27,7 & 15,6 & 43,2 & 86 \\
\hline Setembro & 21,9 & 29,4 & 17,6 & 98,8 & 85 \\
\hline Outubro & 23,1 & $3 i, 2$ & 18,0 & 66,9 & 80 \\
\hline Novembro & 24,6 & 33,3 & 18,1 & 6,5 & 72 \\
\hline Dezembro & 24,8 & 34,0 & 19,1 & 55,5 & 74 \\
\hline
\end{tabular}

$1 /$ Dados fornecidos pela Estação Agrometeorológica do Centro Nacional de Pes quisa de Mandioca e Fruticultura, da Empresa Brasileira de Pesquisa Agropecuāria. Cruz das Almas-Bahia. 
Apêndice 2. Análises químicas de solo da área do Campus Experimental do Centro Nacional de Pesquisa de Mandioca e Fruticultura para experimentos instalados no ano agrícola de 1980/81. Cruz das Almas - $\mathrm{BA}^{\underline{1} /}$

\begin{tabular}{|c|c|c|c|c|c|}
\hline $\begin{array}{c}\text { Anālises Analíticas/ } \\
\text { Experimentos }\end{array}$ & $\mathrm{pH}\left(\mathrm{H}_{2} \mathrm{O}\right)$ & $\begin{array}{l}\mathrm{PO}_{4}^{--} \\
\mathrm{ppm}\end{array}$ & $\underset{\mathrm{ppm}}{\mathrm{K}^{+}}$ & $\begin{array}{c}\mathrm{Ca}^{++}+\mathrm{Mg}^{++} \\
\text {e.mg }\end{array}$ & $\begin{array}{c}\mathrm{Al}^{+++} \\
\mathrm{e} \cdot \mathrm{mg} / 100 \mathrm{ml} \text { tfsa }\end{array}$ \\
\hline Experimento no 1 & $5 ; 2$ & 2,0 & 43 & 5,5 & 0,1 \\
\hline Experimento no 2 & 5,2 & 2,0 & 24 & 1,6 & 0,1 \\
\hline Experimento no 3 & 5,0 & 2,0 & 36 & 1,6 & 0,1 \\
\hline Experimento no 4 & 5,1 & 4,0 & 29 & 1,7 & 0,1 \\
\hline Experimento no 5 & 4,8 & 6,0 & 26 & 2,3 & 0,1 \\
\hline Experimento n? 6 & 4,7 & 5,0 & 17 & 1,5 & 0,3 \\
\hline Experimento n? 7 & 4,9 & 2,0 & 21 & 1,6 & 0,3 \\
\hline Experimento n? 8 & 4,9 & 3,0 & 18 & 1,5 & 0,2 \\
\hline Experimento no 9 & 4,8 & 4,0 & 20 & 1,2 & 0,5 \\
\hline Experimento no 10 & 4,5 & 8,0 & 30 & 1,1 & 0,5 \\
\hline
\end{tabular}

1/ Anālises realizadas pelo Laboratório de Solos do Centro Nacional de Pes quisa de Mandioca e Fruticultura, da Empresa Brasileira de Pesquisa Agropecuária. Cruz das Almas-BA. 